\title{
Die presbyophrene Demenz, deren anatomische Grundlage und klinische Abgrenzung.
}

\author{
Von \\ Oskar Fischer.
}

(Aus der deutschen psychiatrischen Klinik in Prag).

Mit 13 Tafeln.

(Eingegangen am 6. August 1910.)

In einer vorläufigen Mitteilung publizierte ich im Jahre 1907 eine eigenartige, rätselhafte und weder anatomisch noch klinisch entsprechend gewürdigte Veränderung der Hirnrinde, die sich in einer Anzahl von Gehirnen Senil-Dementer vorfand und die ich damals als ,drusige Nekrose" bezeichnete; in all den Fällen ließen sich klinisch gewisse Züge von Presbyophrenie nachweisen, wogegen bei einfach Senil-Dementen die Veränderung nicht vorgefunden wurde. Ein Jahr später habe ich in der Jahresversammlung des Deutschen Vereins für Psychiatrie weitere Befunde mitgeteilt, konnte die klinische Bedeutung derselben bestätigen und machte auch damals auf die morphologische Ähnlichkeit der Drusen mit Bakterienwucherungen aufmerksam. Doch eine ausführliche Publikation über diesen Gegenstand habe ich bis jetzt vermieden; denn es handelte sich mir in erster Linie um die klinische Bedeutung dieses Befundes, und dazu mußte erst ein größeres Material gesammelt und verarbeitet werden. Da jetzt mein Material derartig angewachsen ist, daß dessen Größe zu mehr als approximativen Schlußfolgerungen führt, schreite ich erst $\mathrm{zu}$ einer ausführlicheren Publikation. In der Zwischenzeit haben sich aber bereits mehrere Autoren mit diesem Gegenstande beschäftigt und meine damaligen Resultate in mehr oder weniger ablehnender Weise beurteilt. Allen diesen Arbeiten habe ich den Vorwurf zu machen, daß sie sich auf zu geringes Material stützen, sowohl was die histologische Durcharbeitung, als auch die klinische Bewertung der Befunde anbelangt. Deswegen will ich vorher meine Befunde sçhildern und dann erst zur Diskussion über die bereits erschienenen einschlägigen Arbeiten übergehen.

Wie aus dem vorhin Gesagten ersichtlich, hat sich die Beschreibung des Gegenstandes in zweierlei Richtung zu bewegen: erstens müssen die pathologisch-anatomischen Verhältnisse genau festgestellt und eine Erklärung derselben versucht werden, zweitens muß ermittelt werden, 
ob man irgendwelche klinischen Symptome auf diese Cerebralerkrankung zurückführen kann.

In meiner ersten Mitteilung habe ich zwar einen Teil des jetzt gesammelten Materials geschildert und besprochen; doch das damalige Material war noch gering, die Befunde wiesen noch manche Lücke auf und deswegen - besonders aber um die Einheitlichkeit der Schilderung nicht zu stören - will ich die Einzelheiten der früheren Mitteilungen nicht berücksichtigen, sondern hier zusammenfassend schildern, wie wenn noch nichts von mir berichtet worden wäre.

\section{Anatomischer Teil.}

Die in Betracht kommende Veränderung des Gehirns läßt sich am besten mit der Methode von Biels chow sk y darstellen; mit den meisten der gewöhnlichen und bis jetzt gebräuchlichen histologischen Färbeverfahren färben sich die betreffenden Elemente gar nicht oder so wenig distinkt, daß sie sehr leicht übersehen werden können; darin liegt auch der Grund, warum diese so häufige Veränderung erst so spät bekannt geworden ist.

Zur Technik der Methode von Bielschowsky möchte ich hier bemerken, daß sich Hirnschnitte am besten färben, wenn ihre Dicke etwa $20 \mu$ beträgt; bei dünneren Schnitten läßt die Färbung viel zu wünschen übrig, wogegen sich in $20 \mu$ Schnitten von demselben Material unverhältnismäßig mehr Fasern ausfärben, was auch für die Ganglienzellen und die hier in Betracht kommenden Veränderungen gilt. Man kann aber auch dünnere Schnitte färben, wenn man in dem ammoniakalischen Silberbade 2-3 Schnitte übereinander schiebt, diese übereinanderliegenden Schnitte, so wie wenn man einen einzigen dickeren Schnitt vor sich hätte, auf die Nadel legt, schnell durch das Wasser zieht und ins Formol überträgt.

Die nachfolgende Schilderung der histologischen Befunde bezieht sich, wenn nichts anderes gesagt wird, durchwegs auf Präparate, welche nach der Methode Bielschowskys angefertigt wurden. Bei dem großen Materiale, das mir zurVerfügung steht, würde eine genauere Besprechung der histologischen Einzelbefunde zu viel Zeit und Raum beanspruchen, ohne daß sich daraus ein wesentlicher Nutzen ergeben würde; deswegen werde ich die gefundenen Veränderungen, soweit es geht, summarisch schildern und dabei so vorgehen, daß von den kleinsten eben noch sichtbaren Spuren zu den gröbsten Veränderungen dieser Art übergegangen wird.

Die Veränderung kleinsten Grades findet man in Fig. 1 bei a und 37 (Taf. VII und XVI) abgebildet. Zwischen den sonst ganz intakten Fibrillen finden sich ganz kleine Sternchen eingestreut, welche aus feinsten schwarz gefärbten, in unregelmäßiger Sternform zusammenliegen- 
den Fäserchen bestehen und an kleinste Krystallsternchen erinnern. Diese kleinsten Sternchen haben meist den Durchmesser von etwa $2 \mu$; sie liegen bald einzeln, bald in Gruppen beisammen und konfluieren dann sehr häufig, so daß man größere Konvolute der Fädchen vor sich hat. Konfluieren kleinere Gruppen, so erkennt man in dem Konglomerat noch ganz gut die Einzelsterne (Fig. 1b, Taf. VII), in den etwas größeren Konvoluten (Fig. 1c, Taf. VII), aus denen die Fädchen in längeren wirren Strähnchen hervorragen, ist dies nur noch stellenweise angedeutet. Zugrunde gegangene Elemente oder in Destruktion befindliche Gewebsbestandteile sieht man in der nächsten Nähe der Sternchen nie; sie liegen meistens in dem nicht wesentlich veränderten Fasergewirr der Rinde, wobei die Achsencylinder um die größeren Sternchen immer, um die kleinen sehr häufig bogenförmig verlaufen, ein Verhalten, welches nur als Ausdruck einer Verdrängung des nervösen Gewebes durch die Sternchen, die ich hier auch kurzweg als Drusen bezeichnen möchte, angesehen werden kann.

Die nächstgrößeren Formen, die auf Grund ihres regelmäßigen Baues noch eine größere Ähnlichkeit mit Krystalldrusen besitzen, sind in Fig. 2 und 3 (Taf. VII) dargestellt. In einer kleinen Nische des Gewebes liegen morgensternähnliche Gebilde, deren Größe zwischen 8 und $30 \mu$ schwankt; besonders hervorzuheben ist ein eigenartiges Verhalten derselben bei der Silberimprägnation; ein Teil dieser Drusen färbt sich nämlich wie die vorigen tiefschwarz, aber die meisten derselben nehmen eine braunviolette bis rötlichgelbe Tinktion an, wodurch sie sich sehr deutlich von dem ganz schwarz gefärbten nervösen Geflecht der Rinde abheben ${ }^{1}$ ). In diesen Drusen sind die einzelnen Fäserchen streng radiär angeordnet, verlaufen ganz gerade und sind auch meist gleich lang, so daß die Druse wie gleichmäßig zugeschoren aussieht; nur ausnahmsweise ragen einzelne Fädchen etwas über die anderen heraus. Utber die Beschaffenheit des Zentrums läßt sich bei der Kleinheit der Gebilde und der Dicke unserer Schnitte nichts Sicheres aussagen.

Auch diese morgensternähnlichen Drusen liegen immer frei im Gewebe und verdrängen es, was aus der Ausbiegung der benachbarten Achsencylinder zu ersehen ist. Nie lassen sich in der nächsten Nähe irgendwelche degenerierende oder sonstwie zugrunde gehende nervöse Bestandteile nachweisen. Fig. 4 (Taf. VII) zeigt eine etwas größere Druse. Die Fäserchen sind schwarz gefärbt, zu einer morgensternartigen Bildung zusammengefügt, das Gewebe ist ringsherum retrahiert, so daß ein freier Hof herum entsteht, und an einigen Stellen ragen aus der Peripherie des Morgensterns feine, aus wirr verflochtenen

1) Auf den beigegebenen Tafeln ist diese „,metachromatische“ Färbung der Drusen der Einfachheit halber nur in einer einzigen Nuance dargestellt. 
Fädchen zusammengesetzte Strähnchen hervor, die an die Bildungen der Fig. 1c erinnern. Jn Fig. 5 (Taf. VII) sieht man eine Druse, die mit der letzterwähnten Bildung manche Ähnlichkeit besitzt, nur daß die Fädchen einen bräunlichen Ton angenommen haben, die Zöpfe etwas massiger und länger sind, wie überhaupt die ganże Druse auch etwas größer ist als in der vorigen Figur. Auch in diesem Bilde sieht man die Verdrängung der bogenförmig ausweichenden Achsencylinder. Diesen beiden zuletzt geschilderten Drusen ähnelt in mancher Hinsicht Fig. 6 (Taf.VIII), die - nebenbei bemerkt — bei etwas stärkerer Vergrößerung gezeichnet ist. Aus dem deutlich morgensternartigen zentralen Kern ziehen rötlich gefärbte Strähnchen, welche sich am Rande des Nervengewebes, von diesem durch die Farbe unterschieden, zu einem Halbring verbinden. In Fig. 7 (Taf. VIII) - ebenfalls bei stärkerer Vergrößerung gezeichnet - ist der zentrale Morgenstern nur angedeutet, die radiär verlaufenden Zöpfe sind viel länger und breiten sich stellenweise fächerförmig aus; die ganze Bildung wird von einem aus wirren Fäserchen gebildeten Ring eingesäumt, welcher aus denselben Fäserchen besteht, die hier jedoch ganz wirr verlaufen und ein dichtes Geflecht bilden, welches stellenweise mit den Zöpfen zusammenhängt. Fig. 8 (Taf. VIII) zeigt eine Bildung, in der die Fäserchen schwarz wie die Fibrillen der Umgebung gefärbt sind; man sieht einen ,zentralen Morgenstern", von dem radiäre Zöpfe ausgehen; das benachbarte nervöse Gewebe ist retrahiert und wird von einem aus dichten wirren Fäserchen gebildeten Ring begrenzt, der bei oberflächlicher Betrachtung so aussieht, wie wenn sich die Fibrillen der Umgebung verdichtet hätten. Bei näherem Zusehen, besonders mit stärkerer Vergrößerung (Immersion mit starken Okularen), erkennt man aber, daß dieser Ring aus denselben Fäserchen besteht, aus welchen der zentrale Morgenstern und die Zöpfe zusammengesetzt sind, nur mit dem Unterschiede, daß die Fäserchen im Ring ganz wirr und unregelmäßig sich verflechten. Das beweisen überdies auch die Fig. 6 und 7 (Taf. VIII), in denen die ganze Druse samt dem peripheren Kranz eine andere Farbe als die Achsencylinder angenommen hat.

Eine bemerkenswerte Färbung zeigt sich in Fig. 10 (Taf. VIII); hier ist das Zentrum der Druse und die Faserzöpfe braun, der periphere Ring dagegen schwarz gefärbt; die braunen Zöpfe gehen ins Fasergewirr des schwarz gefärbten Randringes über, wobei man an einigen Stellen die Vermischung der braunen, mehr gerade verlaufenden Fäserchen mit den feineren und unregelmäßig wirr verschlungenen schwarzen Fäserchen sieht. Etwas deutlicher, weil bei stärkerer Vergrößerung gezeichnet, zeigt sich dieses Verhalten in Fig. 11 (Taf. VIII). Man sieht hier sehr schön ausstrahlende breite Zöpfe, die Fächer- und Flammenform aufweisen, und einen aus dichten schwarzen Fäserchen bestehen- 
den Ring, in dem stellenweise kleinste Konvolute braungefärbter Fäserchen eingestreut sind, welche wohl den braunen Zöpfen entstammen.

Auch hier dokumentiert sich die Veränderung des Gewebes in den bogenförmig ausweichenden Achsencylindern; unter Umständen ist das Gewebe etwas mehr retrahiert, als dies in den bisherigen Zeichnungen zu sehen war. Ein solches Verhalten zeigt Fig. 12 (Taf. IX). Die Druse ähnelt im allgemeinen den vorhin geschilderten, nur daß hier der durch Retraktion entstandene Raum größer ist und grau gefärbte, leicht gekörnte, sonst strukturlose und schollig angeordnete Massen einschließt. Unter diesen Massen findet sich (links oben) ein länglicher untergehender Zellkern und mitten durch zieht ein Achsencylinder, beides ein sonst seltenes Vorkommnis.

Der vorigen Figur ähnelt in mancher Hinsicht Fig. 13 (Taf. IX). Auch hier ist ein zentraler Morgenstern, aus dem mehr oder weniger lange Büschel entspringen; der Fädchenring ist ziemlich weit vom Zentrum entfernt, so daß ein großer Hof entsteht, der von den Strähnchen durchzogen wird; zwischen diesen liegen nun kleine, aus denselben Fädchen bestehende sternartige Bildungen und dazwischen rötlich gefärbte, leicht granulierte Schollen. Stellenweise werden einzelne der Schollen von den Fädchen umrandet. In Fig. 14 (Taf. IX) ist ebenfalls ein deutlich morgensternartig zusammengesetzter Zentralkern, der eine rotbraune Färbung angenommen hat und aus dem kürzere Büschel, die hier ganz schwarz gefärbt sind, heraustreten. Der innerhalb des ziemlich dicken und dichten Randringes liegende Hof ist ausgefüllt mit rötlichgrau gefärbten, scharf abgegrenzten Schollen, die deutliche Granulierung zeigen; an einigen Stellen gewinnt man den Eindruck, als ob die Fädchenknäuel in die granulierten Massen übergehen würden. Bei * liegt eine kernartige Bildung, welche wohl einem zugrunde gehenden Zellkern entspricht. Eine der Fig. 13 in mancher Hinsicht verwandte Bildung zeigt Fig. 15 (Taf. IX). Bei schwacher Vergrößerung sieht die hier gezeichnete Druse so aus, wie wenn sie aus krümeligen Zerfallsmassen bestehen würde. Mit der Immersion sieht man, daß die Krümel aus lauter feinsten Fädchen bestehen, die zum Teil sternartig angeordnet sind und stellenweise kleine wirr verlaufende Zöpfe bilden; in der linken oberen Ecke sieht man eine Andeutung von Hofbildung um ein kleines zentrales Faserbüschel; den Rand der Druse bildet ein Ring, der aus feinsten wirr verschlungenen Fädchen besteht und der stellenweise auch eine Masse feinster Körnchen enthält. Zwischen den Fädchenkonvoluten sieht man leicht granulierte grau gefärbte Massen. Rechts, bei $a$, außerhalb der Druse sieht man ganz isoliert und frei im Gewebe eine ganz kleine sternartig gebaute Druse.

Die Ähnlichkeit der Fig. 13 (Taf. IX) und der Fig. 15 (Taf. IX) liegt darin, $d a B$ in beiden die leicht granulierten Schollen sich vorfinden, 
nur daß die Farbe verschieden ist und daß in Fig. 15 die zwischen den Schollen befindlichen Faserbündel kleiner und zahlreicher sind.

Einen von den vorigen Drusen abweichenden Bau zeigt Fig. 16 (Taf. X). In dem zur Seite gedrängten Gewebe sitzt ein dichtes Konvolut dickerer, braunrot gefärbter Fäden, welche, zum Teil zu breiteren Streifen zusammengeschlossen, sich derartig durchflechten, daß die Bildung das Aussehen eines Korbgeflechtes bekommt.

Im Gegensatze zu den früheren Bildungen liegt das nervöse Gewebe dem Faserkonvolut ganz eng an und an einigen Stellen zeigen sich auch Verflechtungen der Fädchen mit den Nervenfibrillen. Nie aber ist auch nur eine Spur eines Überganges des nervösen Gewebes in die Fädchenmassen zu sehen.

Alle bisher beschriebenen Bildungen hatten unter anderem auch das gemeinsam, daß sie eine abgerundete Form hatten und sich ganz scharf von dem umgebenden Gewebe absetzten. Dieselben feinen fädigen Massen kommen aber noch in einer anderen, auf Fig. 17 (Taf. X) dargestellten Formation vor. Hier sieht man bei schwächerer Vergrößerung eine eigenartig fleckige, schwarze Färbung, wie wenn sich das Gewebe fleckweise dichter als sonst gefärbt hätte; die Immersion zeigt, daß diese dunklere Färbung durch ein dichtes, fädig-körniges Maschenwerk bedingt ist, das, ohne scharfe Grenzen zu zeigen, im Gewebe sitzt; an diesen Stellen scheinen im Bielschowsky-Präparate die Achsencylinder mit wenigen Ausnahmen vollkommen zu fehlen, in der Umgebung der ,dunklen Flecken" sind sie spärlicher als sonst und sind nicht so dunkel gefärbt wie in der weiteren Umgebung. Bei sehr starker Abblendung sieht man aber, daß wenigstens ein Teil der Achsencylinder noch besteht, aber keine Farbe angenommen hat.

Stellenweise sind nun diese fädig-körnigen Massen über größere Strecken der Hirnrinde konfluiert (Fig. 18, Taf. X); hier sind an Flächen, welche manchmal auch größer als das Gesichtsfeld einer Immersion sind, die Achsencylinder und das fibrilläre Netzwerk vollkommen geschwunden und deren Stelle wird eingenommen von den erwähnten Massen, die manchmal auch ziemlich scharfe Grenzen aufweisen. Vom nervösen Gewebe persistieren darin nur die Ganglienzellen, die sehr schwer geschrumpft sind und den größten Teil ihrer Fortsätze verloren haben; weiter liegen darin hie und da dunkel gefärbte Zellkerne, welche wohl der Glia angehören.

Ein genauerer Vergleich dieser Fädchenmassen mit den Drusen zeigt, daß sie morphologisch aus denselben Fäserchen bestehen, die den äußeren Ring der größeren Drusen und dessen Übergang in die Faserzöpfe bilden.

Bei Betrachtung der meisten der bisher gebrachten Figuren fällt es auf, daB sich die Drusen immer in der Nähe irgendeines Gefäßes 
befinden; ein solches Zusammentreffen könnte zwar bei der reichen Gefäßverzweigung der Hirnrinde auch zufällig sein, ohne daß ein innerer Zusammenhang zwischen Drusen und Gefäßen angenommen werden müßte, doch ist das Zusammentreffen, und besonders an Serienschnitten untersucht, so regelmäßig, daß ein Zufall unwahrscheinlich wird. Es gibt aber vereinzelte Fälle, in denen die engen Beziehungen der Drusen zu den Gefäßen ganz einwandfrei zutage kommen. Fig. 19 (Taf. X) zeigt diese Verhältnisse. Hier liegen die kugelförmigen Drusen immer irgendeinem Gefäße an oder umscheiden dasselbe meist derartig, daß sie an irgendeiner Biegung des Gefäßes oder zwisehen den Ästen einer Verzweigung lokalisiert sind; in der Abbildung sind zwar auch zwei Drusen eingezeichnet, die zu keinem Gefäße in Beziehung zu stehen scheinen, Serienschnitte zeigen aber, daß auch diese einem Gefäße anliegen, welches sich aber gerade unter oder oberhalb der Schnittfläche befindet.

In mehreren Fällen zeigt sich der enge Anschluß der Drusen an die Gefäße in einer Art, die Fig. 20 (Taf. XI) demonstriert. Die Drusen bestehen hier aus den dickeren geschwungenen, rötlich gefärbten $\mathrm{Fa}$ sern, die den in Fig. 16 (Taf. X) abgebildeten ähneln; stellenweise ist die Färbung der Fasern undeutlich und wie verwaschen; die Drusen sitzen durchwegs den Gefäßen an und dort, wo, wie in der Figur, gerade ein größeres Gefäß längs getroffen ist, sieht man die Drusen halbkugelförmig dem Gefäße anliegen; sie sitzen durchwegs außerhalb der Adventitia des Gefäßes, verdrängen das Gewebe, senden aber immer einige Ausläufer in den etwas retrahierten perivasculären Raum. In dieser Art sind (an Serienschnitten demonstrierbar) oft ganze Gefäßbäumchen von Drusen besetzt.

Ein ganz besonders rätselhaftes Verhältnis der Drusen zu Gefäßen zeigte sich bei zwei anderen Fällen; dasselbe wird in den Fig. 21-24 (Taf. XI) dargestellt. In Fig. 21 (Taf. XI) sieht man ein eigenartig verdicktes Gefäß; man erkennt das Gefäßlumen mit einer Endothelzelle; die linke Wand des Gefäßes ist ganz dünn, hat eine dunkelbraune Färbung und verbreitert sich exzentrisch nach der rechten Seite hinüber; sie bekommt daselbst ein streifiges Aussehen und splittert sich nach der äußeren Peripherie in feinste büschelartig angeordnete Fädchen auf. Das durch das tiefschwarz gefärbte Fibrillennetz dargestellte nervöse Gewebe ist durch einen etwas erweiterten Perivasculärraum von dem Gefäße abgehoben; der Rand des nervösen Gewebes ist durchflochten von einem dichten aus braunen Fäserchen bestehenden Netzwerk, das bei $b$ eine morgensternartige Bildung aufweist und an einer Stelle durch einen aus denselben Fäserchen bestehenden Zopf mit dem das Gefäß umgebenden Fasersaum zusammenhängt. Eine genauere Betrachtung, besonders mit starker Vergrößerung zeigt, daß 
all die braunen Fäserchen identisch sind, nur verschieden gelagert und verflochten erscheinen.

Ein ähnliches Verhalten zeigt Fig. 22 (Taf. XI), die zwei Gefäße desselben Falles darstellt; diese Gefäßchen haben eine Art Pelzbesatz umgelegt, der aus denselben feinen braunen Fäserchen besteht; deren Intima erscheint in Form feiner schwarzer Fäserchen und Lamellen gefärbt, hie und da (aber nicht gerade in der Zeichnung) sieht man noch Endothelzellen. Das Lumen der Gefäßchen ist durchgängig und enthält als Beweis der Durchgängigkeit stellenweise rote Blutkörperchen. An den größeren Gefäßen zeigt sich dieser Pelzbesatz eigenartig modifiziert (Fig. 23, Taf. XI); man bemerkt an dem Querschnitte des Gefäßes als innerste Auskleidung eine Lage gequollener Endothelzellen und eine Menge schwarzer Körnchen, welche wohl als deren Einschlüsse anzusehen sind; weiter folgt eine leichte, gelblich gefärbte Schicht von ungleicher Dicke, die einen etwas gewellten dunklen und nach unten unterbrochenen Rand besitzt. Nach außen davon ist eine ganz hell gefärbte Schichte, die aus feinsten, nur leicht bräunlich gefärbten Fäserchen besteht, und diese ist wieder von einer äußeren dunkler gefärbten und nach innen durch einen noch dunkleren Streifen konturierten Schichte umgeben. Auch diese äußerste Schichte besteht aus Fäserchen, die zwar an der inneren Grenze wenig deutlich hervortreten, nach außen aber dunkler gefärbt stachelförmig vorragen. Die Fäserchen sind streng radiär angeordnet, so daß sie an Schief- oder Längsschnitten des Gefäßes schief oder quer getroffen werden; dasselbe ist auch an dem oberen Pol des etwas schief gehenden Querschnittes unserer Abbildung zu sehen. In ähnlicher Weise sind an einzelnen Stellen beinahe die gesamten Gefäße eines oder mehrerer Gefäßbezirke verändert. Eigenartig sehen diese Gefäßveränderungen bei Färbung mit Hämatoxylin-Eosin oder nach v. Gieson aus. Hier erscheint das Gefäß mit einer hyalin aussehenden Masse umgeben, nur bei starker Vergrößerung sieht man - auch bei dieser Färbung -, daß sich die hyaline Masse wie bei der Silberfärbung in feinste Fäserchen auflösen läßt, und ebenso sieht man, wenn auch nicht so deutlich, die Differenzierung in einzelne Schichten.

Stellenweise findet man in diesen Gehirnen Gefäße von der in Fig. 24 (Taf. XI) dargestellten Art. Diese Gefäße sind von bräunlich gefärbten Massen umschlossen, welche zum Teil eine krümelige Struktur haben, stellenweise aber noch nach außen in feinste zackige Spitzen enden und dabei auch noch morgensternartige Bildungen aufweisen; das Lumen der Gefäße ist stellenweise verschwunden, die Intima ist schwarz gefärbt und in feinste Brocken und Körnchen zerfallen; in diesen Gefäßen sind keine Endothelzellen färbbar, das Lumen scheint auch nicht mehr durchgängig zu sein. 
In welchem Verhältnis stehen nun diese drusigen Bildungen zu dem umliegenden Gewebe? Vorerst ist zu betonen, daß die Drusen das nervöse Gewebe wegdrängen, wie dies an den meisten der vorhin geschilderten Abbildungen und auf Fig. 26 (Taf. XII) zu sehen ist. Die längeren Achsencylinder, welche in der nächsten Umgebung der Drusen verlaufen, biegen in mehr oder weniger ausgesprochenem Bogen um die Drusen herum und sind meist nicht weiter verändert; manchmal weisen sie aber in der Nähe der Drusen spindelförmige Auftreibungen auf, die bald nur kaum angedeutet sind, bald aber auch größere Dimensionen zeigen können. Diese Auftreibungen sind auf Fig. 25-32 (Taf. XII bis XIV) dargestellt; sie finden sich nicht in allen, sondern nur bei einem Teile der Fälle und sind immer kranzartig um die Druse gestellt, und zwar so, daß der dünne Hals nach innen steht, das kolbige Ende nach außen gerichtet ist und das Areal der Druse überschreitet. Die Kolben sind von verschiedener Größe, die kleinsten $1 / 2-2 \mu$ dick und etwa $6 \mu$ lang, doch findet man auch Exemplare von 4-5 $\mu$ Dicke und einer Länge bis zu $20 \mu$. Bei einer großen Zahl dieser Kolben kann man einen direkten Zusammenhang des fädigen, zentral gerichteten Endes mit den Achsencylindern der Umgebung nachweisen, was um so häufiger gefunden werden kann, je dickere Schnitte man untersucht. An diesen sind aus selbstverständlichen Gründen auch die Achsencylinder auf größere Strecken zu verfolgen, so daß, abgesehen von anderen Umständen, eine Verwechslung mit anderen Elementen ausgeschlossen werden kann. Da die fädigen Enden der Keulen nach dem Inneren der Druse gerichtet sind, müssen die Achsencylinder auch in den Rand der Druse einbiegen. Dieses Verhalten zeigt sehr deutlich Fig. 25 (Taf. XII). Die Fibrille $c$ windet sich nach mehrfachen vertikalen, in der Zeichnung nicht darstellbaren Biegungen, und nachdem sie an einer Stelle eine leichte Verdickung erfahren hatte, in die Druse, biegt in scharfem Bogen ab, um in eine große Keule überzugehen und damit zu enden. Ein anderer Achsencylinder zieht ebenfalls nach mehrfachen Windungen zum Rande der Druse und endet hier in kleeblattartiger Dreiteilung mit drei Keulen (bei $b$ ). Häufig zeigt sich, daß die Keulen dort, wo man sie und ihre Achsencylinder auf längere Strecken verfolgen kann, nicht als Endkeulen eines Achsencylinders aufsitzen, sondern als seitlicher Auswuchs sich darstellen. Ein solcher Achsencylinder hat entweder nur einen derartigen seitlichen Auswuchs (Taf. XIII, Fig. 30b) oder mehrere (Taf. XII, XIII, Fig. 28, 29, 30c, d, g). Der Stiel ist am Ansatzpunkte dreieckig verbreitert und endet entweder mit einer einzigen Keule ('Taf. XII, XIII, Fig. 28, 30 b, g), oder aber er teilt sich auch mehrfach, um in mehrere Keulen von verschiedener Größe und häufig auch von verschieden gewundener Gestalt überzugehen. Dadurch kommen häufig mistelartige Formationen zustande (Taf. XII, XIII, XIV, Fig. 25, 28, 
$29,30,31 \mathrm{~b}$ ). Besonders instruktiv und einwandfrei zeigt sich das Verhältnis der Keulen zu dem Achsencylinder in der Fig. 28 (Taf. XII), welche einen Tangentialschnitt einer Druse darstellt; darin ist ein Achsencylinder, der über der Druse verläuft und gerade in deren Randpartie zu liegen kommt, in ganzer Lünge getroffen und zeigt mehrere Auswüchse. Außer den bisher geschilderten, mehr regelmäßigen Keulenformen kommen auch häufig verschiedene unregelmäßige Gestalten der Auswüchse vor; sie sind länglich, oft bandförmig, am Ende mit einem kleinen Knopf versehen, haben einen kürzeren oder längeren Stiel, gehen einzeln oder multipel vom Achsencylinder ab; sie verlaufen gerade oder in mehreren Ebenen oft in ganz wirren und schwer zu zeichnenden Windungen, ihre Form ist oft ganz unregelmäßig und banddartig verschlungen, kurz Bildungen von einer enormen Mannigfaltigkeit, die die Fig. 30a, 31a, b, d (Taf. XIII, XIV) nur annähernd wiedergeben können. Die Keulen, besonders die kleineren, sind in den meisten Drusen am Rande radiär gestellt und manchmal so dicht, daß sie einen sofort in die Augen springenden, dunklen Kranz um die Drusen bilden (Taf. XII, XIV, Fig. 25. 27, 29, 32). Der größte Teil der Keulen ist undurchsichtig, schwarz gefärbt, ein geringerer Teil, besonders in den etwas schwächer gefärbten Präparaten, zeigt eine lichtere graue Färbung (Taf. XII-XIV, Fig. 25, 29, 30, 31) und enthält im Innern ein dichtes, unentwirrbares Netz. Betrachtet man diese Keulen mit sehr starken Vergrößerungen, so sieht man, daß der Stiel von mehr parallel verlaufenden, etwas welligen, feinsten Fäserchen ausgefüllt ist, die dann gegen das kolbige Ende sich verwirren. In Fig. 31 a (Taf. XIV) ist eine Keule dargestellt, aus deren ganz schwarz gefärbtem Stiel mehrere Fibrillen entspringen, die in der nur grau gefärbten Keule isoliert enden. Fig. $31 \mathrm{~b}$ (Taf. XIV) zeigt Keulen, welche das fibrilläre Netz nur in den Randpartien enthalten, wogegen das Zentrum nur diffus grau gefärbt ist. Querschnitte solcher Keulen ergeben bei der sehr starken Vergrößerung ein Bild wie Fig. 33a (Taf. XIV): am Rande ein wirres Maschenwerk quergetroffener Fäserchen, wogegen die Mitte grau resp. rötlich gefärbt erscheint. Bei kleineren Keulen wird der Rand häufig nur durch einen ganz schmalen Fibrillensaum dargestellt und das Zentrum bleibt ungefärbt (Taf. XIV, Fig. 31c). Die in der nächsten Umgebung der Drusen verlaufenden Achsencylinder werden, wie schon bereits erwähnt wurde, durchwegs zur Seite gedrängt, was am deutlichsten an den bündelweise verlaufenden Radiärfasern zu sehen ist. Die unregelmäßig und quer verlaufenden Fasern der Rinde endigen scheinbar am Rande der Drusen, in Wirklichkeit aber winden sie sich mehrfach hin und her und häufig enden sie dann in einer Keule. Die periphere Zone der Drusen enthält demnach häufig ein dichtes Netz von Fibrillen, das Zentrum ist aber meistens frei von Achsencylindern und Nerven- 
fasern, nur ausnahmsweise ziehen auch isolierte Achsencylinder noch durch (Taf. IX, XII, Fig. 12, 25). Weiter zeigen sehr viele Achsencylinder in der Nähe der Drusen spindelförmige Aufquellungen. Entweder sind es nur ganz leichte, manchmal gerade noch merkbare Verdickungen (Taf. XII, Fig. 26), oder sie sind massiger und von beträchtlicher Länge (Taf. VIII, Fig. 6, 27 und 29) oder sie sind von einer Mächtigkeit, die der Größe der Ganglienzellen gleichkommt (Taf. XII, Fig. 25). Ein Achsencylinder hat entweder eine einzige oder mehrere Auftreibungen (Taf. XII, Fig. 29), und manchmal sitzen einem derartig spindelförmig aufgetriebenen Achsencylinder auch Keulen auf (Taf. XII, XIII, Fig. 29, 30 b). Als ein sehr seltenes Vorkommnis sieht man eine Spaltung eines Achsencylinders, das Fig. 30d (Taf. XIII) darstellt, doch ist immerhin auch möglich, daß in diesem Falle die Enden der zwei Spaltfäden zu abgeschnittenen Keulen gehören. Die kolbigen Wucherungen der Achsencylinder kommen nur in etwa $50 \%$ der Fälle vor; dabei auch nur um die größeren Drusen; am häufigsten finden sie sich um das Stadium V, dann um Stadium IV, seltener um Stadium III, nie in der Nähe der Stadien I und II, ebenso auch nie um Stadium VIII. (Siehe Einteilung der Stadien auf Seite 392.) Warum sich in den einzelnen Fällen die Keulen vorfinden, in den anderen nicht, ist nicht klar geworden, im histologischen Verhalten war sonst keine Differenz merkbar.

Eine eigenartige Veränderung der Achsencylinder zeigt sich noch an den Rindenpartien, welche in der in Fig. 17 (Taf. X) dargestellten Form verändert sind. Dort, wo die fädigen Massen das Gewebe ohne deutliche Abgrenzung infiltrieren, sind nur die dickern der durchziehenden Achsencylinder gefärbt, wogegen die größte Mehrzahl derselben ungefärbt, aber bei stärkerer Abblendung noch deutlich sichtbar ist.

Die Ganglienzellen sind in allen Fällen verändert; man findet da wohl alle Formen der Veränderung der Ganglienzellen, von den leichteren bis zu den schwersten. Die Zellen zeigen undeutliche Fibrillen, die Fibrillen verkleben in den Fortsätzen, so daß die letzteren ganz schwarz gefärbt sind, weiter bekommt die Zelle ein körniges Aussehen, enthält nur wenige Fibrillen, meist in der Nähe der Fortsätze, oder aber es ist überhaupt keine distinkt gefärbte Fibrille mehr zu sehen. Bei schwerer Zelläsion hat sich das Silber in unregelmäßigen, scholligen Massen in der Zelle niedergeschlagen, die Zelle ist unregelmäßig geschrumpft, hat die Fortsätze eingebüßt usw. Daneben sieht man auch die verschiedensten Veränderungen des Zellkerns und des Nucleolus. Diese Erkrankung der Ganglienzellen ist nicht in allen Gegenden des Gehirns gleich stark; sehr schwere Veränderungen finden sich in den Rindenabschnitten, welche am dichtesten von Drusen durchsetzt sind, besonders wenn es sich um die Frühstadien derselben handelt. Dabei 
ist zu betonen, daß die obersten Zellagen immer am schwersten affiziert sind, und daß sich die Veränderung nicht auf die den Drusen am nächsten liegenden Zellen beschränkt, sondern mehr diffus ist.

Die allerstärksten Veränderungen der Zellen sind in den Gehirnen anzutreffen, deren Rinde von den fädigen Massen diffus infiltriert wird, und zwar sind diejenigen Ganglienzellen am stärksten affiziert, welche von den Massen direkt umgeben sind; diese Zellen machen den Eindruck von zugrunde gehenden Gebilden (Taf. X, Fig. 18).

Eine eigenartige, ganz unklare Veränderung der Zellen zeigt sich in einer kleinen Zahl von Fällen; dieselbe ist mir schon seit längerer Zeit bekannt und wurde in letzter Zeit bereits von Perusini eingehend beschrieben. Die Veränderung kommt - was ich gleich Perusini gegenüber betonen muß - nur bei einer geringen Anzahl meiner Fälle vor, und zwar immer nur in denjenigen, bei denen sonst allenthalben die Ganglienzellen sehr schwere Destruktionen und meist vollkommenen Schwund der Fibrillen aufweisen. Da findet man dann die Zellen, deren Leib manchmal noch die Ganglienzellform beibehalten hat, häufig aber bereits sehr stark deformiert ist, von eigenartigen dicken, intensiv schwarzen Fasern ausgefüllt, welche den Zellkern in wellig, schraubenförmig, spindel- oder ganz unregelmäßig verlaufenden Zügen umkreisen, in der Zelle selbst enden oder aber auch durch einen Zellfortsatz heraustreten (Taf. XV, Fig. 34). Die Fibrillen sind sehr dick und klumpig; manchmal findet man aber derartige Bildungen, in denen ganz feine, parallel verlaufende Fibrillen in ähnlicher Anordnung zu finden sind, wie in den erstgenannten Zellen, woraus man schließen kann, daß die gröberen Fibrillen nur Konglomerate feinerer Fibrillen sind (Taf. XV, Fig. 34a). Manche dieser Bildungen sind vollkommen kernlos und sehen gar nicht mehr wie Zellen aus, sondern wie freie Wucherungen von Fibrillen; Fig. 35( Taf. XV) stellt eine derartige Fibrillenwucherung von ungewohnter Form dar; es ist möglich, daß diese auch einer derartigen Zelle entstammt, nur ist die Formation viel zu groß dazu; man müßte annehmen, daß dann die Fibrillen daselbst noch außerhalb der Zelle weiter gewuchert wären. Eine derartige Bildung ist mir nur einmal zu Gesicht gekommen, so daß eventuelle Übergangsbilder bis jetzt fehlen. Ebenfalls ganz eigenartig ist die Fig. 36 (Taf. XV), welche aus der Molekularschichte des Kleinhirns stammt; sie zeigt eine sonst nicht gesehene Art der fibrillären Anordnung, in deren Zentrum eine kernartige Bildung liegt; dieses Fibrillenkonvolut dürfte auch in dieselbe Kategorie gehören. Diese ,grobfaserige Fibrillenw ucherung der Ganglienzellen", wie ich diese Formation kurz nennen will, fand ich unter 58 Fällen nur 10 mal, also bei $17 \%$.

In allen Fällen fand sich eine Wucherung sowohl der zelligen als auch der faserigen Neuroglia, in der bei atrophischen Prozessen gewöhn- 
lichen Weise. Einen engeren Zusammenhang der Neuroglia mit den Drusen konnte ich nirgendwo erblicken, was ich gegenüber einigen später noch zu erörternden Angaben a us der Literatur betonen möchte. Es war zwar in der Umgebung der großen älteren Drusen, besonders solcher, welche auch viele Keulen enthielten, häufig die Glia gewuchert, meist in Form der großen multipolaren Gliazellen, die Gliafasern dringen auch manchmal in die Drusen hinein, aber um die kleinen und kleinsten konnte eine Gliavermehrung nicht nachgewiesen werden.

Die Blutgefäße zeigten außer dem bereits oben beschriebenen Fädchenbesatz noch Veränderungen, die man sonst bei senilen und atrophierenden Gehirnen kennt. Auf diese soll hier auch nicht weiter eingegangen werden.

Die bisherigen Schilderungen beziehen sich durchwegs auf Präparate, welche nach der Methode von Bielschowsky hergestellt waren, weil nur damit die Darstellung der fraglichen Gebilde am vollkommensten gelang. Außerdem wurden aber auch noch die meisten der gebräuchlichen Färbemethoden verwendet.

Die kleinsten der Drusen und die infiltrierenden Fädchenmassen konnte ich bisher nur mit der Silberaldehydmethode darstellen. Die größeren Drusen färbten sich dagegen mit den meisten basischen Farbstoffen.

Nach Paraffineinbettung kann man dieselben in mehr oder weniger deutlicher Weise mit beinahe allen basischen Anilinfarben färben, am besten mit Carbolfuehsin oder Methylviolett mit nachfolgender Alkoholdifferenzierung. Diese Färbung eignet sich am besten für die mittelgroßen Drusen. Es färbt sich darin der zentrale morgensternähnliche Kern sehr deutlich, man sieht den radiären Aufbau ähnlich wie im Silberpräparate, dagegen sind der Hof und die Zöpfe zwar auch gefärbt und als Ganzes von dem Nervengewebe abgrenzbar, doch läßt sich daselbst der fädige Aufbau nicht deutlich genug erkennen.

Die Nisslfärbung, besonders nach Celloidineinbettung, läßt die Drusen ungefärbt.

Mit Hämatoxylin-Eosin lassen sich die größeren Drusen ebenfalls ganz deutlich darstellen. Das Zentrum färbt sich dann (Taf. XVI, Fig. 38) in bläulich-dunkler Farbe, der sternartige, fädige Aufbau ist deutlich erkennbar, die Randpartien sind in gleichem Tone gefärbt wie das Nervengewebe und nur durch die Struktur unterschieden. Ähnliches sieht man auch bei der Färbung nach van Gieson.

Alle unsere spezifischen Färbungen ergaben ein negatives Resultat: so die Färbung auf Fibrin, Mucin, Elastin, Fett, Kalk, Eisen und alle spezifischen Bakterienfärbungen; bei allen blieben die Drusen resp. die sie zusammensetzenden Fädchenmassen ganz ungefärbt. 
Bei der Weigertschen Markscheidenfärbung sind die in der markreicheren unteren Rindenpartie liegenden Drusen sehr deutlich als runde Lücken im Gewebe zu sehen, um die herum die Markscheiden bogenförmig ausweichen (Taf. XVII, Fig. 43, 44). Manche der größeren Drusen nehmen bei der Färbung einen etwas dunkleren Ton an als der sonstige, gelbliche Grundton ist und treten dadurch ziemlich scharf und deutlich hervor.

Für die schwache Vergrößerung - also für Utbersichtspräparate -lassen sich die großen Drusen sehr schön darstellen, wenn man nach Pal differenzierte Weigertpräparate mit Methylenblau oder Karmalaun nachfärbt. Dann färbt sich das Grundgewebe grünlich resp. leicht gelblichrot und die Drusen springen in mehr oder weniger dunkelblauer resp. dunkelrot-brauner Tinktion hervor.

Für die Darstellung der feineren Struktur der Drusen eignet sich aber die Methode nicht, sondern nur für die Übersichtspräparate und für die größeren der Drusen.

Eigenartig ist es, daß die Cajalsche Methode die Drusen nur sehr undeutlich färbt, wogegen die Keulen genau so wie die Achsencylinder tief schwarz gefärbt sind. Dagegen färbt Bielschowskys Methode mit Pyridin, bei der die Neuroglia ungefärbt bleibt, die Drusen genau so, wie die gewöhnliche Methode. Die Weigertsche Gliafärbemethode läßt die Drusen vollkommen ungefärbt. Auch die Keulen bleiben ganz ungefärbt, auch dann, wenn man sonst tadellose Ausfärbung der Gliafasern erzielte. Was die Keulen anbelangt, so will ich noch erwähnen, daß sie sich sehr häufig auch mit den Kernfärbemethoden darstellen lassen.

In den betroffenen Gehirnen sind die Drusen in der Großhirnrinde in verschiedener Dichte und Verteilung vorhanden. Es gibt Gehirne, in denen die Drusen so spärlich vertreten sind, daß man oft viele Gesichtsfelder durchmustern muß, bevor man eine Druse entdeckt; von diesem so seltenen Vorkommen der Affektion gibt es alle Abstufungen bis zu einer so dichten Verteilung der Drusen, daß auf $1 \mathrm{~mm}^{2}$ bis 25 Drusen kommen (Taf. XVII, Fig. 41); es ist klar, daß der letzte Fall eine ganz hochgradige Schädigung des Gehirns bedeutet. Dabei finden sich aber die Drusen in den einzelnen Gegenden des Gehirns nicht immer gleich stark vertreten.

Unter den bisher untersuchten 58 Gehirnen, in denen die Drusen vorhanden waren, fanden sich die Drusen nur bei 15 Fällen, also bei $33 \%$, in allen Rindenpartien gleich stark verteilt; bei der Mehrzahl der Fälle gibt es aber Differenzen. Bei 29 Fällen, also 50\%, ist die Stirn immer viel stärker betroffen als die hinteren Partien, ja bei 5 Fällen ist die Veränderung nur im Stirnlappen vorhanden, wogegen sie sonst im Gehirn fehlt. Bei 10 Fällen (17\%) sind die Drusen in der Stimpartie 
weniger relchlich vertreten und von diesen fehlen in 2 Fällen die Drusen in der Stirn vollkommen, wogegen sie in den hinteren Hirnpartien vorhanden sind. Dabei ist die Verteilung meist derartig, daß die gleichen Teile der beiden Hemisphären gleiche Veränderungen zeigen; aber auch da gibt es Ausnahmen. Die Verteilung der Drusen ist manchmal auch sehr unregelmäßig, indem in ganz eng benachbarten Partien die Stärke der Veränderung hochgradig schwankt; ich habe einen Fall z. B. beobachtet, bei dem sich in der oberen Hälfte der Zentralwindung sehr reichliche Drusen vorfanden, wogegen der untere Teil der Windungen vollkommen drusenfrei war.

Die Drusen finden sich regelmäßig in der grauen Hirnrinde, sind dabei am reichlichsten in den oberen Schichten und nehmen nach unten hin immer ab. In dem Markweiß kommen die Drusen überhaupt nicht. vor.

Viel seltener als im Großhirn kommen sie in den anderen grauen Massen des Gehirns vor, so in Thalamus opticus, Nucleus caudatus und lentiformis, in der Rinde des Kleinhirns; dagegen fand ich sie nie in der Medulla oblongata und im Rückenmark.

Stammganglien und Kleinhirn untersuchte ich bei 10 Fällen, deren Hirnrinde reichlich von Drusen durchsetzt war. Von diesen hatten 2 Fälle Drusen im Kleinhirn und ein Fall Drusen in den Stammganglien. Im Kleinhirn waren die Drusen immer nur sehr spärlich vertreten, saßen nur in der Mitte der Molekularschichte, zeigten meist das Stadium III (vide später) und enthielten nie Keulen.

Bei einer so neuartigen, ungewohnten und nicht recht unter die bisher bekannten Prozesse einregistrierbaren pathologischen Veränderung muß man an erster Stelle die Möglichkeit von Kunstprodukten ausschließen. Abgesehen von anderen, noch später im klinischen Teil zu erwähnenden Umständen sprechen gegen Kunstprodukte die Gleichartigkeit der Befunde und die Übereinstimmung bei verschiedenen Färbungen, und schließlich der Umstand, daß man wenigstens die großen Drusen auch im unfixierten und ungefärbten frischen Gefrierschnitt sehen kann. Gerade das letztere Moment schließt eine jede Diskussion über Kunstprodukte aus.

Aus denselben Gründen kann man auch die kolbigen Wucherungen der Achsencylinder nicht als Kunstprodukte ansehen. Hervorheben will ich noch, daß die meisten der Gehirne sehr bald nach dem Tode fixiert und verarbeitet wurden; denn in dem größten Teil der Fälle wurde sofort nach dem Tode mittels einer Lumbalpunktionskanüle Formol in den Duralsack injiziert und auf diese Weise das Rückenmark und Gehirn in situ anfixiert.

Bevor wir zur pathologisch-anatomischen Beurteilung der Befunde übergehen, müssen wir erst untersuchen, ob alle die hier beschriebenen 
Bildungen zusammengehören, ob sie denn wirklich nur verschiedene „Stadien“ eines und desselben Prozesses darstellen.

Wir sind mit gutem Grund gewöhnt, die meisten pathologischen Prozesse, wenn sie in verschiedener Größe auftreten, als verschieden alt anzusehen. Von diesem Gesichtspunkte aus begann auch oben die Schilderung mit den kleinsten und endete mit den größten Drusen. Wenn man nun diese nach der Größe in ein bestimmtes System eingereihten Bilder betrachtet, so kann man nicht umhin, in den einzelnen Bildern auch verschiedene Stadien eines Prozesses zu erkennen.

In Fig. 1 (Taf. VII) ist die kleinste der beobachteten Formen gezeichnet, in der sich die Fädchen als unregelmäßige Sterne darstellen. Dieses Stadium würde ich als Sternchenform bezeichnen. Auf derselben Figur bei b sieht man, wie sich mehrere solcher Sternchen zusammensetzen und dichte Gruppen bilden; im Zentrum dieser Gruppe bildet sich ein wirrer Knäuel und an der Peripherie formen sich die Fädchen in Strähnchen, denen man aber häufig (auch in der Figur) die Genese aus den Sternchen ansieht. Die größeren Drusen haben Morgensternformen in verschiedener Größe (Taf. VII, Fig. 2, 3); sie unterscheiden sich von der Sternchenform dadurch, daß sie durchwegs größer und die Fädchen regelmäßig radiär gestellt sind; auch färben sie sich nicht immer schwarz, sondern manchmal braun oder rot. Fig. 4 (Taf. VII) zeigt an diese Morgensternform angegliedert mehrfach unregelmäßige Strähnchen resp. zopfartige Bildungen, die aus denselben Fäserchen bestehen, und die mit den in Fig. 1o abgebildeten Strähnchen zu identifizieren sind.

Eine sehr häufige Formation zeigt Fig. 5 (Taf. VII); man sieht hier die Strähnchen radiär und ziemlich massig aus dem Morgenstern wenn ich so sagen darf - herauswachsen; in diesem Stadium retrahiert sich das Gewebe und es entsteht ein Hof, der auch auf Fig. 4 (Taf. VII) erscheint; in den weiteren Stadien bildet sich als Abgrenzung vom Nervengewebe eine dichte ringförmige Zone, welche aus denselben Fäserchen besteht und welche zum größten Teil durch die radiär gestellten Strähnchen mit dem zentralen Morgenstern in Verbindung steht, so daß eine Art Rädchen (Taf. VIII, Fig. 7) entsteht.

Alle diese Bildungen sind etwas dem Gewebe der Hirnrinde vollkommen Fremdes; schon die bloße Morphologie stellt sie ganz abseits von den Elementen des Zentralnervensystems. Dasselbe beweist auch deren Verhalten bei der Färbung: die Methode von Cajal färbt die Fädchen beinahe gar nicht, auch wenn alle Achsencylinder gefärbt erscheinen; mit der Weigertschen Neurogliafärbung lassen sie sich ebenfalls nicht darstellen; mit der Methode Bielschowskys färben sie sich zwar häufig auch so schwarz, wie die Fibrillen und Achsencylinder, aber häufig auch in ganz anderen von der Färbung der 
nervösen Elemente differierenden Nuancen. Dabei zeigen die Farben alle Abschattierungen von Rot, Gelb bis Schwarz. Würde dieses tinktorielle Verhalten eine Differenzierung nicht ermöglichen, so könnte vielleicht auch manches Bild falsch gedeutet werden. So kann man bei Fig. 8 (Taf. VIII) leicht den Eindruck gewinnen, daß der das Nervengewebe umgrenzende Ring nur durch eine Verdichtung der Nervenfibrillen dargestellt wäre. Dagegen sprechen viele Momente. Erstens die verschiedene Färbung der ganzen Drusen, wie in Fig. 7 (Taf. VIII), wo sich Zentralkern, Strähnchen und Randring in gleicher Tinktion und als aus denselben Elementen aufgebaut präsentieren; weiter ist zu bemerken, daß auch in den Drusen, wo der Randring schwarz und die Strähnchen bräunlich gefärbt sind (Taf.VIII, Fig. 10, 11), die Fäserchen der letzteren in die ersteren übergehen oder zu mindest sich mit ihnen verflechten; schließlich sind alle diese Fädchen viel feiner als die Nervenfibrillen und ihr Verlauf viel wirrer und eckiger, als man es sonst bei Fibrillen zu sehen gewöhnt ist.

Alle die bisher besprochenen Bildungen müßte man also als verschiedene Entwicklungsstufen eines Prozesses ansehen, der mit der Sternchenform beginnt, zur Morgensternformation übergeht und dann die Strähnchen- und Speichenbildungen zeigt; schließlich entsteht die Rädchenformation; der Randring wäre die jüngste Bildung. Letztere Annahme gewinnt im tinktoriellen Verhalten eine Stütze. Wir sehen nämlich, daß die Sternform als die jüngste Bildung immer nur schwarz gefärbt erscheint, wogegen die Morgensterne und die Strähnchen sehr häufig eine bräunliche Färbung annehmen; wir könnten also daraus auch schließen, daß sich die Fädchen in den jüngsten Stadien schwarz, in den späteren braun färben. Das gleiche Verhalten bemerkt man nun auch im Stadium der Rädchenbildung; die zentralen Partien sind daselbst meist bräunlich oder rötlich tingiert, wogegen der Randring immer schwarz erscheint (nur ausnahmsweise wie in Fig. 7 braun); daraus folgt, daß auch auf Grund des tinktoriellen Verhaltens der Randring als jüngste Bildung der Drusen erscheint.

Auch die im Stadium der Rädchenformation befindlichen Drusen kommen in verschiedener Größe vor; die kleineren derselben sind immer zellfrei; in den größeren findet man hin und wieder Kerne resp. Kerndetritus, deren Provenienz nicht klar ist, gewisse als Übergangsformen zu deutende Bilder sprechen dafür, daß es Reste von Zellen sind, welche von der Druse während des Wachstums eingeschlossen und dadurch zum Untergang gebracht wurden. Doch sind solche Vorkommnisse immerhin eine Seltenheit.

Auch die in manchen der größeren Drusen vorkommenden kernlosen scholligen Massen (Taf. IX, Fig. 14) machen den Eindruck von Resten zugrunde gehender Zellen. 
Bei der Behandlung nach Marchi werden die in diesen Schollen eingeschlossenen Körnchen bräunlich bis schwarz. Eigenartig und schwer erklärlich ist aber das Verhältnis der Schollen zu der Fädchenmasse auf Fig. 13 und 15 (Taf. IX). Ohne daß man Kern- oder Zellreste nachweisen könnte, sieht man auf Fig. 13 (Taf. IX) die Schollen teilweise umgeben von den Fädchen, resp. es sieht so aus, als ob die Fädchenmassen in die Schollen übergehen würden; und auf Fig. 15 (Taf. IX) sind die grauen Massen als kleine Brocken diffus verstreut zwischen den Sternchen und Zöpfen. Weiter fällt es auf, daß die Schollen in den Drusen unverhältnismäßig häufiger zu sehen sind als Zellen und Zellreste; wenn nun erstere aus letzteren entstehen würden, müßte man viel mehr Übergänge sehen, als es in Wirklichkeit zutrifft.

Das Studium einer größeren Zahl solcher Formationen läßt mir die Annahme am wahrscheinlichsten erscheinen, daß wenigstens ein Teil der Schollen durch Zerfallsprodukte der Fädchenmassen gebildet wird. Nach dieser Erklärung würde Fig. 15 (Taf. IX) ein früheres Stadium darstellen, wobei die Fädchenmassen mit den Schollen eng vermischt sind und letztere an Größe überwiegen, in Fig. 13 (Taf. IX) wäre dann der Zerfall weiter gediehen, so daß nur noch spärliche Reste der Fädchen am Rande der Schollen sichtbar werden.

Drusen, deren Abbildung Fig. 16 (Taf. X) bringt, imponieren bereits morphologisch als älteste Bildungen. Auch sie bestehen aus Fäserchen, die aber viel dicker sind und sich in mehr oder weniger parallel ziehenden, etwas wellig angeordneten Strähnen zu einem zierlichen Flechtwerk verbinden. Abgesehen von anderen, später zu erwähnenden Gründen sehe ich diese Formation ,des dickfaserigen Knäuels" als das älteste Stadjum des Prozesses an, schon deswegen, weil sie die größten Dimensionen unter allen Drusen aufweisen.

$\mathrm{Zu}$ diesen aus kleinstem Beginn in ganz bestimmter Art wachsenden Drusen stellt sich in einen auffälligen Gegensatz die infiltrative Ansammlung der Fädchenmassen, indem wir auf einer Seite eine ziemlich scharfe Abgrenzung gegenüber dem nervösen Gewebe sehen, wogegen auf der anderen die Fädchen diffus das Gewebe durchsetzen und direkt zu dessen Untergang führen. Trotz diesem Unterschied läßt sich die Zugehörigkeit der infiltrierenden Fädchen zu den Drusen dadurch erweisen, daß sich die infiltrierenden Fädchenmassen morphologisch von den Fädchen, welche den Randring der Drusen bilden, gar nicht unterscheiden. Weiter kann man eine ganze Reihe von Übergängen zwischen diesen beiden Arten nachweisen. Gar nicht so selten sieht man Bildungen wie in Fig. 40 (Taf. XVI); hier hat der Randring eine besondere Mächtigkeit erreicht und grenzt sich gegen das Gewebe nicht mehr scharf ab, sondern strahlt infiltrierend aus. Wenn eine solche Bildung vom Schnitt nicht gerade in dem Mittelpunkt durchschnitten wird, 
dann bekommt man den Eindruck, daß man eine diffus infiltrierende Scheibe vor sich hat. Auf Fig. 17, 46, 47, 48 (Taf. X, XVIII) sieht man, wie sich disseminierte Einzelkonglomerate der Fädchenmassen zu größeren Flächen zusammensetzen, wobei stellenweise der Aufbau aus den kleinsten Sternchen noch ersichtlich ist (Fig. 48, Taf. XVIII). Der Umstand nun, daß sich diese infiltrierenden Fädchenmassen nur schwarz färben, ähnlich wie der Randring und die Sternchendrusen, könnte auch dafür sprechen (ich betone hier das ,,könnte"), daß wir es hier mit Bildungen jüngeren Datums zu tun haben, d. h. mit Bildungen, die sich kürzere Zeit vor dem Tode gebildet haben, als die anderen Teile der Drusen.

Nach dem Geschilderten unterlieg tes wohl keine $m Z_{w}$ eifel, da $B$ wir in diesen Drusen etwas dem Nervensystem morphologisch und chemisch ganz Fremdes vor uns haben und daß bisher weder die Biologie noch die Pathologie etwas diesen Bildungen Vergleichbares kennt. Der Umstand, daß die Drusen durchwegs bei senilen und atrophischen Gehirnen gefunden werden, könnte zu der Ansicht führen, daß die Drusen nur eine Art von Abbauprodukten, wie es auch bereits mehrfach aufgefaßt wurde, darstellen. Gegen diese Auffassung ließe sich einzelnes einwenden. Wären nämlich die Drusen nur einfache Destruktionsmassen des Nervengewebes, dann müßten dieselben in direktem Anschluß an in Destruktion befindliche Gewebselemente sich finden. Dies trifft wenigstens für die in dieser Beziehung wichtigsten kleinsten Drusen nicht zu; sie liegen unvermittelt in dem sonst nicht weiter destruierten Nervengewebe. In den größeren Drusen finden sich zwar hin und wieder in Destruktion befindliche Zellelemente, die aber nur als durch das Wachstum eingeschlossene Zellen angesehen werden können.

Also als Destruktionsmassen, welche an Ort und Stelle des Gewebszerfalles entstehen, können die Drusen nicht erklärt werden; dagegen könnten es etwa solche Abbauprodukte sein, welche aus einer ursprünglich gelösten Form fern vom Orte ihrer Entstehung niedergeschlagen werden und krystallähnlich zu Drusen sich formen. Gewisse morphologische Ähnlichkeiten sind zwar hier, aber die verschiedene Form, Tinktion und Anordnung in den verschieden großen Drusen spricht doch nicht dafür. Wenn es weiter doch immerhin als merkwürdig angesehen werden müßte, daß unorganisierte Niederschläge, ohne kompakte Massen zu bilden, doch das Gewebe verdrängen, so wäre das Verhalten dieser „Abbauprodukte“" zu den Gefäßen in jener Art, die Fig. 19 und 20 (Taf. X, XI) darstellt, noch merkwürdiger. Weiter soll noch bemerkt werden, daß es zwar zur Regel gehört, daß Abbauprodukte den Weg der perivasculären Lymphräume nehmen, aber dann füllen die Massen auch das Lumen der Spalträume aus; die Drusen sitzen aber trotz ihrer perivasculären Anordnung in dem Gewebe selbst. 
Noch größere Schwierigkeiten ergeben sich aber, wenn man die perivasculären Bildungen der Fig. 21-24 und 50 (Taf. XI, XIX) erklären will. Ein Abbauprodukt, das so schön regelmäßig die Gefäße umscheidet und dabei die Wand des Gefäßes so zierlich und regelmäßig destruiert, würde etwas ganz Sonderbares darstellen. Weiter kommt noch der Umstand in Betracht, da $\beta$ die Drusen streng mit dem Rande des Nervengewebes a ufhören, daß auch diejenigen Rindengefäße, welche von den Drusen auf lange Strecken eingeschlossen werden, diese Umkleidung mit dem Moment verlieren, wie sie in die Meningen oder in die weiße Substanz eintreten.

Es stößt also der Versuch, die Drusen als Abbauprodukte zu erklären, auf große Schwierigkeiten, so daß man ihnen auch als Abbauprodukten eine ganz besonders exzeptionelle Stellung einräumen müßte.

Ich möchte noch darauf aufmerksam machen, daß die Drusen beinahe in allen ihren Stadien eine große morphologische Ähnlichkeit mit Fadenpilzen haben, und man muß zugeben, daß manche morphologischen Eigenschaften sich vielleicht leichter erklären ließen, wenn es sich hier um eine pilzartig organisierte Materie handeln würde: Der Aufbau aus Fädchen, die verschiedene Stellung, Färbung und Dicke bei verschiedenem Alter, das scheinbar aktive Wachstum mit dem konsekutiven Verdrängen des Nervengewebes, das infiltrative Durchwuchern, als Ausdruck einer sehr schnellen Wucherung, bei der das nervöse Gewebe keine Zeit zur Retraktion mehr hatte, und schließlich der enge Anschluß an die Gefäße und das Durchwuchern der Gefäßwand - alle diese Eigenschaften könnten meines Erachtens einer lebenden organisierten Materie etwas leichter zugesprochen werden als einem toten Abbauprodukt.

Aber! - wo bleibt dann die entzündliche Reaktion? In unserem Falle gibt es keine Entzündung um die Drusen; die einzige Reaktion, die das nervöse Gewebe zeigt, sind die kolbigen Wucherungen der Achsencylinder, welche jedenfalls als Ausdruck einer Schädigung des Gewebes durch die fremden Einlagerungen angesehen werden müssen. Aber Pilzwucherungen, welche keine entzündliche Reaktion setzen, sind bisher unbekannt. Wenn es sich nun tatsächlich um Pilze handeln würde, müßte man erwarten, daß sie anch anderswo im Körper, wenigstens andeutungsweise nachgewiesen werden könnten. Ich habe deswegen bei mehreren Fällen auch die meisten Organe des Körpers histologisch durchsucht, aber nichts gefunden, was an die Drusen erinnert hätte. Doch muß ich dazu hervorheben, daß dieses negative Ergebnis gar nichts beweisen müßte. Denn da wir eigentlich keine spezifische Färbung der Fädchen als solcher haben, und wir dieselben im Gehirn nur auf Grund ihrer eigenartigen Gruppierung, also erst als Drusen, erkennen, können wir diese Fädchen, wenn sie nicht als Drusen 
in den anderen Organen vorkommen würden, gar nicht darstellen. Kulturversuche könnten in dieser Richtung mehr Aufschluß geben; dieselben wurden in der mannigfaltigsten Variation versucht, blieben aber ganz ohne Resultat. Auch wurden mit den die Drusen enthaltenden Gehirnen Komplementbindungsversuche angestellt, aber ebenfalls mit negativem Erfolg.

Es ist einstweilen meines Erachtens gleichgültig, als was wir die Drusen ansehen wollen; immer müssen wir anerkennen, daß wir noch keinen pathologischen Prozeß kennen, mit dem wir dieselben identifizieren könnten; jeder Versuch, diese Bildung bereits bekannten Erscheinungen anzugliedern, stößt noch auf eine ganze Reihe von prinzipiellen Schwierigkeiten, die wir nur mit hypothetischen Annahmen überbrücken können. Ich will auch hier nochmals betonen, daß ich für die Drusen keine absolut stichhaltige Erklärung habe, daß sich aber manche morphologischen Eigentümlichkeiten am leichtesten mit der Annahme einer organisierten, pilzähnlichen Substanz erklären ließen. Von den klinischen Konsequenzen will ich hier noch nicht sprechen.

Noch einem möglichen Einwand könnten wir begegnen; man könnte uns vorhalten, daß alle diese geschilderten und besprochenen Bildungen nicht einem und demselben Prozeß angehören müssen. Dies läßt sich leicht mit zweierlei Argumenten entkräften. Erstens konnte man den rein mo phologischen Zusammenhang darstellen und - soweit solche Beweise auch beweiskräftig sein können - erweisen; weiters kann man in ein und demselben Gehirn aber auch mehrere dieser verschiedenen Stadien nebeneinander sehen. Ich habe zwar noch kein Gehirn gesehen, in dem alle Stadien der Drusen nebeneinander vorgekommen wären, aber andererseits findet sich auch nie ein Stadium allein, sondern immer mehrere vertreten. Meistens findet man die jüngsten Stadien nebeneinander, oder die mittleren, oder die ältesten, oder aber auch die jüngsten Drusen mit den mittleren, die mittleren mit den ältesten. Dies kommt nun entweder so vor, daß in allen Gegenden die verschiedenen Altersstufen der Drusen gemischt sind, oder aber daß verschiedene Regionen des Gehirns verschiedene Altersstufen beherbergen, was dafür sprechen könnte, daß die Drusen entweder einen verschieden guten Entwicklungsboden fanden, oder aber daß sie sich in den verschiedenen Regionen nicht gleichzeitig entwickelt haben.

Wenn ich also unsere morphologischen Feststellungen resümieren soll, so komme ich zu folgendem Schlusse:

Wir haben in den Drusen Bildungen vor uns:

1. die für die Pathologie und Biologie einen vollkommen neuartigen Prozeß darstellen,

2. die durch Konglomerate feinster Fädchen gebildet werden, welche im Nervensystem als eine fremde, 
wachsende, das Gewebe verdrängende Masse auftreten,

3. die das Gewebe zwar schädigen, es aber nur ausnahmsweise schwerer destruieren, und zwar dann, wenn sie es diffus infiltrieren oder einschließen,

4. welche sonst nur (in einem kleinen Prozentsatz der Fälle und in bestimmtem Alter des Prozesses) zu Wucherungen der Achsencylinder und Fibrillen führen und

5. keinerlei reaktive Entzündung hervorrufen.

Der Prozeß tritt in folgenden Stadien auf:

I. Stadium der Sternchenbildung, Fig. 1, 37 (Taf. VII, XVI);

II. , , Morgensternformation, Fig. 2, 3, 4 (Taf. VII);

III. ", ", Speichenbildung, Fig. 5, 6,9, 38 (Taf.VII, VIII, XVI);

IV. " , , Rädchenbildung, Fig. 7, 8, 10, 11, 39 (Taf.VIII, XVI);

V. " des dickfaserigen Knäuls, Fig. 16, 41, 42 (Taf. X, XVII);

VI. Pelzartige Destruktion der Gefäßwand, Fig. 21, 22, 23, 24, 50

(Taf. XI, XIX);

VII. Destruktionsstadien der Drusen, Fig. 12, 13, 14, 15, 51 (Taf. IX, XIX);

VIII. Diffuse Infiltration des nervösen Gewebes durch die fädigen Massen, Fig. 17, 18, 45, 46, 47, 48 (Taf. X, XVIII).

Die Stadien $I-V$ sind so aufzufassen, daß I das jüngste, $V$ das älteste darstellt. Die drei letztgenannten Stadien lassen sich schwieriger abschätzen, doch scheint mir Stadium VI und VII zu den ältesten Drusen zu gehören; das Stadium VIII möchte ich wieder als einen jüngeren Prozeß ansehen, gegen dessen Fortschreiten das Gewebe weniger Widerstand aufbringen konnte, so daß ein diffuses Infiltrieren zustande kam.

Für alle diese Formationen, welche wir als Phasen eines einzigen pathologischen Prozesses ansehen müssen, würden wir eine einheitliche Bezeichnung brauchen, schon zum Zwecke einer kürzeren Verständigung, damit wir in dem nächsten Abschnitt mit einem kurzen und deutlichen Terminus operieren können. Zu diesem Zwecke würde ich den Namen:

\section{Sphaerotrichia cerebri multiplex}

vorschlagen, einen Ausdruck, der nichts anderes anzeigen soll, als daß es sich um eine in meist kugeliger Form auftretende Fädchenbildung handelt.

\section{Klinischer Teil.}

Bei einer histologisch so genau charakterisierten Cerebropathie, wie der Sphaerotrichia cerebri multiplex, würde man erwarten, daß dieser so eigenartige anatomische Befund auch regelmäßig mit ganz bestimmten klinischen Krankheitszeichen einhergeht. Schon nach dem kleinen 
Material meiner ersten vorläufigen Mitteilung konnte ich darauf hinweisen, daß die Fälle mit der Sphaerotrichia cerebri ,mehr oder weniger ausgesprochene Presbyophrenien mit Konfabulationen und gröberen Störungen der Merkfähigkeit waren“", und ich schloß damals, daß wir in den ,,drusigen Nekrosen“, wie ich den Prozeß damals nannte, „das wichtigste anatomische Substrat der Presbyophrenie haben". Doch klinische Fragen können mit den 16 Fällen, die damals mein Material ausmachten, zwar angeschnitten, aber nicht gelöst werden; dazu ist ein größeres Material nötig, das man genau durchgehen und sichten muß, und erst dann kann man den Versuch machen, aus dem so häufig unlösbaren Gewirre von Störungen auf Grund eines bestimmten Gesichtspunktes Symptomenkomplexe herauszuschälen, welche einheitlich genug sind, um zur Charakterisierung und Gruppierung der Krankheiten verwendet werden zu können.

Zur Lösung der Frage nach der klinischen Bedeutung der Sphaerotrichia cerebri mußte man nicht nur ein größeres Material von klinisch beobachteten Fällen haben, bei denen sich diese Hirnveränderung vorfand, sondern es mußte auch eine größere Anzahl klinisch gut beobachteter Fälle herangezogen werden, deren Gehirn frei von dieser Erkrankung war.

Die Zahl der in dieser Richtung von mir untersuchten Fälle beläuft sich bereits auf 275 .

Es wurden untersucht:

I. Psychosen über 50 Jahren (mit Ausschluß der Paralyse) . 111

II. Psychosen unter 50 Jahren (mit Ausschluß der Paralyse) . 30 III. Paralysen aller Altersstufen . . . . . . . . . . . 110

IV. Normale von 15-50 Jahren . . . . . . . . . . 15

V. Normale Greise . . . . . . . . . . . . . . . . . . . 9

Die Sphaerotrichia cerebri fand ich bisher immer nur jenseits des 50. Lebensjahres, und zwar in 58 Gehirnen.

Eine Darlegung der klinischen Symptomatologie ist natürlich ohne Krankengeschichten unmöglich. Da aber die Sphaerotrichie nur bei Fällen gefunden werden konnte, welche das 50. Lebensjahr überschritten hatten, kamen eigentlich nur die Krankengeschichten der über 50 Jahre alten Kranken in Betracht. Es ist einleuchtend, daß ausführliche Krankengeschichten jetzt, wo es sich nur um eine gröbere Umgrenzung eines Symptomenkomplexes handelt, überflüssig wären; aus diesem Grunde werden im folgenden nur gekürzte Krankengeschichten gebracht. Als Alter wurde das Alter beim Ableben angeführt.

Es soll gleich anfangs erwähnt werden, daß sich in dem in Frage kommenden Materiale gewisse Unterschiede im klinischen Verhalten zeigen; um die Ubersichtlichkeit des Materiales zu erhöhen und die Besprechung zu erleichtern, wurden die Krankengeschichten in Gruppen 
vereinigt, und erst im Anschluß an die Gruppen folgt die Besprechung der klinischen Symptome und der Versuch einer zusammenfassenden Symptomatologie.

Fall 1. Vacek, Josefa, 71 Jahre.

Anamnese. Seit einem Jahre arbeitet sie nichts, ist sehr vergeßlich, in der letzten Zeit steht sie nachts häufig auf, geht in der Wohnung herum, will überall, z. B. im Bette und in einer Truhe, Feuer machen.

Beobachtung. 11. Juni bis 28. September 1907. Ihr Alter gibt sie mit 50 an; behauptet, hier zu Hause zu sein, nach einer Weile nennt sie ein Nachbardorf, wo sie zu Besuche sei. Glaubt, daß jetzt Dezember ist; macht automatische Kaubewegungen und bchauptet, das sei deswegen, weil sie einen Kuchen im Munde habe (seit 2 Stunden hatte sie nichts im Munde); leichte amnestische Aphasie.

12. Juni. Das Ajter gibt sie heute mit 40-50 an; glaubt hier schon 3 Monate zu sein, nennt ein Nachbarstädtchen ihrer Ortsgemeinde.

Wo sie da ist? Vielleicht in einem Armenasyl; klagt selbst, sie hätte einen schlechten Kopf und vergesse alles.

Im Krankenzimmer verhält sie sich ruhig, ist immer mit der Kleidung beschäftigt, will sich ausziehen und wieder anziehen, zieht sich aber ganz unrichtig an ; ist über die Tageszeit nie orientiert, hat auch das Mittagessen sofort vergessen.

15. Juni. Verlangt heute einen Schemel, sie müsse doch die Kühe melken gehen, sie hätte schon eine Kuh gemolken; läßt sich leicht suggerieren, daß sie auch schon gestem gemolken hätte und gibt auch die Milchmenge an, die sie gemolken; doch die Angaben über die Menge wechseln ständig; eine Kuh hätte auch gekalbt, aber das Kalb sei nach einigen Tagen eingegangen.

17. Juni. Erzählt, man hätte ihr gestern den Arm gebrochen, und ändert es im Nu, daß man ihr beim Begräbnis den Arm angeschlagen hätte.

$\mathrm{Ob}$ das Begräbnis gestern war? Das nicht, er ist gestern gestorben und wird heute begraben.

Wer das? Das weiß ich nicht.

Wird das Begräbnis schon sein? Es wird schon draußen gerichtet.

14. August. Ruhiges Hindämmern, spontan äußert sie keine Konfabulationen, nur wenn sie gefragt wird. Heute zerreißt sie bei der Visite ihr Hemd in Stücke und verschenkt die Fetzen an die daneben liegenden Kranken.

Auf die Frage, wozu sie das macht, sagt sie: Ich muß die Ziege unterlegen.

Wo die ist? Da auf dem Boden.

Wie lange ist schon die Ziege da? Die ist schon weg, ich habe sie ja weggegeben.

Wann? Vor 4 Wochen.

Was sie für die Ziege bekommen hat? 4 Gulden.

Was hier? Ein Häuschen.

Wessen? Das gehört dem Herrn V.

Was sie hier mache? Sie handle mit Obst.

Was die anderen Leute hier? Jeder hat hier sein Quartier.

Was sie gestern machte? Den 2. Tag gelegen.

Wie lange sie hier liegt? 2 Wochen.

$\mathrm{Ob}$ sie vorgestern noch gekocht hatte? Ja.

Was? Erdäpfel.

Wo ist die Küche? Da wo das Fräulein jetzt gerade hingeht (Türe des nächsten Krankenzimmers).

1. September. Den Arzt hält sie bald für einen Viehhändler, bald für einen 
Nachbarn, bald für einen Doktor; behauptet, gestern mit der Wärterin im Walde Tannenzapfen gesammelt zu haben, wäre dabei gestürzt und hätte sich das Bein beschädigt (sie ist jetzt wenig mobil und liegt meist zu Bett).

28. September 1907. Exitus an Dysenterie.

Pathologisch - anatomische Diagnose. Marasmus universalis.

Bronchitis suppurativa. Endocarditis chronica ad valvul. aortae. Hypertrophia cordis. Enteritis necrotisans.

Am Gehirn einfache ziemlich starke Rindenatrophie mit deutlicher Erweiterung der Ventrikel.

Mikroskopisch. Massenhafte Drusen im Stadium I, II und III. In den vorderen Hirnpartien weniger und kleinere Drusen als in den hinteren. In der Stirn gehäufte Fädcheninfiltrate.

Die Ganglienzellen stark verändert. Mittlerer Markgehalt, keine besondere Arteriosklerose.

Fall 2. Zelinka, Marie, 71 Jahre.

Anamnese. Schon seit 4 Jahren dement und verwirrt; in der letzten Zeit in einer Anstalt, wo sie sehr lustig war, behauptete, es gehöre alles ihr, wollte Betten und Wäsche mit nach Hause nehmen, konfabulierte Besuche, erzählte von Geschenken, die sie von hohen Herrschaften bekommen haben wollte. Später maniakalisch erregt, sehr redselig.

Beobachtung. 19. Januar 1908 bis 6. Juli 1909. 20. Januar. Ist ständig schr lustig, plaudert in an Inkohärenz grenzender Ideenflucht; liegt ruhig zu Bett, ist schwer zu fixieren, behauptet, das Haus hier sei ihre Wohnung, wähnt sich sehr reich.

15. Februar. Jetzt sehr häufiger Stimmungswechsel, bald lebhaft, lustig, jovial, bald wieder ärgerlich, schimpft auf die ganze Umgebung; dabei ständig desorientiert, wähnt sich hier zu Hause.

17. Februar. Heute sehr ärgerlich, beschimpft den Arzt mit „ihr Lausbuben, ich werde euch geben, wie könnt ihr euch unterstehen, herzukommen, was habt ihr hier zu suchen, das gehört alles mir und da wollt ihr noch solche Sachen von mir erzählen, daß ich mit euch ins Theater gehen werde, mit solchen Lausbuben, heraus mit euch." Deckt sich dann mit der Decke zu und bleibt ruhig liegen.

18. Februar. Früh wieder sehr lustig, bezeichnet sich als Frau von ..... Ist heute etwas besser zu fixieren, glaubt hier in ihrem Palaste zu sein, sei 66 Jahre alt. Wie lange sie hier ist? Vor einer Weile bin ich doch gekommen, ich habe meine Tochter gesucht.

Wie sie hergekommen ist? Zu FuB, das haben Sie doch gemerkt.

Von wo? Da draußen von der Straße.

Ob sie das erstemal da ist? Das nicht, es gehört ja mir, aber ich bin schon mehrmals dagewesen.

Warum sie zu Bette liegt? Damit ich mich von dem Herumlaufen ausruhe.

Wie lange sie da bleiben wird? Ich werde gleich weggehen.

Was sie hier wolle? Ich ging Kohlen holen.

Zu wem? Zu Frau S.

Wo die wohnt? Aber die kennen Sie doch, Sie sind ja ihr Sohn.

Was sie gestern machte? Zu Hause gekocht.

Was noch? Sonst nichts; aber ich muß schon nach Hause laufen; macht aber keine Miene, dies wirklich zu tun.

29. Februar. Heute weinerlich, behauptet, ihre Mutter sei gerade gestorben; 1/2 Stunde nachher weiß sie nichts davon, die Mutter sei ja ganz gesund; behauptet, man müßte verrückt sein, wenn man etwas derartiges von ihrer Mutter behaupten würde. 
1. April. Zustand unverändert; sehr vergeßlich, behauptet, schon wochenlang nichts gegessen zu haben; konfabuliert.

6. Juli 1909. Exitus an Marasmus.

Das Gehirn von außen deutlich atrophiert, die Ventrikel erweitert, die basalen Gefäße leicht verdickt.

Mikroskopisch. In den vorderen Partien des Gehirns sehr reichliche Drusen im Stadium V mit wenig Keulen; in den hinteren Partien sind die Drusen spärlicher und in Stadien III und IV ohne Keulen. Die Ganglienzellen schwer verändert, einige derselben zeigen die grobfaserige Fibrillenwucherung.

Fall 3. Kopriva, Anna, 84 Jahre.

Anamnese. Seit einigen Monaten sehr vergeßlich, vergißt alles sofort, ist örtlich desorientiert, will weglaufen, sieht des Nachts Gestalten und ist ängstlich; wird häufig gegen die Umgebung, die sie in wechselnder Weise verkennt, aggressiv.

Beobachtung. 23. Februar bis 7. März 1906. Ist örtlich und zeitlich desorientiert, glaubt hier zu Hause zu sein, sucht die Tochter. Weiß ihr Alter nicht, glaubt etwa 30 Jahre alt zu sein; weiß nicht die Namen und die Zahl ihrer Kinder; gibt bald an, der Mann lebe noch, bald wieder, er sei gestorben. Leichte amnestische Aphasie.

24. Februar. Sucht ihre Kinder; will herausgelassen werden, glaubt schon sehr lange da zu sein. Behauptet in einem Wirtshause zu sein, sucht den Wirt, der ihr Verwandter sein soll, verkennt die Umgebung und die Tageszeiten. Am Nachmittag hat sie bereits vergessen, daß sie schon gegessen hatte; auf Suggestion behauptet sie, gerade Bier getrunken zu haben, bestellt sich auch bei der Wärterin, die sie für eine Kellnerin hält, ein Glas Bier, da sie Durst habe. Hält den Arzt für ihren Sohn. Nachts wenig geschlafen.

25. Februar. Zustand unverändert; jammert heute früh, daß ihr gestern die Mutter gestorben sei.

7. März 1906. Exitus an Pneumonie, die im Anschlu B an eine Rippenfraktur entstanden war.

Das Gehirn von außen sehr stark atrophisch, besonders in den vorderen Partien. Die Ventrikel sehr stark erweitert. Die Gefäße fleckweise verdickt.

Mikroskopisch. Massenhafte Drusen im Stadium V mit sehr reichlichen Keulen. Die Ganglienzellen wenig geschädigt.

Fall 4. Kysela, Magdalene, 83 Jahre.

Anamnese. Ist schon $1 \frac{1}{2}$ Jahre vergeßlich und spricht verwirrt; sieht Leute, die Geld von ihr verlangen.

Beobachtung. 3. Juni bis 26. Juli 1908. Ist ärgerlich; schimpft, sieht Soldaten vor den Fenstern, einer der Soldaten ruft ihr witzelnde Bemerkungen zu.

4. Juni. Weiß nicht, wie alt sie ist, wieviel Kinder sie hat; örtlich desorientiert, weiß auch nicht, wie lange sie da ist, glaubt noch nicht gegessen zu haben, trotzdem sie gerade nach einer Mahlzeit ist.

11. Juni. War die ganze Zeit ganz ruhig; nichts Auffälliges geboten; gestern abend erklärte sie, sie müsse weg, sie ziehe hier aus, das Mädchen warte bereits unten auf sie mit dem Korbe; glaubt hier in einem Wirtshause zu sein. Heute erklärt sie, gestern zu Hause gewesen zu sein, hätte dort nichts Besonderes gemacht.

20. Juli. Zustand unverändert; ständig desorientiert und konfabulierend.

26. Juli. Exitus an Marasmus.

Das Gehirn von außen leicht atrophisch, leichte Erweiterung der Seitenventrikel. Keine Gefäßerkrankung.

Mikroskopisch. In der Stimpartie spärliche Drusen, in den hinteren Partien, besonders den Zentralwindungen reichlichere Drusen im Stadium III und IV, keine Keulen. 
Fall 5. Radnitz, Ignatz, 82 Jahre.

Anamnese. Keine; wegen Unruhe eingebracht.

Beobachtung. 2. August bis 15. September 1903. 14. August: Dement, sehr vergeßlich, weiß, daß sein Gedächtnis schon sehr schlecht ist und beklagt sich darüber; bekommt Besuch, weiß in einigen Minuten nichts mehr davon oder bezeichnet andere Personen als Besucher.

23. August. Behauptet, er müsse aufs Begräbnis gehen, da seine Mutter gestern gestorben ist.

Wie alt die Mutter war? 58 Jahre.

Und wie alt sind Sie? Ich werde schon 60 sein.

Wie lange er da ist? Es wird schon an die 2 Monate sein.

Das Alter seiner Mutter gibt er jetzt mit 40 an, sie lebe noch und sei Fleischhackermeisterin.

Wie alt er selbst ist? 36 .

Als man ihm einen Spiegel vorhält, schaut er sich darin an, sagt, ohne verwundert zu sein und ohne zu beachten, daß er gerade etwas anderes gesagt hatte, er müsse wohl schon über 70 Jahre alt sein.

Wie alt die Mutter ist? So an die 80 Jahre; fängt an zu weinen über die arme Mutter, die den einzigen Sohn da hat; sie selbst wäre hier schon einmal zu Besuch bei ihm gewesen.

5. Oktober. Zustand unverändert.

15. Oktober 1903. Exitus an Marasmus und Bronchitis.

Sektionsbefund. Das Gehirn von außen stark atrophisch, deutlicher Hydrocephalus internus; fleckige Verdickung der Basalgefäße.

Mikroskopisch. Reichliche Drusen im Stadium III und IV.

Fall 6. Pulec, Franziska, 85 Jahre.

A namnese. Seit einer vor $1 / 2$ Jahr durchgemachten Pneumonie unruhig, zeitlich und örtlich desorientiert.

Beobachtung. 28. Oktober bis 26. Dezember 1907. 30. Oktober. Ist dement, ruhig; nachts schläft sie wenig; ständig konfabulierend. Früh erzählt sie, sie hätte schon zu Mittag gegessen, gestern Holz gespalten usw., manchmal zerwühlt sie das Bettzeug. Erzählt auch ihre Lebensgeschichte sehr lückenhaft, wenn auch nicht falsch; erkennt ihre Kinder nicht.

23. Dezember. Unverändert.

26. Dezember. Plötzlicher Exitus.

Pathologisch - anatomische Diagnose. Marasmus universalis. Bronchitis diffusa. Embolia arteriae pulmonalis.

Das Gehirn von außen nicht merklich atrophiert, die Ventrikel stark erweitert, basalen Gefäße zartwandig.

Mikroskopisch. In den vorderen Hirnpartien sehr reichliche Drusen in den Stadien I und II; keine Keulen; die Ganglienzellen sehr schwer verändert. In den hinteren Partien die Drusen etwas spärlicher, im Stadium III und IV; die Keulen in spärlicher Anzahl vorhanden, die Ganglienzellen wenig verändert.

Fall 7. Lukesch, Marie, 60 Jahre.

Anamnese. Seit 2 Jahren zunehmend vergeßlich, desorientiert, verkennt die Umgebung, will weglaufen, wenn ihr gewehrt wird, wird sie aggressiv, behauptet, man trachte ihr nach dem Leben.

Beobachtung. 3. Januar 1907 bis 28. März 1908. Hat eine starke amnestische Aphasie, mit Agrammatismus und zeitweise auch paraphatischem Verzerren der Worte; auch gebraucht sie sehr viel Flickworte, wodurch ihre Rede häufig unverständlich wird. Ideatorische Apraxie.

10. Januar. Ist unruhig, will weglaufen, steht bei der Tür und scheint dort 
jemanden zu erwarten; bei jeder Gelegenheit rafft sie Wäschestücke usw. zusammen und drängt weg.

I. August. Zustand im allgemeinen gleich; steht ständig bei der Tür und will heraus; wo sie einen mobilen Gegenstand, gleichgültig welcher Art, sieht, nimmt sie ihn und wickelt ihn in die Schürze; auf diese Weise hat sie in der Schürze immer etwas eingewickelt; manchmal wickelt sie auch die leere Schürze zusammen und hält sie so, wie wenn sie etwas darin hätte.

Früh und abends gibt es immer beim Auskleiden eine große Rauferei, da sie fürchtet, man wolle sie bestehlen. Wegen der Sprachstörung ist ein genaues Examen manchmal recht schwer; immerhin sind Konfabulationen nachweisbar; sie behauptet, bald zu Hause zu sein, bald gerade von zu Hause gekommen zu sein; hätte gerade noch im Garten gearbeitet, hätte sich noch mit den Buben ärgern müssen; trotzdem ihr Mann schon vor längerer Zeit gestorben ist, behauptet sie, mit dem ,Vater" auch in der Arbeit gewesen zu sein.

1. März 1908. Zustand unverändert.

28. März 1908. Exitus an Marasmus.

Pathologisch-anatomische Diagnose. Marasmus senilis. Bronchitis.

Das Gehirn von außen stark atrophiert. Die Atrophie am stärksten im linken Schläfelappen. Die Meningen verdickt und ödematös. Ventrikel stark erweitert, die basalen Gefäße fleckig verdickt.

Mikroskopisch. Reichliche Drusen vom Typus I-IV. Keine Keulen. Die Ganglienzellen stark verändert.

In den Stammganglien und in der Molekularschichte des Kleinhirns spärliche Drusen vom Typus II-IV. In der Med. oblongata keine Drusen. Reichliche grobfaserige Fibrillenwucherung in den Ganglienzellen.

Diese Fälle zeigen eine so einheitliche Symptomatologie, daß deren Zusammenfassung auf keine Schwierigkeiten stoßen kann. Wir wollen versuchen, die Symptomatologie dieser Gruppe durch Herausheben der gemeinsamen Züge summarisch darzustellen.

Heredität scheint, so weit unsere Anamnesen reichen, keine Rolle zu spielen. Die Anamnesen berichten, daß bei den meisten Kranken seit längerer Zeit ein stärkerer körperlicher Verfall gemerkt wird, von psychischer Seite mehr oder weniger auffallende Vergeßlichkeit und Demenz. Auch andere psychotische Erscheinungen werden erwähnt: die Kranken kennen sich nicht mehr in der Wohnung aus, sie erkennen die Umgebung nicht mehr, verkennen sie in wechselnder Weise, suchen verstorbene Angehörige, sie wollen vom Hause weglaufen, werden gewalttätig, wenn man ihnen wehrt, und häufig aggressiv, weil sie die Umgebung nicht mehr kennen; dabei wird meist berichtet, daß sich die Unruhe abends steigert, oder aber, daß sie, wenn der Tag sonst ruhig verlief, gegen Abend ängstlich werden. Sehr häufig erfährt man, daß die Patienten viel von Feuer reden oder mit dem Feuer spielen. Manchmal wird angegeben, daß die psychotischen Symptome nach mehrfachen Schwindelanfällen aufgetreten sind.

Die Kranken sind häufig von leicht gehobener Stimmung, manchmal aber auch ängstlich; die Ängstlichkeit steigert sich dann auch ohne halluzinatorische Zustände meist gegen Abend. Im Vordergrunde der 
Symptome steht die hochgradige Störung der Merkfähigkeit: sie vergessen sehr schnell, manchmal schon nach einigen Sekunden, alles, was um sie herum geschieht; sehr auffällig wirkt - was auch in den Anamnesen bereits erwähnt wird -, daß die Kranken ständig essen wollen, weil sie sofort nach dem Essen vergessen haben, daß sie bereits nach der Mahlzeit sind.

Auf Grund dieser hochgradigen Vergeßlichkeit sind die Kranken ständig desorientiert, sie können sich zeitlich und örtlich nicht orientieren; aber auch über ihre eigene Person sind sie nicht mehr orientiert, da sie manchmal ganze Abschnitte ihres Lebens, wenigstens zeitweise, vergessen; so wissen die Kranken häufig nicht, wie sie heißen, Frauen vergessen, daß sie verheiratet oder verwitwet sind, und geben ihren Mädchennamen an, sie vergessen, daß sie Kinder haben oder wissen nicht, wieviel Kinder sie haben, sie vergessen, daß der oder jener aus der Familie gestorben ist; dabei wechseln die Angaben ständig, da die Kranken auch das sofort vergessen, was sie soeben erzählt haben, und geben wieder etwas ganz anderes an.

Diese Gedächtnisdefekte werden häufig durch Konfabulationen gedeckt. Solche Kranke, mit einer so hochgradigen Merkfähigkeitsstörung, sind nie um eine Antwort verlegen; nach jeder Frage haben sie sofort irgendeine erdichtete Antwort bei der Hand. Die Konfabulationen treten ganz spontan auf, das heißt die Kranken erzählen unaufgefordert ihre erdichteten Erlebnisse, oder aber sie produzieren dieselben nur auf Befragen. Kaum daß sie aber diese oder jene Begebenheit erdichtet haben, vergessen sie dieselbe und erzählen sofort etwas ganz anderes oder etwas ganz Entgegengesetztes. Sehr häufig sieht man, daß den Kranken die Widersprüche nicht auffallen, auch dann nicht, wenn sie die einzelnen Tatsachen der Widersprüche noch nicht vergessen haben konnten; so sagen solche Kranke z. B. längere Zeit, sie hätten ein bestimmtes Alter und geben dieselbe oder eine davon kaum differente Zahl an, wenn sie nach dem Alter ihrer Eltern oder Kinder gefragt werden. Die Unmöglichkeit dessen sehen sie aber nicht ein, auch wenn sie dieselben Zahlen immer wieder angeben. Dabei sind die Kranken der Suggestion sehr zugänglich. Die Konfabulationen sind manchmal vollkommen erdichtet, manchmal aber sind sie nur eine konfabulatorische Umänderung wirklicher Geschehnisse. Auch kommt es vor, daß einzelne Geschehnisse längere Zeit im Gedächtnis bleiben, aber konfabulatorisch immer wieder umgearbeitet werden.

Entsprechend der großen Vergeßlichkeit und der Desorientierung kommt es auch regelmäßig zu unsinnigen Handlungen. Die Kranken wollen weggehen, weil sie glauben, daß sie zu Hause sind; wenn sie urinieren wollen, so tun sie es neben dem Bett auf dem Boden, weil sie glauben, sie seien gerade auf dem Klosett; trotz eventueller hoch- 
gradigster Schwäche wollen sie nicht im Bette bleiben, wollen immex wieder aufstehen und herumgehen, sie suchen überall ihre Kleider, ziehen sich verkehrt an, weil sie sehr häufig die Kleidungsstücke verwechseln; was sie sehen, halten sie für ihr Eigentum, raffen deshalb alles zusammen und wollen es wegtragen; die Frauen nehmen meist allerhand Geschirr und Tafelgeräte, wickeln es in die Schürze, Männer wickeln gewöhnlich ihr Bettzeug in Bündel zusammen, nehmen es unter den Arm und wollen damit weggehen. Reisebereit, in manchmal ganz komischem Aufzuge, stehen diese Kranken immer wieder bei der Tür.

Inmitten dieser Symptome tritt durchwegs eine deutliche Demenz verschiedenen Grades hervor, was ja bei den so schweren und dauernden Störungen des Gedächtnisses beinahe selbstverständlich ist, Nicht selten haben aber die Kranken auch eine, wenn auch nur partielle Krankheitseinsicht, indem sie zugeben, ein schlechtes Gedächtnis zu haben oder selbst von sich sagen: ,sie seien ganz blöd geworden".

Fall 8. Rehak, Franz, 76 Jahre.

A nam nese. Pat. war immer ein starker Trinker; seit 8 Jahren hat er epileptische Anfälle, die immer nur dann auftreten, wenn er viel getrunken hatte; vor $11 / 2$ Jahren war er nach mehreren derartigen Anfällen schlaflos, sah massenhaft Mäuse und Schaben, die er fangen und erschlagen wollte; nach einigen Tagen verging der Zustand. Vor 1/2 Jahr delirierte er nach einigen derartigen Anfällen wieder, wähnte sich mit Pferden und Wagen beschäftigt, kutschierte, dann lief er im Zimmer herum und klagte, er hätte Magenschmerzen. Seit mehreren Jahren ist Pat. sehr vergeBlich, reizbar und bei geringsten Anlässen tätlich, besonders wenn man seinem Verlangen nach Bier und Schnaps nicht nachkommt.

Beobachtung. 25. März bis 14. Dezember 1904. 26. März. Einfach dement; nicht recht orientiert, sehr vergeßlich.

7. Juni und 8. Juni. Je ein epileptischer Anfall.

10. Juni. Glaubt hier erst 2 Tage zu sein.

3. August und 6. August. Je ein epileptischer Anfall.

6. bis 7. August. Auffallend lustig, tanzt im Zimmer herum, plaudert sehr lebhaft; leicht ideenflüchtig.

19. September. Behauptet, erst einen Tag da zu sein, hier wäre vielleicht Prag; gestern wäre er noch zu Hause gewesen; kennt seine Umgebung nicht; kennt nicht seine Bettstelle; hält den Wärter für den Gastwirt und verlangt von ihm Wein und Bier.

7. Oktober. Wieder lustig, lebhaft, tanzt herum, spricht viel und ideenflüchtig; schläft wenig.

6. Dezember. Ein epileptischer Anfall.

10. Dezember. Zustand gleich, hohe Vergeßlichkeit, Konfabulationen gleicher Art wie vordem.

14. Dezember 1904. Exitus an Marasmus.

Sektionsbefund. Das Gehirn von außen deutlich atrophiert; leichte Erweiterung der Ventrikel; fleckige Verdickung der Basalgefäße.

Mikroskopisch. In der Stirnpartie nicht sehr reichliche Drusen, meist im Stadium III, die Zellen wenig verändert; keine Keulen; in den Zentralwindungen keine Drusen. 
Fall 9. Valenta, Josef, 70 Jahre.

Anamnese. Seit 14 Tagen sucht Pat. seine vor einigen Monaten verstorbene Frau, ist örtlich desorientiert, will von zu Hause weglaufen und wird gewalttätig, wenn ihn jemand daran hindert; manchmal sucht er auch etwas in der Luft.

Beobachtung. 21. Januar bis 15. Februar 1908. Behauptet, er sei 40 Jahre alt, sein Sohn sei 36 , weiß, daß seine Frau gestorben ist. Hat eine linksseitige Hemianopsie - sonst keine Herdsymptome.

23. Januar. Weiß, daß er erst den 2. Tag hier ist.

24. Januar. Heute delirant, zerwühlt die Matratzen, hängt sein Leintuch im Bette auf; gefragt, was er da mache, behauptet er, eine Fassade (er war Maurer); gestern hätte er nicht gearbeitet, es wäre Feierabend gewesen.

Wo seine Frau ist? Die ist heute zu Hause.

Wann er mit der Frau zuletzt gesprochen? Heute früh.

28. Januar. Tagsïber ist Pat. meist ruhig, ständig desorientiert, hochgradig vergeßlich und auf Befragen produziert er die verschiedensten Konfabulationen; nachts ständig mit dem Bettzeug beschäftigt, delirant. Bei einer solchen nächtlichen Beschäftigung äußert er folgendes, aus dem der Inhalt seines Delirierens, das in Details wechselt, aber bis zu seinem Ende sich im großen ganzen gleich bleibt, zu ersehen ist:

Was ist das für ein Holz? Oben ist lauter Holz, Alte gib mir die Hacke, ich werde das Holz hacken, du Weib, hole Späne und mache ein Feuer an, es ist doch gar nichts hier, Herr, gib die Hacke her, damit ich das Holz spalte, es ist schon 2 Uhr und ich habe fort kein Holz; das dauert lange mit der Hacke, der Teufel möchte das alte Luder holen, bis sie die Hacke bringt, ich sage ihr schon von früh, noch ist das Holz nicht fertig - du, Josef, gib mir den Kaffee her, bevor er kalt wird, wo ist er denn, warte. Hörst du, reiche mir ein bißl Wasser zum Trinken; also jetzt schauen die Leute uns an, ich wollte Wasser trinken und das alte Luder gießt es mir auf den Kopf.

15. Februar 1908. Exitus an Bronchopneumonie.

Das Gehirn von außen leicht atrophiert, die Meningen verdickt. Ventrikel beiderseits stark erweitert. Basalgefäße fleckig verdickt. Im Pol des Occipitallappens ein etwa haselnußgroßer, ins Mark reichender Erweichungsherd der Rinde.

Mikroskopisch. Reichliche Drusen in den Stadien I-III; dabei auch im Stirnlappen mehrfach eine infiltrative Wucherung der Fädchen zu finden. Wenige Keulen. Die Ganglienzellen sehr stark verändert.

Fall 10. Taussig, Jakob, 66 Jahre.

Anamnese. Seit 2 Jahren vergeßlich (angeblich nach einem geschäftlichen Zusammenbruch); vor 6 Wochen nachts wiederholt desorientiert, wollte weggehen, glaubte nicht zu Hause zu sein; vor 4 Wochen wieder ruhiger, mehr geordnet; seit 14 Tagen wieder Verschlimmerung; er dachte, es sind Leichen im Hause, suchte die Leichen meistens nachts.

Beobachtung. 30. April bis 4. Oktober 1908. Pat. weiß nicht sein Alter, gibt bald 30, bald 90 Jahre an, weiß nicht, wo er sich befindet, glaubt, bald gerade hergekommen zu sein, bald 8 Wochen da zu sein; macht im Laufe von einigen Sekunden die differentesten Angaben über seine Person, sein Alter, den Ort, wo er sich befindet, wie lange er hier ist, und was er vor soundso langer Zeit gemacht hätte; amnestische Aphasie und leichte Paraphasie.

5. Mai. Tagsüber ist er ruhig, nur desorientiert, nachts unruhig, schläft wenig, ruft seine Angehörigen, glaubt die Frau zu hören, drängt weg, zerwirft die Matratzen, sucht etwas drin.

10. Juni. Unverändert.

19. Juni. Vormittags blaß im Gesicht, kalter Schweiß, leichte Cyanose, und 
nach $1 / 2$ Minute Besserung, worauf er sich über Doppelsehen beklagt; Lähmung des Musculus rectus int. des rechten Auges, die sich im Laufe von 5 Tagen wieder vollkommen zurückbildet.

30. Juni. Zustand unverändert; vielfache ständig wechselnde und widersprechende Konfabulationen, erkennt nicht seine Angehörigen. Nachts unrubig, manchmal delirant, hilft Mehl auf Wägen aufladen (Pat. war Müller).

20. Juli. Jetzt auch bei Tag unruhig, drängt weg, delirante Beschäftigung; will wegfahren, schirrt Pferde an, sucht Flaschen am Boden, uriniert am Boden und glaubt in der Hand eine Urinflasche zu halten; manchmal ängstlich, ruft um Hilfe, erkennt nicht die Ärzte, verkennt die Umgebung.

4. Oktober 1908. Exitus.

Sektionsbefund. Marasmus universalis. Arteriosklerosis universalis. Hypertrophia cordis. Atrophia renum. Das Gehirn von außen atrophiert. Die Ventrikel leicht erweitert. Die Basalgefäße leicht fleckig verdickt. Im Marke des rechten Stimhirns eine walnußgroße frische Blutung.

Mikroskopisch. Viele Drusen im Stadium IV und V. Wenige Keulen. Mäßige Veränderung der Ganglienzellen.

Fall 11. Martinek, Ludmilla, 103 Jahre.

Anamnese. Seit einigen Monaten Aufregungszustände.

Beobachtung. 7. Juli bis 10. August 1907. Ist persönlich vollkommen orientiert, weiß, daß sie ein sehr schlechtes Gedächtnis hat und manchmal sei sie verwirrt; glaubt hier schon einige Tage zu sein, wäre hier zur Arbeit; gestern hätte sie noch am Felde hier gearbeitet, dann sei sie hier beim Herm im Stalle beschäftigt.

9. Juli. War nachts sehr unruhig, ängstlich.

10. Juli. Nachts wieder unruhig.

12. Juli. Nachts delirant; ärgerlich ruft sie: „Franz, stehe auf, wir fahren schon“"; schimpft den „Faulenzer", weil er nicht aufstehen wolle, droht ihm mit Ohrfeigen.

13. Juli. Ruhig, schläft nachts.

17. Juli. Wieder nachts unruhig, zerwühlt die Betten, sucht etwas darin; ihr Alter bezeichnet sie bald mit 19, bald mit 103; ist weinerlich, sie hätte gerade die Mutter begraben, und im Handumdrehen erzählt sie wieder, die Mutter werde morgen begraben; dazu erzählt sie diverse Details, die aber sehr stark wechseln, da sie im $\mathrm{Nu}$ alles vergißt, wodurch ihre Erzählung ins Unsinnigste entstellt wird - durch Fragen werden ihre Konfabulationen in beliebiger Richtung geändert.

20. Juli. Zustand unverändert.

Wie alt? 103.

Was macht Ihre Mutter? Die macht nichts, sie liegt heute.

Was ist ihr geschehen? Sie ist gestorben.

Wann? Gestern.

Wann wird sie das Begräbnis haben? Vielleicht heute, der Herr Pfarrer war ja hier.

Wie alt sind Sie? 103.

Und die Mutter? 103.

Wie alt sind Sie? 16 oder 17 .

Da sind Sie also jung? Denke nicht sehr, ich habe ja einen Sohn, der ist so alt wie Sie, hat gerade ausgedient und wird nach Hause kommen.

Wie alt ist der Sohn? Der ist um ein Jahr älter als ich.

Wie alt sind Sie? 16 oder 17.

Was macht der Mann? Der ist bei der Waldarbeit.

Wie alt ist der? Jung ist der nicht, er hat so große Kinder wie Sie. 
Wie alt sind Sie? $103-\ldots-$ und in ähnlicher Weise geht das weiter.

10. August 1907. Exitus an Marasmus und Bronchitis.

Das Gehirn von außen leicht atrophiert, die Ventrikel erweitert, die basalen Gefäße fleckig verdickt.

Mikroskopisch. Sehr reichliche Drusen im Stadium IV. Keine Keulen. Sehr schwere Veränderung der Ganglienzellen.

Fall 12. Braunold, Franziska, über 70 Jahre.

Anamnese. Seit einem Jahre hochgradig dement, vergeßlich. Entlauft von zu Hause und trifft nicht zurück.

Beobachtung. 20. Juni 1905 bis 12. Juni 1909. 22. Juni. Von gehobener Stimmung, sehr gesprächig, witzelt; örtlich und zeitlich desorientiert, glaubt gerade hergekommen zu sein, behauptet alle zu kennen, ihr Alter gibt sie bald mit 20, bald mit 70 an; gestern wäre sie noch zu Hause gewesen, was sie aber sonst machte, wisse sie nicht, weil sie ein schlechtes Gedächtnis habe; ist hochgradig vergeßlich, indem sie auch ganz ungewöhnliche Dinge, die in der Umgebung geschehen, sofort vergißt.

30. Juli 1905. Immer euphorisch, sehr vergeßlich; verlangt häufig zu essen, da sie sofort vergißt, daß sie schon gegessen hatte; beim Ankleiden zieht sie die Kleider verkehrt an; versucht man ihr in ihrem Gebaren irgendwie zu wehren, wird sie sehr ärgerlich, schlägt um sich, aber im Handumdrehen schlägt die wütende Stimmung in die gewohnte heitere über; den Arzt, den sie täglich sieht, behauptet sie bald nicht zu kennen, bald verkennt sie ihn in ständig wechselnder Weise.

22. April 1907. 29. April 1907. 28. Juli 1907. Je ein epileptischer Anfall.

11. Oktober. Beschäftigt sich manchmal im Bette, indem sie das Bettzeug zerwühlt und behauptet, sie wasche oder verrichte irgendwelche Hausarbeiten; leicht amnestische Aphasie.

15. Oktober. Epileptischer Anfall.

18. Oktober. Brummt stumpf dement vor sich hin; auf die Frage, was sie heute machte, sagte sie prompt: Holz hätte sie gespalten, sie hätte übrigens schon sehr viel Arbeit geleistet; später behauptet sie, bereits Suppe gekocht zu haben. Auf die Frage, wo sie die Materialien zum Kochen hernimmt, zeigt sie draußen auf den Garten und sagt: „Im Hofe"; von wem sie alles bezieht, wisse sie aber nicht.

8. März 1909. Epileptischer Anfall.

12. Juni 1909. Exitus an Marasmus.

Das Gehirn von außen leicht atrophiert, die Meningen verdickt, die basalen Gefäße nicht merklich verdickt. Mittelstarke Erweiterung der Ventrikel.

Mikroskopisch. Reichliche Drusen in den Stadien I-IV. In der Stirn auch Infiltrationsstadium. Die Verteilung der Drusen in verschiedenen Partien verschieden, aber ohne eine bestimmte Gesetzmäßigkeit, wobei auch die einzelnen Hemisphären sich auch nicht gleich verhalten. Keine Keulen. Die Ganglienzellen stark verändert, in einzelnen Gegenden zeigen dieselben die grobfaserige Fibrillenwucherung.

Im Kleinhirn und den Stammganglien keine Drusen. Im Kleinhirn an einigen Stellen kernlose Reste von Ganglienzellen mit grobfaseriger Fibrillenwucherung.

Fall 13. Hock, Anna, 79 Jahre.

Anamnese. Seit einigen Monaten unruhig.

Beobachtung. 14. Juni bis 3. August 1907. Eingebracht sehr vergeßlich, verlangt immerfort zu essen, sie hätte schon tagelang nichts gegessen, rafft alles Mobile im Zimmer zusammen, will nicht im Bette bleiben, zerwühlt das Bettzeug, trennt die Überzüge ab, hüllt sich damit in phantastischer Weise sehr ungeschickt ein, sucht überall ihre Kleidungsstücke. Schläft beinahe gar nichts. 
18. Juni. Thren Namen nennt sie richtig, glaubt aber etwa 25 Jahre alt zu sein.

Wo sie hier ist? Ich wohne hier bei der Frau ; glaubt schon mehr als eine Woche hier zu sein.

Heute früh hätte sie schon das Vieh gefüttert. Behauptet, Kinder zu haben, weiß aber nicht wie viele.

Wie alt die Tochter ist? Ich weiß nicht, ich gebe auf so was nicht Obacht.

20. Juni. Heute setzte sich eine Wärterin neben sie; Pat. jagt sie weg und schimpft: „Du Lausbub, du willst heiraten, ich bin zu alt dazu."

22. Juni. Verlangt früh vom Arzte 2 Kreuzer, denn sie hätte sich ihr Hemd zerrissen und müsse Zwirn kaufen. Es wird $\mathrm{ihr}$ darauf ein neues Hemd gegeben, das sie sich über das alte (gar nicht zerrissene) anzieht. Nachmittags grüßt sie den Arzt wie einen alten Bekannten, hält ihn für einen Oberförster, der ihr vor mehreren Jahren ein Hemd geschenkt hätte; hier sei sie beim Herrn Baron, bei dem sie gestern noch am Felde gearbeitet hätte; heute will sie weggehen, aber man wolle sie nicht weglassen.

23. Juni. Erkennt heute den Arzt nicht, weiß vom Hemd nichts mehr.

2. Juli. Das gleiche Verhalten; will immer herumlaufen; alles, was sie sieht, nimmt sie weg und rafft es zusammen, da es ihr gehöre; dabei zieht sie alles in verkehrter Weise an; heute zog sie einer Pat. 2 Hausschuhe weg, behauptete, die gehören ihr, sie hätte sie doch vor einigen Tagen beim Kaufmann gekauft; wieviel sie dafür gegeben, wisse sie nicht. Im Bette reißt sie die Überzüge herunter, wirft alles durcheinander, zieht die Bettwäsche als Kleid an, verlangt ständig zu essen, da sie schon tagelang nichts gegessen hätte.

3. August 1907. Exitus an Marasmus.

Bei der Sektion zeigte sich außer universellem Organschwund nichts Pathologisches.

Das Gehim leicht atrophiert, die Ventrikel stark erweitert, die basalen Gefäße unverändert.

Mikroskopisch. Reichliche Drusen in den Stadien I--IV. Wenig Keulen. Nicht sehr starke Veränderung der Ganglienzellen.

Fall 14. Bezchleba, Franz, etwa 70 Jahre.

Anamnese. Vor 4 Jahren ein Kopftrauma; vor 2 Jahren ein Schlaganfall der rechten Seite; nach $1 / 2$ Jahr ein zweiter Anfall mit epileptischen Krämpfen; seit der Zeit ist Pat. auf der rechten Seite gelähmt und sehr dement. In der letzten Zeit nächtliche Angst und Unruhe.

Beobachtung. 13. Juli 1908 bis 25. März 1910. Weiß sein Alter nicht, meint, er sei 22 Jahre ; bald behauptet er, verheiratet, bald ledig zu sein; ob er Kinder hat, weiß er nicht; wechselnde Angaben über die Dauer seines hiesigen Aufenthaltes. Auf die Frage, wo er hier sei, wendet er sich im Bette um, um seine Schwester zu fragen, da er glaubt, seine Schwester liege im Bett daneben. Sehr vergeßlich und stumpf.

Somatisch rechtsseitige Hemiparese.

4. September. Bei Tag stumpf, unrein, steht häufig auf; glaubt, daß neben dem Bette ein Klosett ist und uriniert auf die Erde; nachts schläft er wenig, spricht vor sich; glaubt, erst gestern gekommen zu sein. Dann wähnt er sich wieder zu Hause, steht häufig auf, rollt seine Decke zusammen, nimmt sie unter den Arm und will damit weggehen; sucht häufig etwas unter dem Strohsack und brummt vor sich, er müsse nach Hause gehen.

1. Mai 1909. Zustand unverändert, nachts immer leicht delirant, tagsüber auf Befragen konfabulierend, je nach Art der Fragestellung; ständig desorientiert.

1. Dezember. Unverändert. 
25. März 1910. Exitus an Bronchopneumonie.

Mikroskopisch. Viele Drusen im Stadium III und IV. Sehr spärliche Keulen. Starke Veränderung der Ganglienzellen.

Fall 15. Bicek, Wenzel, 65 Jahre.

Anamnese. Potator; arbeitete seit 3 Jahren wegen Odem der Beine nicht mehr; seit 4 Wochen sprach er unsinnig, verstumpfte, nachts war er unruhig, spricht von viel Arbeit, die er habe, will weglaufen, wird gewalttätig; von Schlaganfall nichts bekannt.

Beobachtung. 6. Januar bis 10. Januar 1910. Pat. hat eine spastische Parese des rechten Beines, ist stumpf, unrein; dabei auch sensorisch paraphatisch; weiß nicht sein Alter; nicht die Zahl und Namen seiner Kinder; ist zeitlich und örtlich vollkommen desorientiert; sonst stumpf dement.

8. Januar. Kennt sich nicht in der Umgebung aus, hochgradig vergeßlich, konfabuliert ständig; behauptet, gerade in der Arbeit gewesen zu sein, und erzählt ganz wechselnd von dem Erfolg seiner Tätigkeit; will häufig aufstehen und weggehen, trotzdem er sich kaum vom Bette rühren kann; nachts besonders unruhig, schreit unartikuliert, ist unrein.

10. Januar 1910. Exitus an Pneumonie.

Das Gehirn von außen leicht atrophiert, Meningen nicht verdickt; die basalen Gefäße stellenweise fleckig verdickt und verkalkt. Im rechten Nucleus lentiformis mehrere kleine Erweichungen, in der rechten Hälfte des Pons eine halberbsengroße, bräunlich gefärbte Erweichung, die bereits in Resorption begriffen ist.

Mikroskopische Untersuchung. Drusen in mäßiger Anzahl im Stadium I-IV. Spärliche Keulen. Starke Veränderung der Ganglienzellen.

Fall 16. Brabec, Josef, 55 Jahre.

Anamnese. In der letzten Zeit (wann?) mehrfache apoplektische Insulte; nachts ist er immer unruhig, halluziniert, will weglaufen.

Beobachtung. 4. Oktober bis 24. Oktober 1907. Stark herabgekommen, die Extremitäten spastisch-paretisch, mit Bevorzugung der rechten Körperseite; sensorische Aphasie mit Paraphasie; starke Verstumpfung; unrein; einzelne Angaben über seine Person gibt er richtig an, einzelne falsch, dabei ist es nicht sicher, ob die unrichtigen Angaben in der Desorientiertheit, der Verstumpfung oder im Sprachdefekt ihre Ursache haben.

10. Oktober. Tagsüber ist Pat. stumpf, unrein, nachts meist unruhig, schläft sehr wenig, brummt etwas Unverständliches vor sich hin, will weglaufen.

15. Oktober. Behauptet kurz nach dem Frühstück, man hätte ihm noch nichts zu essen gegeben.

24. Oktober 1907. Exitus an diffuser Bronchitis.

Bei der Sektion fand sich starke Endarteriitis mit Herzhypertrophie und diffuse Bronchitis.

Das Gehirn von außen leicht atrophiert, Meningen wenig verdickt. In beiden Linsenkernen mehrere ganz kleine ältere, cystische Erweichungsherde.

Mikroskopisch. Wenige Drusen im Stadium IV. Viele Keulen. Mäßige Erkrankung der Ganglienzellen.

Fall 17. Novotny, Marie, 88 Jahre.

Anamnese. Seit $1 / 2$ Jahr schläft Pat. wenig, ist nachts häufig unruhig, steht auf, geht herum, kennt sich nicht in der Wohnung aus, halluziniert fremde Personen.

Beobachtung. 12. Oktober bis 24. Oktober 1907. Gibt ihren Namen richtig an, aber das Alter ganz wechselnd, von 40 Jahren aufwärts; weiß nicht, wieviel Kinder sie hat; wei $B$, da $B$ sie ein schlechtes Gedächtnis hat; will immerfort aus dem Bett herauslaufen, sie habe es sehr eilig; behauptet, bald am Markte, bald 
in den Gassen zu sein; das Bettzeug zerwühlt sie, sucht ihre Sachen, die man ihr ins Kloster gegeben hätte.

24. Oktober 1907. Exitus an einer Phlegmone des Armes.

Pathologisch-anatomische Diagnose: Marasmus universalis. Bronchitis supp. Endarteriitis chron. def. Morb. Brightii chron. Hypertrophia cordis. Phlegmone antibrachii.

Das Gehirn von außen stark atrophiert. Die Ventrikel stark erweitert. Starke fleckweise Verdickung und Verkalkung der basalen Gefäße.

Mikroskopisch. Massenhafte Drusen vom Typus I-III, dabei auch sehr viel Infiltrationsstadium. Keine Keulen. Die Ganglienzellen schwer verändert.

Fall 18. Granat, Antonie, 79 Jahre.

Fnamnese. Seit 1/2 Jahr zunehmende Demenz, konnte nicht mehr nach Hause treffen; in der letzten Zeit verwirrt und aufgeregt, ist sehr vergeßlich, vergaß sofort nach dem Essen, daß sie gegessen hatte, erkannte die Kinder nicht mehr.

Beobachtung. 13. Februar bis 9. Juli 1909. Etwas ängstliche Alte; sie zeigt eine vornehmlich amnestische Aphasie, spricht mit lauter Flickworten, so daß ein Examen schwer durchführbar und auch schwer der Grad ihrer Orientiertheit $\mathrm{zu}$ beurteilen ist.

14. Februar. Rafft alles zusammen und will damit weggehen, sie müsse nach Hause, man solle sie nicht zurückhalten; am unruhigsten des Nachts; sie spricht immerfort, wobei die Sprache viel besser jst, als beim Examen.

16. Februar. Wirft tags und nachts ihr Bettzeug durcheinander, zieht sich aus, packt alles Mobile zusammen, zerreißt auch das Bettzeug, schläft trotz Schlafmittel beinahe gar nichts.

20. Februar. Bei Tag meist ruhig; nachts immer delirant, eifrig beschäftigt, spricht dabei ständig, häufig ängstlich, aber es ist nicht zu erfahren, womit sie sich zu beschäftigen glaubt. Auf Schlafmittel etwas Schlaf.

30. März. Zustand unverändert; über ihr Vorleben gefragt, antwortet sie immer, ,sie weiß nicht, sie sei blöd“. Zunehmender Marasmus.

9. Juli 1909. Exitus an Marasmus und akuter Enteritis.

Das Gehirn von außen leicht atrophiert, Meningen wenig verdickt, basale Gefäße etwas verdickt. Am Durchschnitte sehr starke Erweiterung der Ventrikel.

Mikroskopisch. Ziemlich viele Drusen im Stadium I-IV. Viele diffuse Infiltrationen. Keine Keulen. Starke Veränderung der Ganglienzellen.

Fall 19, Fritz, Johann, 68 Jahre.

Anamnese. Seit 5 Jahren zunehmend dement, vergeßlich; in den letzten Jahren progrediente Sprachstörung sensorischer Art.

Beobachtung. 7. September bis 4. Oktober 1908. Pat. zeigt das Bild ziemlich vorgeschrittener amnestischer Aphasie; die Sprache versteht er zumeist, aber seine Antworten bestehen zum Teil aus ganz unsinnig zusammengesetzten Flickworten, Hauptworte wendet er beinahe überhaupt nicht an; Alexie, Agraphie und ideatorische Apraxie. Sonst stumpf und unrein.

10. September. Schläft schlecht, will nachts aufstehen und weggehen, spricht von seinem Sohn, rollt ständig die Decke auf und zu.

17. September. Nachts unruhig, sucht im Bette herum, hebt den Strohsack immer wieder in die Höhe, wirft die Decke ständig weg.

18. September. Tagsüber ruhig, stumpf; nachts unruhig, will nicht liegen bleiben, geht zur Tür, er müsse zur Arbeit gehen, macht dann eine lange Zeit geldzählende Bewegungen mit den Händen.

19. September. Sucht tagsüber seine Frau und seinen Sohn; unrein.

28. September. Tagsüber ist er immer stumpf, nachts immer unruhig, ge- 
schäftig, delirant; wirft die Matratzen herum, nestelt an der Decke, rollt sie unter den Arm und will weggehen.

4. Oktober 1908. Zunehmender Marasmus; Exitus an Pneumonie.

Die Sektion zeigte außer Marasmus stärkere Arteriosklerose und lobuläre Pneumonie der rechten Lunge.

Das Gehirn deutlich atrophiert, leichte Erweiterung der Ventrikel, geringe fleckige Verdickung der basalen Gefäße.

Mikroskopisch. Kolossale Massen von großen Drusen im Stadium V (Fig. 41). Viele Keulen. Schwere Veränderung der Ganglienzellen.

Fall 20. Pobuda, Franz, 83 Jahre.

Anamnese. Keine.

Beobachtung. 26. März bis 8. April 1910. Sehr marantisch; weiß nicht sein Alter; macht darüber ganz wechselnde Angaben, bald ist er 18, bald $30 \mathrm{Jahre,}$ glaubt, daß seine Frau noch lebt, weiß nicht die Zahl und Namen seiner Kinder. Ist zeitlich und örtlich vollkommen desorientiert. Einen Tag nach der Aufnahme glaubt er hier bereits 2 Jahre zu sein, verfertige hier Besen.

Nachts drängt er aus dem Bette fort, sucht seine Tochter, glaubt hier in einer Räuberhöhle zu sein.

8. April 1910. Exitus an Marasmus.

Das Gehirn leicht atrophisch mit geringer Verdickung der Ventrikel. Basalgefäße unverändert.

Mikroskopisch. Massenhafte Drusen im Stadium III, IV und V. Keine Keulen. Sehr starke Veränderung der Ganglienzellen; spärliche grobfaserige Fibrillenwucherung in denselben.

Fall 21. Havlik, Katharina, 76 Jahre.

Anamnese. Seit $1 / 2$ Jahr zunehmend vergeßlich, seit $1 / 4 \mathrm{Jahr}$ ist die Vergeßlichkeit so stark, daß sie im Handumdrehen alles vergißt. Sie schläft schlecht, verlangt eine neue Wohnung; will die Nachbarn aus der Wohnung heraustreiben, weil die Wohnung ihr gehöre; wenn man ihr wehrt, wird sie ärgerlich, schimpft, schreit, man wolle sie töten, sie werde sich lieber selbst umbringen.

Beobachtung. 31. März bis 17. Juni 1906. Eingebracht ganz ruhig; wähnt sich hier im Krankenhause, negiert die Aufregung zu Hause, sagt, man hätte sie nur geärgert; ist persönlich vollkommen orientiert; Rechnen schlecht.

1. April. Ganz ruhig, weiß, daß sie gestern gekommen.

2. April. Glaubt, hier schon eine Woche zu sein. Schläft nachts wenig.

7. April. Liegt ruhig da, ist sehr vergeßlich, weiß nicht, wie lange sie da ist; sofort nach dem Essen vergißt sie, daß sie gegessen hatte; behauptet, vor kurzer Weile von dem Sohn und einem Bekannten besucht worden zu sein, die nur ins Wirtshaus gegangen sind und wieder kommen wollen. Bald darauf verlangt sie wieder weg, weil sie glaubt, ihr Sohn warte schon draußen auf sie.

24. April. Sehr vergeßlich, spärlich konfabulierend, glaubt, von dem oder jenem |besucht worden zu sein, hält den Arzt für ihren Sohn oder auch für jemanden anderen, ganz wechselnd, inkonsequent; halluziniert besonders abends, hört ihre Angehörigen draußen im Garten oder am Gang und will heraus zu ihnen.

16. Mai. Tagsüber ist sie ruhig, stumpf, abends ärgerlich, hört ihre Angehörigen draußen und will zu ihnen hinaus.

17. Juni 1906. Exitus an Pneumonie.

Das Gehirn von außen wenig atrophiert, starker Hydrocephalus internus, zarte Basalgefäße.

Mikroskopisch. Reichliche Drusen im Stadium I-IV; in den hinteren Rindenpartien prävalieren die größeren Drusen; dabei die Anordnung in beiden 
Hemisphären gleich. Sehr schwere Zellveränderung. Keine Keulen. Im Kleinhirn und den Stammganglien keine Drusen.

Fall 22. Plátek, Anna, 80 Jahre.

Anamnese. Beginn unsicher.

Beobachtung. 25. August bis 1. Dezember 1908. 26. August. Ständig mit ihren Kleidern und Matratzen delirant beschäftigt; schimpft zum Fenster hinaus, sieht Feuer; alles, was sie sieht, gehöre ihr, und wenn jemand etwas vom Tische wegnimmt, ruft sie nach einem Schutzmann. Glaubt, hier schon 14 Tage zu sein, von wo sie hergekommen, weiß sie nicht, weiß auch nicht, wo sie hier ist, behauptet, hier alle zu kennen.

1. Oktober. Zustand unverändert, nachts die Unruhe viel stärker, schlief sehr wenig; nachher weiß sie meist nichts davon, daß sie unruhig war.

3. November. Sieht nachts ihre Kinder und Verwandten.

8. November. Hört nachts menschliche Stimmen aus einem Schrank, hat Angst, man habe dort jemanden eingesperrt, den man umbringen wolle. Behauptet, sie hätte vor einigen Tagen 50000 geschenkt bekommen, die man ihr gestohlen hätte, dafür behandle man sie so schlecht.

1. Dezember 1908. Nachdem der Zustand unverändert blieb, Exitus an Marasmus.

Das Gehirn von außen leicht atrophiert, die Ventrikel deutlich erweitert, basale Gefäße zart.

Mikroskopisch. Ziemlich viele Drusen in den Stadien II-IV. Stellenweise Stadium VIII. Keine Keulen. Starke Veränderung der Ganglienzellen.

Fall 23. Rajdl, Franz, 78 Jahre.

Anamnese. Seit 3 Jahren schon sehr vergeßlich, vergaß alles im $\mathrm{Nu}$; in der letzten Zeit sprach er immer nur von Feuer und wollte schon einmal Feuer legen; in der Nacht lief er unbekleidet heraus und schrie, daß es brenne.

Beobachtung. 22. Januar bis 31. Januar 1908. Bei der Einbringung ruhig, örtlich vollkommen desorientiert; nachts deliriert er, zerriß Matratzen, warf das Roßhaar heraus.

23. Januar. Namen gibt er richtig an, Alter ganz wechselnd; ist örtlich nicht orientiert, je nach Suggestion ist er zu Hause oder in einem Gasthause, glaubt, hergekommen zu sein, um Almosen zu bekommen, die Zahl und Namen seiner Kinder kennt er nicht, glaubt, hier schon lange Zeit zu sein.

25. Januar. Auf Befragen wechseln seine Angaben; aufs Alter gefragt, gibt er zuerst 22 an, nach einigen Minuten auf dieselbe Frage 45, dann wieder 22; wähnt sich zu Hause; glaubt, hier bald 2 Tage, bald 4 Wochen zu sein, denn es sei schon sehr lange, so daß er es sich nicht merken könne, vielleicht $1 / 2 \mathrm{Jahr}$, dann wieder eine Woche. Weiß seinen Namen nicht.

Leicht amnestische Aphasie mit aprakt. Störungen, behauptet, hier schon viel gearbeitet zu haben, die Umgebung verkennt er.

31. Januar 1909. Exitus an Pneumonie.

Das Gehirn von außen leicht atrophiert, deutliche Erweiterung der Ventrikel. Zarte Basalgefäße.

Mikroskopisch. In der rechten Hemisphäre nur sehr spärliche Drusen im Stadium IV, in den anderen Gegenden keine. In der linken Hemisphäre fehlen die Drusen im Occipitallappen, wogegen sie in den anderen Gegenden in spärlicher Zahl vertreten sind, und zwar in den Stadien III und IV. Geringe Zellveränderung; keine Keulen.

Fall 24. Roth, Franz, 83 Jahre.

Anamnese. Seit 2 Jahren wird Pat. zunehmend schwachsinnig und vergeßlich; die Krankheit begann mit Schwindelanfällen, nach denen er ganz verwirrt 
war; seit mehr als einem Jahr ist er nachts unruhig, halluziniert Gestalten und Tiere im Zimmer.

Beobachtung. 22. Februar bis 8. Juni 1908. Pat. ist beinahe vollkommen taub; dadurch eine Verständigung sehr erschwert; in der Klinik liegt er tagsüber stumpf, gleichgültig zu Bette, nachts schläft er wenig, meist will er aufstehen, ruft seine Kinder, will weglaufen, seine Kleider haben, droht den Wärtern mit Erschießen. Dann wieder zerreißt er das Bettzeug und zerwühlt die Matratzen, beschäftigt sich ständig damit, legt es hin und her und brummt dazu immer etwas Unverständliches; nichts von Aphasie; dieser Zustand bleibt unverändert bis zu seinem am 8. Juni 1908 erfolgten Exitus an Marasmus und Bronchitis.

Das Gehirn sehr stark atrophiert, die Meningen verdickt und getrübt. Die basalen Gefäße fleckweise verdickt. Die Ventrikel sehr stark erweitert. Im rechten Thalamus opticus und Nuclus lentiformis je eine kleine bräunlich gefärbte cystische Erweichung.

Mikroskopisch. Reichliche Drusen; in den vorderen Partien sehr viel Infiltrationsstadien, in den hinteren nur die Stadien II-IV. Keine Keulen. Schwere Veränderung der Ganglienzellen.

Fall 25. Urban, Johann, 84 Jahre.

Ana mnese. Keine.

Beobachtung. 6. Juni bis 30. September 1908. Einfach dement, euphorisch; hochgradige Merkfähigkeitsstörung, vergißt sofort alles und deckt die Defekte mit Konfabulationen; ist persönlich desorientiert, kennt sein Alter nicht; ebenso weiß er nicht, wo er sich befindet, gibt sozusagen von Minute zu Minute wechselnde Angaben an, behauptet bald, seine Frau sei gestorben, bald, sie lebe, ebenso gibt er widersprechende Angaben über seine Kinder; entsprechend befragt, erzählt er Konfabulationen wechselnder und widersprechender Art über seine Tätigkeit an den vorhergegangenen Tagen.

Nachts schläft er sehr wenig, ohne Schlafmittel gar nichts, ist immer mit seinem Bettzeug beschäftigt, wickelt es zusammen und will damit weggehen, ruft Bekannte, verkennt die Umgebung in deliranter Art.

30. September 1908. Exitus an eitriger Bronchitis.

Das Gehirn von außen leicht atrophiert. Ventrikel stark erweitert. Basalgefäße zart.

Mikroskopisch. In der Stirnpartie massenhafte Fädcheninfiltrate, darunter spärliche Stadien III und IV. Schwere Zellveränderung. In den hinteren Partien viele Drusen in Stadien III und IV; die Ganglienzellen wenig verändert. Spärliche kleine Keulen.

Fall 26. Vojna, Anna, 77 Jahre.

Anamnese. Beginn unbekannt; desorientiert, rennt im Dorfe herum, nimmt Feuer aus dem Ofen und will an verschiedenen Orten Feuer machen.

Beobachtung. 25. August bis 27. September 1905. Ist eingebracht desorientiert, glaubt, zu Hause zu sein, hält die Wärterinnen für alte Bekannte; plaudert in einem fort, behauptet, alles gehöre ihr und will es an sich nehmen; wird gewalttätig, wenn man es ihr verwehrt.

Beim Ausfragen über ihren Namen denkt sie nach, das Alter sagt sie überhaupt nicht; auf viele Fragen antwortet sie ganz widersinnig, weil sie sofort die Frage wieder vergessen hat; keine amnestische Störung; nachts ist sie immer unruhig, schläft sehr wenig.

1. September und 24. September. Drei epileptische Anfälle, nachher soporös. 27. September 1905. Exitus an Pneumonie.

Fall 27. Stovicek, Antonie, 89 Jahre.

Anamnese. Seit 6 Jahren sehr schwerhörig, seit einem Jahr beinahe ganz 
blind ; etwa ein Jahr ist sie hochgradig vergeßlich, verlangt gleich nach dem Mittagessen zu essen, da sie sofort vergißt, daß sie schon gegessen hatte; hat Angst, daß man sie umbringen will, versteckt sich vor halluzinierten Personen; erkennt nicht mehr ihre Tochter, hält sie für ihre eigene Mutter, hat vergessen, daß ihre zweite Tochter bereits verstorben ist.

Beobachtung. 4. November 1903 bis 27 . Mai 1904. Ist vollkommen desorientiert, kennt nicht ihr Alter, weiß nicht, daß sie verheiratet ist, nennt ihren Mädchennamen, bald wieder behauptet sie, ihr bereits verstorbener Mann lebe noch; ist sehr vergeßlich; verkennt die Umgebung; kriecht immer wieder aus dem Bette und sucht ihre Kinder; glaubt, zu Hause zu sein.

14. Januar 1904. Ist sehr ängstlich, scheint Männer zu halluzinieren, denn sie schreit nachts: „Ihr Lausbuben, warum schlagt ihr mich, ihr Jungen"; früh behauptet sie, ihre Enkel hätten sie geneckt und geprügelt.

5. Februar. Will immer weggehen, will nicht im Bette bleiben, sehr vergeß. lich und behauptet, sie bekomme gar nichts zu essen; manchmal behauptet sie, sie müsse weg, sie müsse kochen gehen, man warte schon auf sie.

27. Mai 1904. Exitus an Marasmus.

Das Gehirn von außen leicht atrophiert, Ventrikel deutlich erweitert. Die basalen Gefäße zart.

Mikroskopisch. In beiden Stirnlappen keine Drusen. In den anderen Rindenpartien ziemlich viele Drusen im Stadium III und IV. Spärliche Keulen. Starke Veränderung der Ganglienzellen.

Fall 28. Zábransky, Marie, 74 Jahre.

Anamnese. Seit 3 Jahren sehr vergeßlich, in der letzten Zeit (genaue Zeitangabe unbekannt) ist sie unruhig, schläft nicht, lauft herum, wird gewalttätig.

Beobachtung. 8. Juli bis 13. September 1908. 15. Juli. Sehr vergeßlich, weiß ihr Alter nicht, ständig desorientiert. Alles Mobile, am liebsten Wäschestücke, rafft sie zusammen und will damit weggehen, weil es ihr gehöre; produziert massenhaft Konfabulationen: Erzählt, sie wäre gestern auf einem Begräbnis gewesen und hätte dann ihren Vater und Mutter besucht, hier arbeite sie viel, sei ja hier zu Hause, erzählt je nach Wunsch, wo sie gestern gekocht hätte, hält die Anwesenden für Bekannte, den Arzt für ihren Bruder.

Beschäftigt sich häufig im Bette damit, daß sie immer wieder die Decke zertrennt und die Matratzen hin und her wälzt. Sonst Zustand unverändert.

13. September 1908. Exitus an Dysenterie.

Das Gehirn von außen sehr stark atrophiert. Basalarterien fleckig verdickt.

Mikroskopisch. In allen Gegenden beider Hemisphären sehr reichliche Drusen in den Stadien IV und V und auch Stadium VIII. Im rechten Occipitallappen reichlicher „Pelzbesatz" um die Gefäße. Reichliche Keulen; stellenweise die grobfaserige Fibrillenwucherung. In den Stammganglien keine Drusen. Im Kleinhirn mehrfache Gefäße mit „Pelzbesatz“, der häufig eine krümelige Destruktion aufweist.

Fall 29. Záruba, Josef, 76 Jahre.

A na mnese. Seit $3 / 4$ Jahren verwirrt, in der letzten Zeit deliriert er, glaubt mit Pferden zu fahren, zu ackern, ist sehr vergeßlich, zerreißt die Wäsche.

Beobachtung. 30. September bis 19. Oktober 1909. Gibt sein Alter richtig an, ist örtlich desorientiert, glaubt in der Nähe seines Wohnortes zu sein; glaubt, hier schon eine Woche zu sein; im Handumdrehen erzählt er, er habe gestern beim Schmied geschlafen, wäre auch im Gasthause gewesen und habe ein Seidel Bier getrunken.

1. Oktober. Ist tagsüber ruhig; nachts schläft er sehr wenig, will fortgehen, da er zur Arbeit müsse. 
3. Oktober. Glaubt, hier schon 2 Jahre zu sein; wähnt sich hier in einer Mühle und suche hier Dienst.

19. Oktober 1909. Exitus an Bronchopneumonie und chronischer Nephritis.

Das Gehirn von außen leicht atrophisch, Ventrikel stark erweitert, Basalgefäße zart.

Mikroskopisch. Sehr reichliche Drusen meist vom Typus II, III, IV, stellenweise auch Infiltrationsstadium. Keine Keulen. Sehr schwere Veränderung der Ganglienzellen.

Fall 30. Zrno, Joşef, über 70 Jahre.

Anamnese. Wegen deliranter Zustände eingebracht, Dauer unbekannt, wahrscheinlich nur ganz kurze Zeit.

Beobachtung. 5. Januar bis 23. Januar 1908. Bei der Einbringung glaubt er, schon von gestern da zu sein; das Alter gibt er mit 70-80 an. Gibt selbst an, sehr vergeßlich zu sein. Behauptet, den Arzt von früher schon zu kennen; als Zahl seiner Kinder gibt er bald 2 , bald 5 an.

7. Januar. Ist tagsüber ruhig, nachts schläft er; wechselnd desorientiert, Konfabulationen derart, daß er behauptet, vor kurzer Zeit gerade gearbeitet zu haben, meistens im Sinne seiner früheren Beschäftigung, er war Straßenkehrer.

12. Januar. Tagsüber meist ruhig, nachts meist delirant, ist mit Straßenkehren oder mit Pferden beschäftigt, zerwühlt die Matratzen, ruft seine Frau.

23. Januar 1908. Exitus an Bronchitis.

Das Gehirn stark atrophiert, die Ventrikel erweitert.

Mikroskopisch. Reichliche Drusen im Stadium I und II. Auch reichliches Infiltrationsstadium. Keine Keulen. Schwere Zellveränderung.

Fall 31. Zrubek, Franz, 83 Jahre.

Anamnese. Ein Sohn geisteskrank gewesen. Seit 6 Monaten halluziniert der Kranke meist nachts; in der letzten Zeit will er immerfort herumlaufen, seit 4 Wochen ist die Sprache sehr schlecht.

Beobachtung. 11. Januar bis 17. Januar 1904. Pat. spricht paraphatisch, versteht die an ihn gerichteten Fragen ganz gut; tagsüber ist er stumpf, ruhig, nachts deliriert er, zerwühlt sein Bettzeug, unterhält sich mit delirierten Personen, schimpft, arbeitet im Bette herum und schläft erst gegen früh ein. Dasselbe wiederholt sich beinahe jede Nacht.

17. Januar. Exitus an Marasmus und Herzkollaps.

Das Gehirn von außen leicht atrophisch, die Ventrikel erweitert, der linke Schläfelappen stärker verkleinert.

Mikroskopisch. Sehr reichliche Drusen im Stadium V mit sehr vielen keuligen Wucherungen der Achencylinder, die Ganglienzellen sehr stark verändert.

Die Drusen in allen Hirnpartien gleich stark vertreten.

Fall 32. Danzer, Anton, 78 Jahre.

Ana mnese. Keine.

Beobachtung. 29. Juli 1907 bis 6. April 1908. Pat. ist hochgradig vergeßlich, vollkommen desorientiert, auch über seine eigene Person; tagsüber ist er meist stumpf, nachts deliriert er und ist mit seinem Bettzeug ständig beschäftigt.

6. April 1908. Exitus an Pneumonie.

Das Gehirn von außen leicht atrophiert, die Ventrikel leicht erweitert.

Mikroskopisch. Sehr reichliche Drusen in den Stadien II-IV, mit sehr spärlichen Keulen; die Drusen befinden sich aber nur in den Stirnpartien, wogegen sie in den Zentralwindungen und in den hinteren Hirnpartien vollkommen fehlen.

Die Fälle bilden wieder eine Gruppe, welche alle die der ersten Gruppe zukommenden Symptome aufweist, zu denen aber noch ein 
deliranter Zustand ganz vom Typus des Beschäftigungsdelirs zukommt. Die Kranken suchen immerfort etwas, zerwerfen ihr Bett, trennen die Matratzen auf, zerwühlen das Roßhaar, zerreißen das Leintuch, hüllen sich damit oft in phantastisch-unsinniger Weise ein; manche Kranke wähnen sich in ihrer früheren Beschäftigung, zählen Geld, melken, kochen, sind bei der Maurerarbeit, kutschieren, laden auf, schirren Pferde an, hacken Holz; ein gewesener Maurer hängte sein Leintuch im Gitterbette auf und behauptete, er werfe gerade eine Fassade an; ein Kranker urinierte auf die Erde und behauptete, er hätte ja gerade den Nachtopf in der Hand; dabei hielt er auch die Hand so, wie wenn er tatsächlich ein Gefäß in der Hand halten würde.

Die deliranten Zustände treten meist nachts auf, wogegen sich die Kranken tagsüber meist ruhig verhalten; es kommt aber auch vor, daß der delirante Zustand bei Tag und bei Nacht besteht; dann ist das Delirium bei Nacht viel stärker ausgesprochen. Sehr häufig kommt es dabei zu massenhaften Halluzinationen optischen und akustischen Inhaltes.

Nachdem diese Symptome längere Zeit in mehr oder weniger unveränderter Form gedauert hatten, gehen die Kranken an Marasmus zugrunde; bei diesen besprochenen Fällen beträgt die Durchschnitsdauer der Krankheit 13 Monate.

Fall 33. Heipeter, Eleonora, 86 Jahre.

Anamnese. Pat. war bis vor 3 Jahren Gemüseverkäuferin; seit der Zeit lebt sie beim Sohn. Vor einem Jahre ein deliranter Zustand von vier Wochen langer Dauer. Sie war nachts sehr unruhig, ängstlich, wollte weglaufen, war desorientiert, glaubte, auf der Gasse oder am Markte zu sein, wollte nach Hause, war mit diversen delirierten Gegenständen beschäftigt, besonders mit Klauben ganz kleiner Gegenstände vom Boden. Tagsüber war sie meist ganz ruhig.

Der Zustand verging allmählich und Pat. wurde nachher geistig ganz normal, genau so wie früher gar nicht vergeßlich.

Seit 14 Tagen derselbe Zustand wie damals; besonders delirant des Nachts, klaubt Geld vom Fußboden auf, sammelt delirierte Glasscherben und verkauft Stiefel, zankt mit delirierten Personen, sieht Wasser fließen, Soldaten marschieren, glaubt, am Markte unter vielen Leuten zu sein.

Beobachtung. 19. Februar bis 22. Februar 1906. Weiß ihr Alter nicht, glaubt, hier schon lange zu sein, wo aber, wei $\beta$ sie nicht. Nachts war sie unruhig, schläft gar nichts, ständig mit Halluzinationen des Gesichts und Gehörs beschäftigt; sie wundert sich, daß hier so viel Militär unter dem Tische ist, fürchtet sich vor drohenden Gesichtern und lacht über die verrosteten Säbel der Soldaten; will wiederholt welgaufen, man warte schon zu Hause auf sie, glaubt, es regne von oben, die Decke falle auf sie herunter. Zeitweise klaubt sie delirierte Fäden und Haare auf und wirft sie weg; hört ein Kind schreien, sieht am Fußboden Glas, Rosenkränze und will sie anfheben. Zerrt am Leintuch und schimpft, daß der Karfiol so hart sei und nicht ausgebrochen werden könne.

20. Februar. Tagsüber ruhig; abends wieder delirant.

22. Februar 1906. Exitus.

Pathologisch-anatomische Diagnose: Marasmus univers. Endocarditis chron. def. Morbus Bright. chron. Hypertrophia cordis. Lipomatosis cordis destr. 
Das Gehirn von außen stark atrophiert, die Ventrikel deutlich erweitert, basalen Gefäße leicht verdickt.

Mikroskopisch. In beiden Stimlappen reichliche Drusen im Stadium I-III und dazwischen sehr reichliches Infiltrationsstadium. In den hinteren Hirnpartien vereinzelte Drusen im Stadium II und III. Spärliche Keulen. Geringe Veränderung der Ganglienzellen.

Diese Kranke bot eigentlich nur Symptome eines Deliriums, das von einem alkoholischen Delirium kaum zu unterscheiden war. Die Kranke ging zugrunde, ohne daß noch andere Symptome dazugetreten wären. Besonders bemerkenswert ist aber, daß ein Jahr vorher ein ganz identisches Delirium in vollkommene Heilung übergegangen war.

Fall 34. Stemproch, Marie, 71 Jahre.

Anamnese. Seit einem Jahre progrediente Vergeßlichkeit, wollte immer essen, da sie vergessen, da $B$ sie gerade gegessen hatte, ist zeitlich nicht mehr orientiert, rafft alles zusammen und wollte es wegtragen, irrte draußen herum; konnte sich auch schon in der letzten Zeit nicht recht ankleiden; der inzwischen eingetretene Tod des Mannes machte auf sie keinen Eindruck; sie hatte es entweder vergessen, denn sie suchte ihn ständig, oder aber glaubte sie, er wäre gerade gestorben und wollte ihm auf das Begräbnis gehen.

Beobachtung. 22. März 1906 bis 25. März 1909. Nennt zuerst ihren Mädchennamen, dann den richtigen; behauptet, keine Kinder zu haben (unrichtig), nachher gefragt, mit wem sie hergekommen ist, sagt sie mit dem Sohn.

Wie alt der Sohn ist? 28.

Und Sie? Werde auch so sein.

Sie können doch nicht so alt sein wie der Sohn? Darauf antwortet sie mit der Frage: Warum nicht?

Wie alt sie ist? Schon alt, ich habe schon alte Söhne. Was sie hier macht? Zum Begräbnis des Mannes.

Weiß, daß sie ein schlechtes Gedächtnis hat, rechnet sehr schlecht, zählt auch die Monate schlecht auf. Ist örtlich nicht orientiert, glaubt, zu Hause zu sein; dann wähnt sie sich wieder in einem Nachbardorf.

Ihr Alter gibt sie jetzt mit etwa 20 an; je nach der Frage glaubt sie, es sei hier entweder eine Sparkasse oder ihr Haus; letzteres bekräftigt sie damit, daß es ihr Mann selbst gebaut hätte.

Auf eine Rechenaufgabe antwortet sie: "Ich bin über $20^{\prime \prime}$ (sie scheint die Frage vergessen zu haben und antwortet auf eine konfabulierte Frage).

Auf eine gleiche Rechenaufgabe: „Die Eltern sind schon gestorben." Vater."

Auf die Frage, bei wem sie wohnt, sagt sie: „Bei der Mutter und bei dem

26. März. Ist hochgradig vergeßlich, vergißt im Handumdrehen alles, zeitlich, örtlich und persönlich desorientiert, in rasch wechselnder Weise, glaubt, bald zu Hause, bald beim Sohn, bald in einem Nachbardorf zu Besuch zu sein.

Die Umgebung wird verkannt; nach jeder Frage produziert sie massenhafte variierende Konfabulationen; alles Mobile, das sie sieht, klaubt sie auf, hält es für ihr Eigentum, rollt es in die Schürze ein und will damit weggehen; steht immer bei der Tür, hat die Schürze bündelartig zusammengerollt und verlangt, man solle sie weggehen lassen.

Wenn man sie fragt, was sie gestern oder gerade gearbeitet hätte, bekommt man ständig wechselnde Angaben, haarklein schildert sie allerlei Arbeiten, die sie gerade geleistet haben will.

Abends will sie sich nie ausziehen, schreit, daß man sie bestehlen wolle; 
früh beim Anziehen ist auch immer großer Lärm, da jammert sie dann immer, man wolle sie umbringen. Nachts immer ganz ruhig; schläft ziemlich gut.

1907. Zustand unverändert.

1908. Etwas apathisch, konfabuliert nicht mehr spontan, sondern nur auf Fragen; häufig bettlägerig.

31. Oktober. Epileptischer Anfall.

1909. Vollkommen verstumpft und apathisch.

25. März 1909. Exitus an Marasmus und Bronchopneumonie.

Das Gehirn von außen stark atrophisch, Ventrikel stark erweitert, die basalen Gefäße leicht verdickt.

Mikroskopisch. Massenhafte Drusen im Stadium V. Wenige Keulen. Starke Veränderung der Ganglienzellen. Viele derselben zeigen die grobfaserige Fibrillenwucherung.

Fall 35. Valchár, Josefa, 58 Jahre.

Anamnese. Seit $1 / 2 \mathrm{Jahr}$ sehr vergeßlich, seit der Zeit die Psychose, sie nimmt anderen Leuten Geschirr weg, behauptet, es gehöre ihr; verirrt sich häufig, weiß nicht, wohin sie gehen wollte, mischt beim Kochen alles durcheinander; wenn man sie zum Kaufmann schickt, weiß sie nicht, was sie kaufen soll, wollte auch für den ganzen Wochenlohn Brot kaufen; sie besorgte sich nicht, sich selbst überlassen, bleibt sie gänzlich verwahrlost; wollte am Sonntag oder in der Nacht in die Fabrik in die Arbeit gehen; wollte immer essen, da sie gleich nach dem Essen alles vergessen hatte, glaubt, daß ihre Eltern noch am Leben sind, erkennt ihre Kinder zeitweise nicht.

Fürchtet sich in der Wohnung, weil dort lauter alte Kerle seien, die sie umbringen wollen; in der letzten Zeit sucht sie ihren Mann, der in ein Krankenhaus geschickt wurde, unter dem Bette, machte aus Kleidern und Wäsche Bündel und wollte damit weg, behauptete, sie müsse zu den Eltern gehen.

Beobachtung. 14. November 1901 bis 27. Dezember 1903. Eingebracht zeigt Pat. eine ziemlich starke amnestische und später auch sensorische Aphasie; dabei auch ideatorische Apraxie, scheinbar wegen großer VergeBlichkeit; ist sehr vergeßlich, kennt die Umgebung kaum, nur im Laufe der Zeit eine einzige Kranke, neben der sie schläft; wegen ihrer schweren Sprachstörung ist ein Examen nicht recht möglich, einfach stumpf, dement, dabei ständig euphorisch vor sich lächelnd.

27. Dezember 1903. Exitus an Pneumonie.

Das Gehim stark atrophjert, besonders in der linken Hemisphäre, die Ventrikel stark erweitert, die basalen Gefäße fleckig verdickt.

Mikroskopisch. Reichliche Drusen im Stadium IV und V. Wenige Keulen.

Fall 36. Kratina, Wenzel, 77 Jahre.

Anamnese. Keine.

Beobachtung. 16. November 1905 bis 1. März 1907. 17. November. Glaubt, 30 Jahre alt zu sein; sei hier schon sehr lange, wie lange, wisse er nicht, er hätte ein schlechtes Gedächtnis.

26. November. Liegt zu Bette ganz ruhig; behauptet, noch heute früh gearbeitet zu haben, hätte einen Rock genäht und dann wäre er spazieren gewesen.

28. Dezember. Zustand unverändert; seine Merkfähigkeitsstörung ist so hochgradig, daß er sich im Zimmer nicht einmal auskennt; erkennt sein Bett nicht, erkennt seine Mitpatienten, Wärter und Årzte nicht, obzwar er behauptet, sie kommen ihm bekannt vor.

10. Januar 1906. Ständig konfabulierend; behauptet täglich, er arbeite, zählt auch auf Verlangen auf, was für eine Arbeit er gerade abgeliefert hätte; die Wärter bezeichnet er als Herren aus demselben Hause, wo er wohnt.

21. Januar. Ein Ohnmachtsanfall. 
12. Februar. Setzt sich heute im Bette auf, nimmt die Decke zur Hand, macht, als ob er nähen würde, zieht alle Fäden aus dem Überzuge heraus. Gefragt, was er mache, sagt er: „Man muß sich anstrengen, wenn man die paar Kreuzer verdienen soll, ich möchte gern heute damit fertig werden." Nach einer Weile nimmt er die Decke über die Hand, wie Schneider sonst die Kleider zu tragen pflegen und geht im Zimmer herum, behauptet, er muß die Arbeit abliefern gehen (Pat. war Schneider).

1. Februar. Zustand gleich, stumpf, vergeßlich und hie und da besonders auf Ausfragen konfabulierend.

15. Februar. Einfach stumpfe Demenz.

1. März 1907. Exitus an Dysenterie.

Das Gehirn von außen stark atrophiert, die Ventrikel erweitert, die basalen Gefäße fleckig verdickt.

Mikroskopisch. Sehr reichliche Drusen im Stadium V mit massenhaften Keulen. Die Ganglienzellen stark verändert. Stellenweise Zellen mit grobfaseriger Fibrillenwucherung.

Fall 37. Knotek, Marie, 75 Jahre.

Anamnese. Seit $1 / 2 \mathrm{Jahr}$ sehr vergeßlich; will immerfort essen, da sie sofort vergißt, wenn sie gegessen hatte.

Beobachtung. 16. September bis 12. November 1906. Weiß selbst, daß sie ein schlechtes Gedächtnis hat; weiß nicht die Zahl und die Namen ihrer Kinder, ihr Alter auch nicht, es werde so über 70 sein. Mit wem sie hergekommen, weiß sie nicht, weiß aber, daß es heute war. Glaubt, sie wäre nur 1/2 Stunde hergefahren (trotzdem es mehrere Stunden dauerte).

17. September. Schläft nachts sehr wenig; war meist sehr unruhig, suchte einen „Buben“, schimpfte auf ihn, daß er nicht komme, wo er sich so lange herum. treibe, er hätte ihr die ganze Wäsche weggenommen; hält das Gaslicht für Petroleum und will es auslöschen, „man müsse sparen", glaubt, in ihrer Wohnung zu sein; hält eine andere Mitpatientin für ihren Mann und will sich $\mathrm{zu}$ ihr legen; weigert sich, zu essen; wenn man ihr wehrt, schreit sie, man hätte ihr die Hand gebrochen, den Arzt hält sie für einen Oberförster.

18. September. Heute ist der Zustand gleich, auf Schlafmittel etwas Schlaf. Glaubt, hier schon sehr lange zu sein, schon mindestens ein Jahr, und sei hier beim Herrn Oberförster.

20. September. Zustand unverändert; hat ein Erysipel am Arm; auf die Frage, wo sie das her hat, sagt sie, das hätte ihr der Bub mit der Zigarette gemacht.

10. Oktober. Jetzt stumpfes Hinbrüten; auf Schlafmittel Schlaf; schimpft nur, wenn man sich um sie kümmert, sie umbettet; dabei verkennt sie die Umgebung in ganz wechselnder Weise.

1. November. Vollkommen verstumpft.

12. November 1906. Exitus an Dysenterie.

Das Gehirn von außen stark atrophiert, die Ventrikel sehr stark erweitert, die basalen Gefäße fleckig verdickt.

Mikroskopisch. Sehr reichliche Drusen in den Stadien I, II, III, IV. Wenig Keulen. Ganglienzellen mäßig erkrankt.

Im Kleinhirn, den Stammganglien und der Medulla oblongata keine Drusen.

Fall 38. Hrb, Rosalie, 71 Jahre.

Anamnese. Seit 2 Jahren zunehmende Demenz; häufig unruhig, schlug die Kinder; wollte auch einigemal „Feuer legen“".

Beobachtung. 23. Januar bis 31. Juli 1907. Stumpfe Demenz, ihr Alter gibt sie mit 20 an, hätte noch kleine Kinder ; Namen und Wohnort gibt sie richtig an; glaubt aber, zu Hause zu sein. 
25. Januar. Gibt ihr Alter mit 30 an, glaubt, schon sehr lange da zu sein, den Arzt kenne sie noch vom Sommer her; will aus dem Zimmer häufig weglaufen, rafft alles Mobile zusammen und will es wegtragen.

2. Februar. Hat Andeutungen von amnestischer Aphasie und ideatorischer Apraxie; die Sprache dabei langsam und stockend, mit initialem stotterähnlichen Anstoßen, häufiges Nachziehen der Endlaute.

1. März. Einfach stumpf-dementes Wesen, ganz unrein, vollkommen interesselos.

31. Juli 1907. Exitus an Pneumonie.

Das Gehirn von außen stark atrophiert, die Ventrikel stark erweitert.

Mikroskopisch. Sebr reichliche Drusen im Stadium V. Wenige Keulen. Die Ganglienzellen sehr wenig verändert.

Fall 39. Sindelár, Josef, 80 Jahre.

Anamnese. Seit 1/2 Jahr sehr vergeßlich, dement, desorientiert, nachts unruhig, lauft im Dorfe herum und macht Lärm.

Beobachtung. 9. November 1906 bis 15. Juni 1907. 10. November. Den Namen nennt er richtig; auf das Alter gefragt, sagt er 21. Behauptet, er sei verheiratet und hätte 3 Kinder.

Wie alt die sind? Auch so alt.

Als man ihn darauf aufmerksam macht, das sei nicht möglich, sagt er: „Dann werden sie jünger sein."

Später behauptet er, 5 Kinder gehabt zu haben, jetzt hätte er keine mehr (unrichtig), glaubt, hier schon ein Jahr zu sein; auf das Alter gefragt, sagt er nichts, erst als man ihm mehrere Zahlen sagt, entscheidet er sich für 60 .

I. Dezember. Stumpf, dement, zeitlich und örtlich desorientiert, gibt wechselnde Angaben über sein Alter, die Zahl und das Alter seiner Kinder.

1. Juni 1907. Die ganze Zeit stumpfe Demenz.

15. Juni 1907. Exitus an Marasmus.

Das Gehirn von außen leicht atrophiert, starke Erweiterung der Seitenventrikel. Basalgefäße zart.

Mikroskopisch. Massenhafte Drusen im Stadium V. Wenige Keulen. Ganglienzellen stark verändert.

Fall 40, Roucek, Anna, 73 Jahre.

Anamnese. Erst in der letzten Zeit psychotisch. Kennt ihren Mann nicht mehr, halluziniert fremde Leute in der Stube, läuft nachts auf die Straße hinaus.

Beobachtung. 1. April 1909 bis 13. Februar 1910. Ist persönlich nicht recht orientiert, weiß ihr Alter nicht, weiß nicht, wo sie sich befindet, wo sie gewohnt hat; amnestische Störung angedeutet; weiß aber, daß sie ein schlechtes Gedächtnis hat.

4. April. Ganz stumpf. Nachts läuft sie manchmal aus dem Bett heraus.

7. und 8. April. Ist abends immer ängstlich, sonst ganz stumpf.

13. Februar 1910. Exitus an Bronchopneumonie.

Mikroskopisch. Zahlreiche Drusen meist im Stadium III. Keine Keulen. Starke Veränderung der Ganglienzellen. Viele Zellen mit der großfaserigen Fibrillenwucherung.

Fall 41. Schanda, Anna, 87 Jahre.

Anamnese. Keine.

Beobachtung. 4. bis 11. September 1904. 5. September. Stumpf dementes Wesen; glaubt, hier schon eine Woche zu sein; ist örtlich nicht recht orientiert; glaubt früh, daß schon Nachmittag ist und zählt auch auf, was sie gerade zu Mittag gegessen hätte.

11. September 1904. Exitus an Pneumonie. 
Das Gehirn von außen leicht atrophiert, die Ventrikel erweitert, die basalen Gefäße etwas starrwandig.

Mikroskopisch. Reichliche Drusen im Stadium III und IV. Keine Keulen. Starke Veränderung der Ganglienzellen.

Die zuletzt geschilderten Fälle 34-41 enden im Gegensatz zu den früher geschilderten mit stumpfer, apathischer Demenz. Wenn man solche Kranke erst im Stadium dieser Verstumpfung zur Untersuchung und Beobachtung bekommt, dann verlieren sich selbstverständlich alle Anhaltspunkte für die Diagnose, besonders dann, wenn - wie dies ja zur Regel gehört nur eine ungenügende Anamnese vorliegt. Ein gutes Beispiel dafür gibt der Fall 41, der ohne Anamnese in schwerer Verstumpfung eingebracht wurde und noch dazu nur wenige Tage beobachtet werden konnte. Trotz der Verstumpfung ließen sich aber dennoch gewisse Symptome herausgreifen, welche zur Charakteristik unserer Krankheitsgruppen gehören als: Desorientiertheit und Andeutungen von Konfabulationen. Etwas Ähnliches zeigt auch der Fall 40, der nur eine schwere Verstumpfung geboten hatte neben nur leichten Störungen der Orientierung, die aber auch auf die Stumpfheit bezogen werden konnte; dagegen erzählt die Anamnese von ganz zweifellosen halluzinatorischen Zuständen.

Bemerkenswert ist, daß die Durchschnittsdauer dieser in Verstumpfung endigenden Fälle 26 Monate beträgt, also mehr als das Doppelte als bei den Fällen der ersten zwei Gruppen.

Fall 42. Svejda, Marie, 82 Jahre.

Anamnese. Aus dem Krankenhause wegen deliranter Unruhe zur Klinik transferiert.

Beobachtung. 29. September 1904 bis 15. August 1908. 30. September. Bei der Aufnahme ruhig, euphorisch, behauptet, bald 8 Tage im Krankenhause gewesen zu sein, bald will sie wieder nichts davon wissen. Weiß nicht, wo sie hier ist, es läßt sie aber gleichgültig; nimmt alles, was sie sieht, an sich, da es ihr gehöre, und will damit weggelassen werden.

Bezeichnet ihr Alter mit 60; gibt ganz wechselnde Angaben darüber, wie lange sie da ist; bald sind es 8 Tage, bald ist sie gerade hergekommen, und ebenso gibt sie wechselnd an, wo sie zu sein glaubt. Ebenso gibt sie an, bald 3 Kinder, bald 14 Kinder zu haben.

3. Oktober. Hatte Besuch der Tochter, erinnert sich dann nachmittags noch daran; behauptet dann, sie wäre um $2 \mathrm{Uhr}$ gekommen, um 3 Uhr wäre die Tochter schon dagewesen; sagte zum Besuche, sie glaube hier im Kriminal zu sein, wisse a Jer nicht warum, vielleicht weil sie einmal am Markte (sie war früher Butterverkäuferin) gefälschte Butter verkauft habe. Eine Stunde später erklärt sie dem Arzt, hier sei die Untersuchungsstation und man hätte sie Samstag am Markt wegen gefälschter Butter angehalten.

6. November. Behauptet, erst seit gestern da zu sein; denn bis gestern war sie im Gefängnis wegen der gefälschten Butter. Den Arzt behauptet sie von der kiarkthalle zu kennen. 
24. November. Sehr vergeßlich; wundert sich täglich, daß der Arzt sie schon kennt, sie wäre doch gerade hergekommen, um im Handumdrehen zu behaupten, den Arzt von der Markthalle zu kennen.

Wurde lumbalpunktiert, wobei sie sehr jammerte, und $1 / 2$ Stunde nachher weiß sie nichts mehr davon.

Infolge ihrer Vergeßlichkeit geht sie fortwährend auf den Abort; geht aber zur Tür und wieder ins Zimmer zurück, nach einigen Minuten wieder hin, weil sie behauptet, schon lange nicht am Abort gewesen zu sein.

20. Januar 1905. Neben der Pat. liegt eine kleine Epileptica, die zeitweise Krämpfe hat. Heute hat dieselbe während der ärztlichen Visite Krämpfe. Die Patientin sagt dazu: „Schauen Sie, Herr Doktor, die hat schon wieder einen Anfall, das hat sie öfter." Sie wird darauf gefragt, wie lange sie selbst hier ist, darauf die prompte Antwort: „Seit gestern abend."

Als sie darauf gefragt wird, wieso sie dann weiß, da B die Kleine häufig Anfälle bekommt, sagt sie: „Ach die ist ja aus unserem Ort, sie hat lange bei mir gewohnt.“"

14. Mai. Immer gleich vergeßlich, doch treten jetzt Konfabulationen viel seltener auf; auf die meisten Fragen sagt sie jetzt zum Gegensatz zu früher: ,Ich vergesse jetzt alles, ich bin schon sehr alt." Aufs Alter gefragt, gibt sie immer zur Antwort, es werde schon über 70 sein.

2. Februar 1906. Im allgemeinen gleicher Zustand; heute behauptet sie, erst 14 Tage hier zu sein.

1. August. Täglich behauptet sie, sie sei hier erst 14 Tage.

1. Januar 1907. Jetzt zwar immer sehr vergeßlich, aber nichts mehr vom konfabulatorischen Decken der Defekte; weiß, daß sie schon sehr lange da ist, daß sie auch manchmal Besuche bekommt; gibt das Alter immer mit ,über $70^{\text {" an. }}$

Auf die meisten Fragen sagt sie, sie habe kein Gedächtnis.

1908. Zustand im allgemeinen unverändert.

15. August 1908. Plötzlicher Exitus.

Pathologisch-anatomische Diagnose. Marasmus universalis. Embol, arteriae mesenter. infer.

Das Gehirn von außen sehr stark atrophiert, die Ventrikel sehr stark erweitert, die Basalgefäße leicht fleckig verdickt.

Mikroskopisch. In der Stirn und im Temporallappen Drusen im Stadium IV in nicht sehr reichlicher Zahl; in den anderen Partien keine Drusen. Dabei verhalten sich beide Hemisphären ganz gleich. In den die Drusen enthaltenden Partien die Ganglienzellen stark verändert und spärliche Keulen.

Bei dieser Kranken haben wir am Anfang der Erkrankung ein gleiches Krankheitsbild vor uns, wie in den vorigen Fällen; im späteren Verlauf nimmt die Produktivität der Konfabulationen bei sonst gleicher Störung der Merkfähigkeit immer mehr ab, bis schließlich die Kranke einfach dement und hochgradig vergeßlich wird; doch erreicht die Demenz nicht den Grad wie bei den Fällen 34-41; sie bewahrte auch insofern Krankheitseinsicht, als sie ihre Vergeßlichkeit vollkommen einsah. In diesem Zustande verblieb sie $1 \frac{1}{2}$ Jahre. Wir hätten darnach in diesem Falle eine Art Heilung der schweren amnestisch-konfabulatorischen Störung vor uns.

Fall 43. Patzelt, Franziska, 62 Jahre.

Anamnese. Vor 4 Monaten erkrankte Pat. an einer Rippenfellentzündung; nachdem sie vom Krankenlager aufgestanden war, kränkte sie sich darüber, $\mathrm{daB}$ sie nichts mehr arbeiten konnte und äußerte wiederholt, sie wolle sich des- 
wegen umbringen, um den anderen nicht zur Last zu fallen; sie wurde immer trauriger, und etwa eine Woche später verlangte sie, man möchte sie umbringen, jammerte, daß ihr etwas Furchtbares bevorstehe, sie hätte doch nichts Böses angestellt; in den letzten Tagen wollte sie sich die Augen ausstechen, damit sie das Elend nicht sieht, das über sie und ihre Familie einbrechen werde, behaup. tete, die Leute sprechen von ihr: „Das ist auch so eine, die muß verbrannt werden.“

Beobachtung. 17. Juli 1906 bis 24. August 1908. Eingebracht brütet sie stumpf-ruhig vor sich hin; nachts schrie sie mehrmals ängstlich auf. Früh sehr ängstlich, rief ihre Tochter, schlug sich gegen die Stirn, raufte sich das Haar, wollte sich die Augen auskratzen, klammerte sich ängstlich an das Bett; hält eine Pat. für ihre Tochter.

19. Juli. Ist ständig in großer agitierter Angst, äuRert: „Hier gibt es eine Schinderei, die Augen werden einem ausgestochen, der Bauch wird einem aufgeschnitten, die Eingeweide werden einem herausgerissen, die Füße werden einem abgehackt, das wäre doch schrecklich, was auf mich wartet, was machen sie mit dem Fleisch, das von uns heruntergenommen wird, das könnt ihr doch nicht gebrauchen, das ist doch nicht Rindfleisch; und der Doktor, der schneidet einem jeden den Kopf ab und am schlechtesten wird es mir ergehen, genau so wie der heiligen Cäcilie." Glaubt schon, ihre letzte Stunde sei gekommen; ist sonst zu keiner Auskunft zu haben, ständig jammert sie, will nichts essen, läßt sich nur mit Mühe etwas einflößen.

7. August. Abstiniert und muß mit der Sonde genährt werden.

16. November. Ist jetzt zu einsilbigen Antworten zu haben, gibt ihr Alter richtig an, auch einzelne Daten aus ihrer Lebensgeschichte, aber auf eine genauere Schilderung ihrer Krankheit geht sie nicht ein.

1. April 1907. Ganz stumpf jetzt, sitzt immer in einer Ecke, die Schürze über den Kopf gezogen, brummt manchmal etwas Unverständliches vor sich, manchmal wird sie ängstlich und behauptet, man warte schon draußen auf sie; wenn man ihr die Schürze wégzuziehen versucht, lacht sie verschämt; Antworten nicht zu erhalten; ißt zwar selbst, aber immer nur ganz verstohlen in einer Ecke.

29. Oktober. Lief abends aus dem Bette zur Tür und rief in großer Angst: „Da werden die Leute zerhackt und in die kochende Scheiße geworfen; die alten Krieger wurden wenigstens erschossen, aber die jetzigen werden gegeißelt, alle hören es doch, die Leute sagen es doch auch, ich weiß, was sie machen, etwas Schreckliches wird hier geschehen; bätten sie mich doch lieber zu Hause gelassen; wir haben drei Häuser, ich habe eines und der Bruder hat zwei (stimmt nicht, Pat. ist sowie ihre ganze Familie sehr arm), er ist glücklich, hier geht es schrecklich $\mathrm{zu}$, was sie nur mit den Leuten treiben, ich habe ja alles gehört, das heißt hier Klinik? Da schmeißt man die Leute herein, und all dieser Qual kann man nicht entrinnen; meiner Schwester haben sie den Kopf abgehackt, die Arme bat sich sicher nicht gedacht, daß sie einmal in den Abort geworfen und in der Scheißo gekocht werde. Die Schwester hatte eine fürstliche Wohnung, es könnten Fürsten darin wohnen; und meine Tochter ist auch seit Weihnachten gut aufgehoben, genau so wie meine arme Schwester.

24. August 1908. Exitus an starker Enteritis catarrhal.

Das Gehirn von außen nicht atrophisch, leichte Erweiterung der Ventrikel. Normale Basalgefäße.

Mikroskopisch. Sehr reichliche Drusen in den Stadien III, IV und V, nur wenige im Stadium I. Keine Keulen. Die Ganglienzellen sehr stark verändert.

Fall 44. Auer, Emilie, 80 Jahre.

Anamnese. Beginn der Psychose unbekannt. Seit einigen Wochen unruhig; aggressiv, da sie befürchtet, man wolle sie vergiften, man wolle ihr des

Z. f. d. g. Neur. u. Psych. o. III. 
Nachts das Leben nehmen, sieht nachts verdächtige Gestalten, hört Stimmen, schreit, will entfliehen, sich aus dem Fenster stürzen.

Beobachtung. 1. März bis 11. A pril 1904. Bei der Einbringung ist die Kranke örtlich, zeitlich und persönlich orientiert; ist unwirsch, sehr einsilbig, ängstlich und äußert nur Furcht vor einem „Jesuiten“, behauptet, sie sei dort, wo sie früher war, verfolgt worden, man hätte ihr nach dem Leben getrachtet, hätte sie vergiften wollen.

3. März. Auf gestern ruhig geschlafen, gestern tagsüber stumpf-ruhig; abends ängstlich, schimpft auf die Jesuiten, hat Angst, daß man sie umbringen will; schläft wenig und schreit viel um Hilfe.

7. März. Die letzten Tage meist ruhig; gestern nachmittag wieder ängstlich, hält die Ärzte für Jesuiten, die sie umbringen wollen, schläft wenig; heute behauptet sie, von nichts $\mathrm{zu}$ wissen.

14. März bis 5. April. Tagsüber ruhig, nachts schläft sie beinahe nichts, nur auf Schlafmittel, äußert ständig Furcht, ist unruhig, schreit, schimpft, behauptet, man hätte hier ihre Tochter geschlachtet, alles sei vergiftet, weigert sich $\mathrm{zu}$ essen.

11. April 1904. Exitus an Marasmus.

Das Gehirn von außen leicht atrophisch, die Ventrikel leicht erweitert, die basalen Gefäße nicht verdickt.

Mikroskopisch. Reichliche Drusen in den Stadien II, III und IV; spärliche Keulen. Sehr schwere Veränderung der Ganglienzellen.

Fall 45. Stöhr, Wilhelmine, 70 Jahre.

Anamnese. Seit längerer Zeit beinahe ganz taub; seit 3 Wochen geisteskrank; spricht mit niemandem, geht nachts im Hause herum, stößt alle, die sie fragen, warum sie herumgehe, ärgerlich weg.

Beobachtung. 25. Mai bis 18. Oktober 1908. Einfach dement, sehr schwerhörig, so daß eine Verständigung schwer möglich ist, liegt stumpf-ruhig da; sonst Opticusatrophie und erloschene Sehnenreflexe an den Beinen.

1. Juli. Ist jetzt etwas apathisch und hört auch besser; ist persönlich ganz gut orientiert, weiß auch annähernd richtig, wie lange sie da ist und wo sie sich befindet, weiß, daß sie unruhig war, bevor sie her kam, bejaht, daß sie sich aufgeregt hätte; ihre Lebensgeschichte wird anscheinend richtig erzählt.

16. Oktober. Behauptet, man wolle sie von hier transferieren, eine Frau wolle sie wegnehmen, aber sie wisse nicht, was sie tun soll; dann ist sie ängstlich, man stehle ihr hier die Kleider, und bis sie nach Hause gehen werde, werde sie nichts mehr haben.

18. Oktober 1908. Exitus an Bronchopneumonie.

Das Gehirn von außen leicht atrophisch. Die Ventrikel stark erweitert. Basalgefäße zartwandig.

Mikroskopisch. Wenige Drusen im Stadium I und II. Sehr spärliche Keulen. Schwere Veränderung der Ganglienzellen.

Im Rückenmark ausgesprochene Tabes mit chronischer Meningitis. Die Meningen des Gehirns leicht verdickt, aber nicht infiltriert. Keine entzündlichen Veränderungen im Gehirn.

Fall 46. Trnka, Franziska, 71 Jahre.

Anamnese. Seit $1 / 2$ Jahr Verfolgungsideen, hat Angst, man wolle sie bestehlen, wacht die ganzen Nächte, geht mit dem Licht in der Wohnung herum, verkennt die Umgebung und abstiniert in der letzten Zeit.

Beobachtung. 17. bis 29. Juni 1906. 18. Juni. Glaubt, hier schon mehrere Tage zu sein ; ist persönlich halbwegs orientiert, weiß, daß sie sich in einem Krankenhause befindet, ist sehr ärgerlich. Jammert in einem fort, man möchte sich 
ihrer erbarmen, sagt aber nicht, warum man sich ihrer erbarmen soll und was ihr fehlt. Schläft nachts beinahe gar nichts und jammert in einem fort, ißt auch sehr wenig, muß immer dazu gedrängt werden.

29. Juni 1906. Exitus an Pneumonie.

Das Gehirn von außen leicht atrophisch, Ventrikel stark erweitert. Basalgefäße zart.

Mikroskopisch. Viele Drusen im Stadium III und IV.

Alle diese vier Krankheitsfälle haben als gemeinsames charakteristisches Symptom einen mehr oder weniger ausgesprochenen paranoischen Symptomenkomplex mit stark ängstlich affektuöser Betonung. Am deutlichsten ist dies im Falle 43 ausgesprochen; der Beginn war da zuerst melancholieähnlich, doch allmählich änderte sich das Bild: bei sonst vollkommener persönlicher, zeitlicher und örtlicher Orientiertheit kam es zu großer Angst, zu Halluzinationen, die bereits ein gewisses persekutorisches Wahnsystem verrieten; die Kranke machte Fluchtversuche und verkannte die Umgebung im Sinne ihres Verfolgungswahns; sie glaubte dann, daß ihre Angehörigen bereits umgebracht werden, jammerte, daß sie Menschenfleisch zu essen bekomme, sie hörte, wie Menschen bereits unter den größten Qualen umgebracht werden, und erwartete dasselbe Los; bei Nacht war die Angst viel stärker, die Halluzinationen gehäufter. Allmählich wurde die Kranke stumpfer, der Angstaffekt nahm ab, aber bei der äußeren Verstumpfung verblieben die alten Wahnideen und Halluzinationen.

Im Falle 44 ist das Krankheitsbild zwar nicht so mannigfaltig, aber immerhin noch, was die paranoischen Züge anlangt, ganz einwandfrei. Dagegen treten in den Fällen 45 und 46 die paranoischen Symptome sehr wenig hervor; im Falle 46 waren dieselben eigentlich nur in der Anamnese ausgesprochen, beim Falle 45 traten sie erst in den letzten Tagen der etwas kurzen Beobachtung auf.

Fall 47. Dolejs, Antonie, 75 Jahre.

Anamnese. Wurde am 27. Februar 1900 in ein Krankenhaus gebracht, weil sie sehr ängstlich war, nachts zwecklos mit dem Lichte im Hause herumging und die Nachtruhe störte; behauptete, sie höre Hilferufe, als ob jemand im Hause Mädchen umbringen würde. In dem Krankenhause halluzinierte sie ständig, indem sie Mädchenstimmen hörte, die von ihr Brot verlangten, weil sie Hunger hätten.

Am 5. März 1900 in eine öffentliche Irrenanstalt aufgenommen; dort eingebracht etwas stumpf, ist ziemlich orientiert, gibt selbst an, ein schlechtes Gedächtnis zu haben, erzählt von ihren Halluzinationen konform mit der Anamnese; hört hier das Mädchen ebenfalls.

10. März 1900. Ist sonst ganz geordnet; heute beim Erwachen sah sie einen Lichtschein und die Heiligen.

23. März. Hörte gestern abend eine bekannte Frau mit einem bekannten Mädchen sprechen, daß man ihr Geld geben werde, damit sie nach Wien fahren könne; wollte mit Gewalt „hinaufgeführt" werden; hörte dann Schimpfworte and ihre Tochter weinen.

24. März. Hörte die Stimme einer „Baronin“ über sich. 
22. April. Hört immer im oberen Stock einen „Baron“" und „Baronin“"sprechen, die erzählen, daß sie nach Hause soll; dann verlangt sie stürmisch ihre Entlassung; ist sonst ganz ruhig und arbeitet auch.

3. Mai. Abstinierte kurze Zeit, da ihr der "Baron" geraten habe, nicht zu essen und mit ihm wegzufahren.

19. Juni 1901. Ist notiert: Auí ihren Namen gefragt, nennt sie einen andern, glaubt, sie sei eine Hauptmannswitwe, die Tochter des Kaisers, der gestern da gewesen wäre; ist zeitlich und örtlich desorientiert; die Aussagen sind verwirrt, unzusammenhängend; dement, ziemlicher Marasmus.

19. September. Ruhig-stumpfes Wesen; hat inkohärente Wahnideen, halluziniert ständig, hört Gehen, Sprechen, Schreien, der „,Baron" und „Kajser Josef" sind unten, man spricht von ihr, man hinterlege Geld für sie, ,ihre Töchter machen Tote lebendig und reparieren alle Knochen", ist auch manchmal infolge der Halluzinationen verwirrt; weiß nicht, wie lange sie da ist, beklagt sich über ,"Mutationen im Kopfe"; zeitweise sehr ängstlich, behauptet, man hätte ihr alles gestohlen. Dieser Zustand bleibt im allgemeinen unverändert.

Beobachtung. 4. Dezember 1905 bis 11. Januar 1906. Hat ein Ulcus cruris; marantische Alte. Den Geburtsort nennt sie richtig, behauptet, erst 30 Jahre alt zu sein; sie sei die Frau des Hauptmanns $K$. und sie selbst sei ,kaiserlicher Rat" (alles vollkommen unrichtig); wann sie geboren wurde, weiß sie nicht, glaubt hier schon mehrere Jahre zu sein. Die Wunde am Fuße hätte sie davon, daß sie jemand vom Fenster aus angeschossen hätte; ebenso hätten dort, wo sie war, die sogenannten Ärzte, die aber keine Ärzte waren, auf sie geschossen, so daß̊ sie davon ohnmächtig wurde; man hätte sie dort auch sexuell attackiert, den „Baron" hätte man schon ermordet, sie selbst hätte ein großes Vermögen, das beim Kaiser liegt.

11. Januar 1906. Exitus infolge einer Gangrän des rechten Fußes.

Pathologisch-anatomische Diagnose. Marasmus universalis. Morb. Brigh. chron. Endart. chron. def. Hypertr. cord. ventr. sin. Thromb. art. popl. d. subsequ. gangraena pedis et cruris d. Bronchitis suppur.

Das Gehim Jeicht atrophisch. Basale Gefäße nicht verändert.

Mikroskopisch. Ziemlich viele Drusen im Stadium III und IV. Keine Keulen. Geringe Veränderung der Ganglienzellen.

Dieser Fall ähnelt insofern den vorigen, als auch hier die Krankheit mit einer Ängstlichkeit begann, aus der sich dann Halluzinationen meist ängstlichen Inhaltes entwickelten; zu einem ausgesprochenen Wahnsystem kam es aber nicht, die Kranke wurde zerfahren, die Halluzinationen verloren den Zusammenhang, es entwickelte sich eine ausgesprochene Demenz bei hochgradiger Vergeßlichkeit und ständiger Desorientiertheit. Eine Ähnlichkeit mit gewissen Formen der Dementia praecox ist nicht zu verkennen.

Fall 48. Kohn, Morite, 69 Jahre.

Anamnese. Seit mehreren Jahren viel getrunken, seit einem Jahre nichts gearbeitet, sehr roh und brutal gegen die Familie, verlangte von den erwachsenen Töchtern den Coitus und wird dann rabiat.

1. Beobachtung. 28. Oktober 1906 bis 14. Dezember 1908. Ist vollkommen orientiert, einfach dement, ziemlich selbstbewußt, negiert alle in der Anamnese erhobenen Angaben, behauptet, man hätte ihn zu Hause nur gereizt und ihm alles absichtlich gemacht; ist auch hier ziemlich unverträglich. 


\section{Aufenthalt.}

Anamnese. Seit 2 Monaten äußert er Verfolgungsideen: man wolle ihn vergiften, erschlagen; er wollte auch zu Hause nichts essen, weil überall weißes Pulver aufgestreut gewesen sei. Seit 10 Tagen ist Pat. bei Nacht sehr unruhig, will weglaufen, lief durch alle Zimmer, schlug in die Türen, behauptete, auch draußen vor der Wohnung viele Menschen zu sehen, welche drohende Mienen machen.

2. Beobachtung. 20. August bis 25. November 1909. 22. August. Ist vollkommen ruhig, zeitlich, örtlich und persönlich vollkommen orientiert; weiß sich auf seinen früheren Aufenthalt zu erinnern, weiß, daB er zu Hause unruhig war, und behauptet, er hätte nur so schreckliche und schreckhafte Dinge geträumt und davon wäre er beim Aufwecken unruhig gewesen; schläft nachts ganz gut.

23. August. Wurde nachts unruhig, schrie Feuer, man wolle ihn ermorden, rief die Wache; dann wieder ruhig geschlafen.

24. August. Wieder nachts unruhig, verlangte die Kleider, draußen warten die Verwandten auf ihn; glaubt, hier schon 10 Tage zu sein, weiß, daß er nachts unruhig war, meint aber, daß er Ursache dazu hatte.

27. August. In der Nacht unruhig, will weggehen, behauptet, er müsse Ansichtskarten verkaufen gehen. (Pat. war früher Ansichtskartenverkäufer.)

7. September. Ist jetzt ruhiger, nachts schläft er, ist aber immer besorgt, daß man ihm nach dem Leben trachte.

17. September. Hielt heute einen Mitpatienten für seinen Bruder.

3. Oktober. Befürchtet ständig, daß man ihm nach dem Leben trachte.

15. November. Heute nachts unruhig, zerwirft das Bett, vermutet jemanden unter den Matratzen.

16. November. Ausgesprochene Störung der Merkfähigkeit, glaubt, gestern zu Hause gewesen zu sein. Heute nachmittag plötzlich vorübergehende Paraphasie, leichtes Fieber.

24. November. Behauptet, er wäre gestern zu Hause gewesen und hätte beim Umziehen geholfen, sagt dann wieder, er wäre hier zu Hause.

25. November 1909. Exitus an Bronchopneumonie.

Das Gehirn von außen leicht atrophiert, die Ventrikel mäßig erweitert.

Mikroskopisch. In verschiedenen Gegenden der Hemisphären sind die Drusen im Stadium III, IV und VII in verschiedener Reichhaltigkeit vertreten, in manchen Gegenden fehlen sie, in manchen sind sie spärlicher, in manchen reichlicher vertreten; aber ohne eine bestimmte Regelmäßigkeit. Stellenweise gibt es spärliche Keulen. Starke Zellveränderung.

In diesem Falle finden sich Symptome, welche die einzelnen Gruppen der im vorigen angeführten Krankheitsformen z u verknüpfen imstande sind. Der Kranke bot bei seinem ersten Aufenthalte nur das Bild der einfachen Demenz mit sehr stark hervortretenden moralischen Defekten; erst bei seinem zweiten Aufenthalte treten paranoide Symptome hervor, die vollkommen den Symptomen vergleichbar sind, welche wir bei den Fällen der letztgeschilderten Gruppe gesehen haben: auch hier Persekutionsideen, er glaubt, er solle vergiftet werden, sieht überall weißes Pulver aufgestreut; besonders nachts ist Patient unruhig, halluziniert mehr, ist aber dabei sonst ziemlich orientiert. Später wird er desorientiert, konfabuliert, und 
wiederholt treten nächtliche delirante Zustände auf von der gleichen Art wie bei den Fällen der zweiten Gruppe.

Fall 49. Unger, Marie, 74 Jahre.

Anamnese. Schon seit einem Jahre unruhig, läuft von Ort zu Ort, kennt sich zu Hause nicht recht aus. Vor 4 Wochen kam Pat. nach Hause und behauptete, sie hätte einen Fremden getroffen, der ihr gesagt hätte, daß sie sehr vie] Geld bekommen werde; 2 Tage nachher wollte sie auch schon einen größeren Geldbetrag in der Lotterie einkassieren; als ihr nichts ausgeliefert wurde, wurde sie unruhig, weinte und schimpfte, querulierte bei den Behörden, daß man sie bestohlen hätte. Seit der Zeit klaubt sie Steinchen, Papier, Holzstückchen auf, küßt es, behauptet, es sei von Christus, das seien ,ihre Tausende“; erzählt, daß sie große Geschenke vom „Herrn Jesus" bekommen habe, daß sie vom Kronprinzen 10 Kronen geschenkt erhielt, zeitweise wieder schimpft sie, man wolle sie bestehlen und attackiert die Passanten.

Beobachtung. 15. April bis 13. Juli 1909. Eingebracht ruhig, sehr redselig, von gehobener Stimmung. Weiß annähernd ihr Alter, auch richtig die Wohnung; wo sie hier ist, weiß sie nicht, glaubt, bald ein Kloster, bald ein Krankenhaus, bald Prag, bald Jerusalem; sehr gehobene Stimmung, sie sei überglücklich, weil sie viele Millionen gewonnen habe, Jesus selbst hätte ihr das gesagt; Jesus sei überhaupt schon ein alter Bekannter von ihr, aus der zartesten Jugend; auch in der Nacht komme er häufig zu ihr, heute war er auch bei ihr; der Arzt sei ein Prinz, den sie schon lange kenne, auch zu Hause hätte sie häufig mit Prinzen gesprochen, und vor kurzer Zeit wäre der Kaiser durchgefahren und hätte sie gesegnet. Zu Hause wäre wegen dem „Franzel“ ein großer Brand eingetreten, so daß sogar die Kirche brannte.

1. Mai. Behauptet, Jesus sei jede Nacht bei ihr, sieht draußen vor dem Fenster Affen, auf die sie schimpft.

16. Mai. Behauptet, sie hätte hier Besuch gehabt, sie hätte es gehört, aber man hätte es nicht zugelassen.

13. Juli 1909. Exitus an Pneumonie.

Das Gehirn von außen leicht atrophisch, geringe Erweiterung der Ventrikel.

Mikroskopisch. Nur in den Stirnlappen spärliche Drusen im Stadium II und III. Sehr spärliche Keulen. Starke Veränderung der Ganglienzellen. In den anderen Hirnpartien keine Drusen.

Fall 50. Nekvasil, Antonie, 60 Jahre.

Anamnese. Seit 3 Monaten sehr aufgeregt, schlaflos; ist obscön, glaubt, man wolle sie vergiften, verweigert deswegen die Nahrung; wird häufig gegen die Umgebung tätlich.

Beobachtung. 30. Juni bis 9. September 1909. Sehr erregt, ideenflüchtig, manisch-lustiger Zustand, so daB sie sich kaum zu Antworten fixieren läßt; behauptet, sie sei schwanger. Gibt ihr Alter ganz wechselnd an, verkennt die Umgebung; schläft sehr wenig; spricht in einem fort, dabei das meiste an das gerade Gesebene oder Gehörte anknüpfend; hin und wieder erzählt sie ein wirres Durcheinander der verschiedensten Reminiszenzen aus dem Leben.

9. September 1909. Exitus an Bronchopneumonie.

Das Gehirn von außen leicht atrophiert, Ventrikel kaum erweitert, die basa. len Gefäße zart.

Mikroskopisch. Reichliche Drusen rom Typus I und stellenweise Infiltrationsstadium. Keine Keulen. Sehr starke Veränderung der Ganglienzellen.

Fall 51. Ruzicka, Marie, 70 Jahre.

Anamnese. Psychotisch seit 2 Jahren; der Beginn scheint paranoid ge- 
wesen zu sein, sie wurde häufig ängstlich und gewalttätig; später vollkommen desorientiert; nach dem ärztlichen Bericht besteht seit längerer Zeit Sprachverwirrtheit.

Beobachtung. 14. September 1908 bis 1. März 1910. Euphorische, sehr gesprächige Alte. Spricht in einem fort in schnellster Ideenflucht, die häufig in ganz unsinnige Inkohärenz übergeht; die Kranke läßt sich fixieren, versteht alle Fragen, bezeichnet Gegenstände richtig, antwortet auch auf gestellte Fragen, kommt aber immer wieder in ihr inkohärentes Geplauder; dabei spricht sie sehr häufig von viel Geld, vielen Millionen, Höfen und Klöstern, die sie zu besitzen behauptet; sie ist persönlich, zeillich und örtlich vollkommen desorientiert, gibt auf die darauf sich beziehenden Fragen ganz wechselnde, oft auch ganz unsinnige Antworten.

1. März 1910. Exitus an Marasmus.

Mikroskopisch. Reichliche Drusen im Stadium III und IV, auch viel Infiltrationsstadium. Keine Keulen. Sehr schwere Veränderung der Ganglien. zellen.

In diesen letzten drei Krankengeschichten treten zwei Symptomenkomplexe hervor: Dasjenige Symptom, welches all den Fällen das eigentliche äußere Gepräge gibt, ist die maniakalische Exaltation; aber dahinter bergen sich noch andere Symptome, welche eine Art Bindeglied zu der vorigen Krankheitsgruppe darstellen. Im Falle 49 ist es die mangelnde äußere Orientiertheit, dann Konfabulationen, Halluzinationen auch von paranoider Verarbeitung, die sich besonders nachts zeigen. Im Falle 50 ist dies die paranoide Stellungnahme gegen die Umgebung und die mangelnde persönliche Orientiertheit. Die Vermengung all dieser Symptomenkomplexe gibt besonders dem ersten der Fälle einen eigenen Anstrich. Im Falle 51 können wir eigentlich nichts anderes als ein maniakalisches Zustandsbild mit stärkerer maniakalischer Desorientiertheit erkennen, und nur in der Anamnese wird von paranoiden Symptomen gesprochen, die aber klinisch sonst kaum verwendet werden könnten.

Ein kontrastierendes Gegenstück zu diesen drei Fällen bilden die folgenden zwei Krankengeschichten:

Fall 52. Faltys, Barbara, 74 Jahre.

Ansmnese. Seit 8 Wochen ängstlich und traurig, wollte ein Suizid durch Erhängen machen.

Beobachtung. 2. September 1907 bis 22. März 1909. Eingebracht ängstlich gehemmt, drängt unter ängstlichen Gebärden weg und wird gewalttätig; läßt Stuhl und Urin unter sich, abstiniert; läßt sich nicht examinieren, antwortet meist gar nicht, wird beim Ausfragen noch ängstlicher; schläft sehr wenig.

24. September. Ist zwar immer noch ängstlich, aber schon etwas zugänglicher, ißt schon und ist nicht mehr unrein; nennt ihren Namen, Alter weiß sie nicht, es werde etwa 50 sein; nennt richtig den Namen des Mannes, weiß, daß sie das zweitemal verheiratet ist (richtig).

1. Februar 1908. Zustand unverändert; allmählich etwas zugänglicher, sie gibt dann auch sehr spärliche und richtige Angaben aus ihrem Vorleben an, ist aber zeitlich und örtlich nicht recht orientiert.

22. März 1909. Exitus an Marasmus. 
Das Gehirn von außen leicht atrophiert, die Ventrikel wenig erweitert, die basalen Gefäße zart.

Mikroskopisch. Reichliche Drusen im Stadium III und IV, und spärliche im Stadium I. Keine Keulen. Geringe Zellveränderung.

Fall 53. Lansky, Katharina, 85 Jahre.

Anamnese. Keine.

Beobachtung. 30. September bis 10. Oktober 1908. Pat. ist taub, meist ärgerlich, verhüllt sich den Kopf, schreit, wenn man sie aufdeckt; schreit häufig „Feuer", in der Nacht läuft sie herum, ohne darüber Aufklärung zu geben, warum; ist zeitlich und örtlich desorientiert, ihr Alter weiß sie nicht.

19. Oktober 1908. Exitus an Marasmus und diffuser Bronchitis.

Das Gehirn von außen leicht atrophiert, die Ventrikel leicht erweitert, die basalen Gefäße fleckig verdickt. In beiden Linsenkernen mehrere kleine cystische Erweichungsherde mit glatter Wand. Zwei Herdchen von Halberbsengröße in der rechten Hälfte des Pons.

Mikroskopisch. Reichliche Drusen im Stadium III und IV. Keine Keulen. Starke Veränderung der Ganglienzellen und an vielen Rindenpartien grobfaserige Fibrillenwucherung.

Beiden Fällen ist der ängstliche Stupor gemeinsam; beide waren sehr stark zurückhaltend, sprachen beinahe gar nichts, so daß irgendwelche Aufschlüsse über eventuelle Wahnideen nicht zu bekommen waren. Beim Fall 53 könnte man die einigemal nachts gemachten Äußerungen „Feuer“ als Ausdruck von halluzinierten Vorgängen ansehen, doch ob mit Recht, ist mir etwas zweifelhaft.

Fall 54. Bocek, Mathias, 82 Jahre.

Anamnese. Angeblich keine Belastung, kein Alkoholismus, immer gesund gewesen; Pat. arbeitet seit 3 Jahren wegen Altersschwäche nicht mehr ; seit 6 Wochen auffällig, liegt viel zu Bett, singt ständig ein unsinniges Durcheinander, ist nachts meist unruhig; will weglaufen, und wenn man ihm daran wehrte, so wurde er aggressiv.

Beobachtung. 26. Juni bis 14. August 1909. Bei der Einbringung ruhig; ist persönlich vollkommen orientiert; beschwert sich gegen die Umgebung zu Hause, daß man ihn ständig gekränkt hätte; die Umgebung habe Spaß mit ihm getrieben, hat ihm Steine ins Fenster geworfen, nachts habe man ihm mit Licht. lein ins Fenster geleuchtet, dann sagte man ihm, man werde ihn am Genitale aufhängen, man verderbe ihm sein Weib, man sehe ihn scheel an und sagte von ihm, er sei ein schlechter Mensch; darüber hätte er sich aufgeregt.

30. Juni. In der Klinik liegt er ruhig da, spricht meist nichts, ist durch nichts auffällig; zeitweise brummt oder singt er in langsamem Tempo wie skandierend, sehr eintönig mit derselben Melodie, schlägt dazu den Takt; der Inhalt ist ein ideenflüchtiges Herumreden. Nachts schläft er wenig.

3. Juli. Pat, zeigt eine lustige Miene und brummt etwas in eintönigem Singsang vor sich, dessen Inhalt zuerst nicht recht verständlich ist; auf alles antwortet er in dem erwähnten Singsang.

Wann hergekommen? Entschuldigt sich sehr weitschweifig, man möchte ihm alle seine Sünden verzeihen.

Wie er heiße? Wie man mich getauft hat; mit Gott heiße ich mit Christus, wie sie heißen die anderen -

Wo er hier ist? In Prag im Spital.

Kennen Sie mich? Sie kommen mir bekannt vor, aber ich, ich weiß es nicht. 7 habe ich nichts gegessen. 
$\mathrm{Ob}$ er verheiratet ist? Ich bin zweimal verheiratet.

$\mathrm{Ob}$ er Kinder habe? Und ich weiß nicht, wer der ist, er sagt mir Vater und wir betteln um ein Stïck Brot und allem und ihn, und ich weiß von gar nichts und er kennt mich auch schon bißchen und sicher und ich möchte ihn auf den Händen tragen, wenn ich ihn so lange nicht gekannt hatte, so muß ich meinen Dienst machen, der Herr Papst und der Herr Kaiser haben ihn über alle gestellt, damit wir ihn lieben, er ist doch über Christus, ich war doch bei der Beichte, ich werde bitten alle Heiligen, ich werde bitten den Herm Kaiser, von einem türkischen Krieg, - und w ürde weitersprechen, aber aufgefordert, zu schweigen, schweigt er prompt.

Wann er hergekommen? Gott und Papst hat uns geleitet, und wir werden zur Zeit kommen, wenn ich Zeit habe, habe ich Zeit, aber ich habe nicht genug Zeit -

Wann er hergekommen ist? Ich bin voriges Jahr, wie Herbst war, vom Militär gekommen.

Wie alt er ist? Ich bin vielleicht noch sündhaft.

Wo er zuletzt gewohnt hatte? Dort in meinem Häuschen, wo mein Gott gewohnt hatte.

Nach Ermahnung, bei der Sache zu bleiben, sagt er: „In D ... (richtig), aber ich weiB nicht, was dort war, vielleicht ein Gasthaus, und wir sind hineingegangen."

Bei wem zuletzt gewohnt? Beim Sohn nicht, aber ich habe mich geirrt wie Gott und habe mit ihm gesprochen wie mit Gott; Gott hat mich gekannt und ich bin der Geist Gottes und der Papst hat mich geschaffen, weil ich gesündigt habe, das Herz meines Lebens.

Ob er gedient hat? Ich habe gedient dem Kaiser und meinem Gott und dem Papst und der heiligen Maria und sie hat mich ins Genitale gestoßen mit dem Fuß und dann hat sie so mit dem Finger auf mich gemacht.

Wei $\beta$, daß er in Italien mitgekämpft hat, nennt einige Städtenamen, wo Schlachten gescblagen wurden, weiß, wann der preußisch-österreichische Krieg war; rechnet schlecht, respektive löst die einfachsten Einmaleins-Aufgaben gar nicht.

19. Juli. Betet den ganzen Tag in seinem gewohnten Singsang; behauptet, er sei hier in der Kirche, geht zum Tisch und kniet nieder, hält den Wärter für den Pfarrer; in der Nacht immer etwas unruhig.

22. Juli. Probe seines Selbstgespräches: „Es war dort der Herr General, aber der Arme ist schon tot, und wenn Gott es geben wird, wird es ihm besser gehen als mir, wir müssen den gnädigen Herrn schon lassen und das Ganze lassen, und Macek und Pacek, die muBten mir was anderes geben, und ich will nicht, was dex nicht wollte und gab mir eine Ohrfeige, wenn Gott das von einem Engel sagen sollte, und mir ist kalt und mein Mütterchen und Gott hat mich angerührt (es wird jetzt eine Uhr gezeigt), aber die Uhr hat er mir nicht gegeben, denn er braucht es mehr als ich."

Wenn ihm Worte zugerufen werden, so greift er sie auf, indem er sie wiederholt und daran mehrere ähnlich klingende Worte ausspricht, an die er ein ähnliches Geplauder wie oben anschließt.

26. Juli. Schreit heute laut auf: „Ich bin ein Kaiser" und dreht sich dabei mit erhobenen Armen im Bette herum.

14. Oktober. Zustand unverändert; nach Defäkation plötzlicher Exitus an Lungenembolie.

Das Gehirn von außen leicht atrophiert, geringe Erweiterung der Ventrikel, keine Verdickung der Basalgefäße. 
Mikroskopisch. Sehr reichliche Drusen meist in den Stadien III und IV. Mittelstarke Veränderung der Ganglienzellen.

Hier tritt bei ursprünglich erhaltener Orientiertheit das in den früher angeführten Fällen geschilderte Zustandsbild mit nächtlichen Halluzinationen zutage. Dazu kommt aber ein in den anderen Krankengeschichten nicht beobachtetes Symptom einer starken sprachlichen Ideenflucht, die sich bis zur vollkommenen Inkohärenz steigert und häufig mit verschiedenen Stereotypien verbunden ist. Später ließ sich trotz der Unzugänglichkeit des Kranken eine Desorientiertheit nachweisen.

Fall 55. Novak, Johann, 65 Jahre.

A nam nese. Seit $1 \frac{1}{2}$ Jahren sehr dement, in der letzten Zeit läuft er im Walde planlos herum.

Beobachtung. 10. Juni bis 3. August 1907. Im Krankenzimmer ist er unruhig, zerwirft die Matratzen, sucht etwas darin, will weglaufen, ist gewalttätig, dabei schreit er meist ein aus ganz unverständlichen und immer wieder sich wiederholenden unsinnigen Silben bestehendes Kauderwelsch, das aber häufig auch richtige Worte enthält. Fragen versteht er, beantwortet sie auch manchmal richtig, jedoch sehr einsilbig, um dann wieder in sein Kauderwelsch zu konmen; kommt er in Affekt, so schimpft er ganz verständlich; nachts ist die Unruhe immer stärker; zeitweise sind Andentungen von ideatorischer Apraxie vorhanden.

3. August 1907. Exitus an Pneumonie.

Pathologisch-anatomische Diagnose: Cystitis suppur. Prostatitis suppur. Abscessus renum. Bronchitis suppur. Pneumonia lobul.

Das Gehirn stark atrophiert, die rechte Hemisphäre stärker als die linke. Die Ventrikel deutlich erweitert; fleckige Verdickung der basalen Gefäße.

Mikroskopisch. Reichliche Drusen in den Stadien I-IV. In den Stirnpartien auch reichliche Infiltrationsstadien; schwere Veränderung der Ganglienzellen und stellenweise grobfaserige Fibrillenwucherung in den Ganglienzellen. Keine Keulen.

Dieser Fall reiht sich an den vorigen insofern an, als er in seinem ganzen Verhalten das Bild der deliranten Fälle zeigte, wozu ebenfalls eine sprachliche Inkohärenz sich zugesellte; nur war hier die Inkohärenz bis zum ganz unverständlichen Wortsalat gediehen. Um eine aphatische Störung hat es sich hier nicht handeln können, denn der Kranke verstand alles, was zu ihm gesprochen wurde, er konnte auch fixiert werden, und dann waren seine sprachlichen Äußerungen vollkommen verständlich, ebenso wie er im Affekt in ganz korrekter Sprache zu schimpfen verstand. Immer wieder $\mathrm{kam}$ er aber in seinen früheren Wortsalat hinein.

Fall 56. Zamrazil, Katharina, 65 Jahre.

Anamnese. Pat. soll schon seit 7 Jahren sehr vergeßlich sein, war desorientiert, unordentlich und zu keiner Arbeit zu gebrauchen. Vor 3 Jahren hat sich der Zustand verschlimmert, doch Genaueres darüber ist unbekannt; vor 3 Monaten ein epileptischer Anfall, worauf Pat. unruhig wurde, ständig schrie und ganz unsinnige Sachen durcheinander sang. 
Beobachtung. 16. November 1907 bis 13. August 1908. 18. November. Sitzt ständig zusammengekauert im Bette, starrt vor sich, knüllt häufig das Bettzeug zusammen, oder reibt sich in gleichartig sich wiederholender Weise die Hand an der Wange oder die Hände aneinander; ist dabei nicht ein Weilchen still, singt Bruchstücke verschiedener Lieder und Melodien, meist ohne Text; häufig aber auch mit unterschobenem, meist unsinnigem Text; manchmal singt sie auch Bruchstücke von Gebeten, aus denen sie einzelne Worte perseveriert und ins Unsinnige permutiert, so daß oft ein ganz unsinniges Silbengeklingel entsteht.

Ein Examen ist undurchführbar, da Antworten überhaupt nicht zu erzielen sind, doch hört die Kranke jeder Frage zu, faßt diese auch sicher so auf, daß sie etwas gefragt wird; denn während sie etwas gefragt wird, bleibt sie immer still, wogegen sie Äußerungen, welche nicht in fragendem Tone gesagt werden, kaum beachtet. Kaum hat man die Frage beendet, so knüpft sie sofort mit ihrem früheren Singsang an, indem sie meist das zuletzt gehörte Wort auffängt und es in der früher erwähnten Weise permutiert. Dabei starrt sie vor sich, wie wenn sie nichts sehen würde. Dinge, die ihr vorgehalten werden, fixiert sie nicht, sie muß auch gefüttert werden, da sie das Essen gar nicht beachtet. Annäherung an die Augen führt zu keinerlei Blinzelbewegungen; bei stärkerer Beleuchtung mit einer elektrischen Nernstlampe reagiert sie mit dem Worte „Sonne"; Pat. schläft bei Nacht beinahe gar nichts, nestelt ständig an Bettzeug und Wäsche herum.

21. Dezember. Ein epileptischer Anfall.

1. Januar 1908. Zustand unverändert; manchmal ist sie ganz stumpf, manchmal fixiert sie aber auch; wenn man sie mit vieler Mühe dazu bringt, einen Gegenstand zu ergreifen, so greift sie immer daneben; die sie besuchende Tochter erkennt sie nicht.

13. August 1908. Exitus an Marasmus.

Das Gehirn von außen leicht atrophiert. Ventrikel leicht erweitert. Basalgefäße leicht fleckig verdickt.

Mikroskopisch. Reichliche große Drusen im Stadium III und IV. Reichliche Keulen. Schwere Veränderung der Ganglierıellen.

In dieser Krankengeschichte kann man eigentlich nur den Sy mptomenkom plex der katatonen Demenz erblicken: Stereotypien der Handlung und Stereotypien der Sprache mit schwerstem Wortsalat und vollständige Inkohärenz beherrschen das klinische Bild. Nur weit entfernt erinnert das ständige eigenartige Nesteln mit dem Bettzeug an das Nesteln der deliranten Fälle; aber diese Ähnlichkeit ist zu weit entfernt, als daß sie, wenn nicht andere Bindeglieder vorhanden wären, irgendwie in Betracht gezogen werden könnte.

Dies sind die Fälle, bei denen sich durchwegs die Sphaerotrichia cerebri multiplex nachweisen ließ. Bei allen Paralysen, auch denen, welcheim Seniumerstaufgetreten waren, fehlte die Sphärotrichie, ebenso bei allen anderen Psychosen unter 50 Jahren.

Bei einem Teil der Psychosen, welche im Alter von mehr als 50 Jahren aufgetreten sind, fehlte die Sphärotrichie ebenfalls; die Krankengeschichten dieser Fälle sollen im folgenden gebracht werden, und zwar in Gruppen je nach den vorhandenen klinischen Symptomenbildern. 
Fall 57. Hlavatochek, Franziska, 82 Jahre.

Anamnese. Keine.

Beobachtung. 27. Juli bis 23. August 1904. Stumpf, dement, sonst ruhig; weiß ihr Alter annähernd, weiß, wie und wann sie herkam, klagt über ihr schlechtes Gedächtnis; weiß nicht die Namen ihrer Kinder, aber hat für diese Defekte volle Krankheitseinsicht.

23. August 1904. Exitus an Pneumonie.

Fall 58. Novak, Marie, 83 Jahre.

A namnese. Seit $1 / 2$ Jahr vergeßlich und manchmal gereizt.

Beobachtung. 24. Februar bis 5. März 1910. Schwerkranke Alte, hat starkes Emphysem, Myodegeneratio cordis, Decubitus; die Atmung sehr keuchend. Sprache sehr mühsam; ist unrein wegen Schwäche; einfach dement, unaufmerksam, fühlt sich sehr elend, ist sonst auch ganz orientiert; nichts von sonstigen psychischen Störungen.

26. und 27. Februar je ein epileptischer Anfall.

Fall 59. Vlk, Barbara, etwa 70 Jahre.

Anamnese. Keine.

Beobachtung. 17. Oktober bis 31. Dezember 1908. Totale einfache Verblödung und Verstumpfung; Ungeschicklichkeit der linken Hand.

Fall 60. Dlouhy, Franz, 68 Jahre.

\section{Aufenthalt.}

A nam nese. Seit 6 Jahren zunehmend vergeßlich; jetzt schon ganz blöd, kennt seine Angehörigen nicht, will weglaufen.

Beobachtung. 25. April bis 22. Mai 1905. Dement-stumpfes Wesen; Alter annähernd richtig; behauptet, noch in der letzten Zeit gearbeitet zu haben; glaubt, hier zu Hause zu sein, seine Frau werde auch hier sein.

1. Mai. Liegt ruhig da, manchmal unrein, behauptet, mehrere Jahre da zu sein; hätte gestern am Felde gearbeitet; leichte amnestische Störungen.

\section{Aufenthalt.}

Anamnese. War jetzt ein Jahr zu Hause, dabei ganz stumpf-dement; in den letzten Monaten will er weglaufen, ist sehr reizbar, spielt mit dem Feuer; kennt seine Angehörigen nicht mehr.

Beobachtung. 18. Mai bis 30. Juni 1907. Im Zustande schwerster Demenz, sehr unaufmerksam, stumpf, lacht blöd vor sich, ist unrein, antwortet höchst einsilbig, nennt kaum seinen Namen, behauptet, 20 Jahre alt zu sein; aber auf die meisten Fragen antwortet er gar nicht, oder sagt höchstens ein stumpfsinniges , ,ja“.

30. Juni 1907. Exitus an Marasmus.

In diesen Fällen ließ sich nur eine einfache Verblödung und Verstumpfung konstatieren, die aber besonders im Falle 60 einen sehr hohen Grad erreichte. In der letzten Krankengeschichte sind auch einige konfabulatorische Aussagen enthalten.

Fall 6l. Knösl, Mathilde, 71 Jahre alt.

A namnese. Immer ein verschrobenes Individuum gewesen: zänkisch, unverträglich, boshaft, lief mehrmals vom Manne weg, kümmerte sich nicht um die Familie, flamendierte, trotzdem sie aus guter Familie stammt, herum; wurde auch im späteren Alter von der Familie gemieden, nur pekuniär unterstützt; vor einem Jahre fiel sie auf den Rïcken und seit der Zeit kann sie nicht gehen; liegt zu Bett, ist sehr zänkisch, roh und schimpft in der Krankheit so viel, daß man sie als geisteskrank in die Anstalt schaffte. 
Beobachtung. 20. Januar 1906 bis 1. Dezember 1907. Pat. ist körperlich ziemlich heruntergekommen, zeigt eine ausgesprochene, sehr gut beeinflußbare Abasie und Astasie, ist vollkommen orientiert; Intelligenz gering, doch scheint auch ein angeborener Schwachsinn zu bestehen.

1. Februar. Ist sehr schwer zu behandeln, möchte, alles soll immer nur um sie herumspringen, wie ihr nicht alles zu Willen geschieht, schreit sie, rauft sich wütend die Haare, schlägt mit den Fäusten auf den Kopf, aber so, daß sie sich ja nichts macht, strampelt. pfaucht, wirft das Bettzeug heraus, behauptet, sie werde sich umbringen, und wenn sie das Personal am meisten ärgern will, benäßt sie sich; ebenso sekiert sie die Ärzte, schimpft sie in der ordinärsten Weise und bleibt in dieser Art ganz unverändert.

1. Dezember 1907. Exitus an Marasmus.

Auch in diesem Falle haben wir nichts anderes als eine einfache senile Verblödung vor uns, die aber bei einem hysterisch degenerierten und wahrscheinlich auch sonst intellektuell minderwertigen Individuum aufgetreten war, wodurch die Psychose eine besondere Färbung erhielt.

Fall 62. Jírinec, Anna, 79 Jahre.

Anamnese. Keine.

Beobachtung. 29. Juli 1900 bis 22. Fehruar 1904. Sensorische Aphasie und Paraphasie; apraktische Störungen; ist schwer dement, stumpf, häufig unrein; beim An- und Ausziehen wehrt sie sich, weil sie glaubt, man wolle ihr etwas antun.

22. Februar. 1904 Exitus an einer beginnenden Gangrän des Beines.

Das klinische Bild besteht hier aus zwei Symptomenkomplexen: erstens der einfachen stumpfen Verblödung, etwa der gleichen Art wie in den vorigen Fällen, zweitens aber aus aphatischen Symptomen, welche auf e:ne Läsion des linken Schläfelappens bezogen werden mußten. Bei der Obduktion zeigte sich auch dementsprechend eine hochgradige Atrophie des linken Schläfelappens, die durch den ,spongiösen Rindenschwund“"1) verursacht war.

Fall 63. Bodsky, Marie, 62 Jahre alt.

\section{Aufenthalt.}

Anamnese. Früher nie psychisch krank gewesen, keine Heredität; vor 4 Monaten ein Armbrucb, der gut ausheilte; Pat., die früher geistig immer gesund war, wurde jetzt traurig, beschuldigte sich, daß sie den Angehörigen zur Last falle, daß sie Hungers sterben werde, besser, wenn man sie umbringen würde, schlief sehr schlecht.

Beobachtung. 2. Juli bis 4. August 1907. Pat. ist ängstlich, traurig, weinerlich, persönlich vollkommen orientiert, ist etwas weniger attont, zeigt nichts Dementes, rechnet nur sehr schlecht, klagt selbst über Gedächtnisschwäche; weiß, daß sie traurig ist, behauptet, immer traurig gewesen zu sein; mit einer alten Person sei es am besten, man bringe sie um; sie sei krank, hätte den Kopf ganz leer, alles verdrieße sie, sie habe eine große Unruhe im Körper.

5. Juli. Ganz ruhig, etwas gedrückter Gesichtsausdruck, wenn man sich ihr nähert, fängt sie an zu jammern; schläft auf Schlafmittel.

1) Beschrieben in meinem Referat über die Lues-Paralyse-Frage in der Allgem. Zeitschr. f. Psychiatrie 1909. 
20. Juli. Hat keine Angst mehr, aber behauptet, als man ihr die Schlafmittel entzieht, nicht schlafen zu können; schläft aber auf maskierte Pulver.

14. August 1907. Genesen entlassen.

2. Aufenthalt.

Anam nese. 5 Wochen war sie gesund; seit der Zeit ist sie ängstlich, jammert ständig in eintöniger Weise vor sich hin.

Beobachtung. 14. Oktober bis 21. Dezember 1907. Eingebracht sehr ängstlich jammernd, sie wolle sterben, sie könne es nicht mehr aushalten; wie man sich ihr nähert, steigert sich ihr Jammern in übertriebener Weise; sie behauptet, sie wisse nicht, daß sie schon dagewesen ist, sie kenne auch niemanden da, behauptet, sie sei 40 Jahre alt und wolle sterben; jammert sich immer mehr in den Affekt hinein, befiehlt dem Tod, er möchte sie holen, behauptet, auch ihre Tochter müsse sterben, weil sie es wolle. Auf die Frage, was der Kopf macht, schlägt sie sich in utrierter Wut auf den Kopf und behauptet, der sei nichts wert, es klopfe immer drin; auf Vorhalt, sie werde gesund, jammert sie, das nützt nichts, wenn sie «päter wieder krank wird; das Gejammer macht einen sehr theatralischen Eindruck; Anästhesie für Nadelstiche.

16. Oktober. Ist jetzt schon viel ruhiger, weiß sich genau zu erinnern, daß und wie sie das erstemal da war, behauptet, sie habe keine Angst mehr; aber wie sie ron ihrem Zustand erzählt, gerät sie immer mehr in den Affekt hinein und jammert wie gestern.

21. Dezember 1907 wird sie genesen entlassen.

\section{Aufenthalt.}

Anamnese. Bis vor einer Woche gesund; seit der Zeit - nach der Hochzeit der Tochter - sehr ängstlich, unruhig, schläft nicht, wollte immer weglaufen, wollte sich die Ohren abschneiden, am besten sich und die ganze Familie umbringen.

Beobachtung. 12. März 1908 bis 16. Mai 1909. 13. März. Ist sehr ängstlich, stöhnt, jammert, rennt zur Tür, man solle sie weglassen, man solle sie töten, läßt sich nicht fixieren, jammert in ganz eintöniger Weise immer wieder; das ganze Gejammer macht einen sehr übertriebenen theatralischen Eindruck; als man ihr sagt, man dürfe sie nicht töten, zappelt sie wie ein kleines Kind und wimmert: „Ich will getötet werden."

Dieser Zustand bleibt in allgemeinen unverändert.

3. Juni 1908 macht sie einen Suizidversuch durch Erhängen und am 16. Mai 1909 Exitus an chronischer Lungentuberkulose.

Fall 64. Kut, Veronika, 59 Jahre.

Anamnese. Seit 14 Tagen ängstlich.

Beobachtung. 22. Dezember 1908 bis 29. April 1909. Ist ängstlich, deprimiert, behauptet, sie werde gestraft, weil sie einmal zur Kommunion ging, ohne gebeichtet zu haben.

31. Dezember. Ist ständig ängstlich; manchmal ratloser Gesichtsausdruck, spricht ziemlich viel in gedrücktem Tone und erzählt immer nur von ihren Sünden, für die sie gestraft werde; nachts gewöhnlich mehr ängstlich; schläft wenig.

6. Januar 1909. Ängstlicher, agitiert, jammert und stöhnt, drängt weg; äußert hypochondrische Ideen, die Ameisen hätten ihr alles im Kopfe weggefressen, so daß sie kein Gedächtnis habe.

12. Januar. Starke Ratlosigkeit, klagt darüber, daß sie nicht wisse, was mit ihr vorgehe, behauptet, sie könne nichts zahlen, sie dürfe auch deswegen nichts essen.

1. Februar. Ständig ratlos, ängstlich, verwirrt, spricht sehr wenig; einmal durch kurze Zeit sehr gesprächig gewesen mit einem Einschlag ins Euphorische. 
8. Februar. Sehr ängstlich, wünscht, man möchte sie umbringen.

7. April. Bisher unverändert; heute äußert sie, das gesamte Wasser der Welt werde sich hier ansammeln und alle werden ertrinken, schon komme das Wasser, doch ist schwer zu eruieren, ob sie es schon erwartet oder sieht; schreit, man hätte ihr die Zunge herausgerissen, sie werde sich am besten an den Haaren erwürgen, hält die anderen Kranken für tot, behauptet, Schlangen kriechen schon hier herum.

29. April 1909. Bis zum heutigen Tag Zustand unverändert; Exitus.

Fall 65. Krátky, Anton, 62 Jahre.

A namnesc. Vor $3 / 4$ Jahren starb die Fran; seit der Zeit war Pat. schlaflos, traurig und sehr versehlossen; vor 2 Monaten brannte ihm sein Häuschen ab; seit der Zeit hatte er die Idee, daß man ihn für den Brandleger halte, daß er gerichtlich verfolgt werde, und um sich vor den vermeintlichen Verfolgungen der Gendarmen zu retten, versuchte er einen Selbstmord; einige Wochen nach dem Brande fiel er zufällig von einer leiter auf den Kopf, ohne sich aber zu verletzen.

Beobachtung. 26. Oktober 1907 bis 4. November 1908. Ist vollkommen orientiert, traurig, leicht gehemmt; gibt zu, traurig zu sein, gibt auch den Suizidversuch und Persekutionsideen $\mathrm{zu}$, wenn auch ungern; versucht $\mathrm{zu}$ dissimulieren; glaubt auch hier, daß man ihn seltsam anschaue und über ihn lache; keine Erinnerungsdefekte.

21. Dezember. Ist sehr ängstlich, behauptet, hier gehört zu haben, daß er hier ,50 Jahre Kriminal bekomme“.

15. Januar 1908. Jetzt wieder ruhig, deprimiert, geordnet.

10. März. Jetzt wieder stumpf, ängstlich und verweigert das Essen.

10. August. Klagt darüher, daß es ihm hier sehr schlecht gehe, er könne schon 2 Monate nicht zu Stuhl gehen und sei davon ganz voll.

3. November. Ein Ohnmachtsanfall.

4. November 1908. Exitus an Dysenterje und Marasmus.

Fall 66. Stríbrny, Marie, 58 Jahre.

1. Aufenthalt.

Anamnese. Seit 4 Monaten depressiv, mit Verfolgungsideen, man trachte ihr nach dem Leben, wolle sie erschlagen, gebe ihr das Essen ungekocht.

Beobachtung. 30. Juli bis 4. November 1903. Ängstlich, ratlos; gibt sehr einsilbige Antworten, behauptet, sie wisse nicht, was mit ihr geschehe, wo sie ist, was sie ist, sie sei ganz hölzern, sei wie verblödet, sei ganz verwirrt.

25. August. Äußerlich ruhig, ißt wenig, schläft viel, stumpf-ängstlicher Gesichtsausdruck; jagt lächelnd ihre sie besuchende Tochter weg, mit den Worten: „sie hätte die Kathi herausgeprügelt".

1. September. Will nichts essen, das Loch im Halse sei zugewachsen, sie bekomme auch keinen Atem.

5. November. Behauptet, das eine Bein sei weg und will sich vom Gegenteil nicht überzeugen lassen; auf alle Fragen gibt sie zur Antwort, sie wisse nicht, sie habe keinen Kopf, kein Herz, keine Nase, keine Augen.

18. Oktober. Macht wiederholt Suizidversuche durch Erhängen; schiägt sich mit den Fäusten gegen den Kopf, auf Vorhalt erklärt sie: „Es ist nichts da, ich bin auch nicht da, gar nichts ist da, das habe ich nicht gemacht."

Wird in diesem ganz unveränderten Zustand in eine andere Anstalt trans. feriert und dann nach Hause.

\section{A ufenthalt.}

Beobachtung. 23. Mai 1904 bis 29. Juli 1904. Stumpf-dementes Wesen, liegt gleichgültig da, behauptet, sie sei überhaupt nicht, hat überhaupt nichts als die Haare, sonst ist alles weg, der ganze Körper ist weg, sie könne nicht essen, 
wei sie keinen Mund hat, atmen könne sie nur noch mit den Haaren; wenn man sie sticht, sohreit sie, behanptet aber, das sei nichts, deswegen hat sie doch keinen Körper.

25. Mai. Liegt stumpf da, ist unrein; Kotschmieren; heute behauptet sie, sie habe nur die Brüste und klatscht sich in einem fort unter dementem Lächeln anf die Brust, bis die Haut ganz rot ist; sonst unverändert.

29. Juli 1904. Exitus an Marasmus.

Fall 67. Svec, Marie, 71 Jahre.

A namnese. Keine.

Beobachtung. 15. Juni 1908 bis 22. Januar 1909. Pat. sehr ängstlich, spricht nichts, antwortet nur sehr einsilbig, scheint persönlich orientiert; nachts unruhig, schläft nicht, drängt heraus; jammert, sie habe kein Geld, alles ist verbrannt, alle Töchter sind verbrannt.

Eine Unterredung mit ihr kaum möglich, da sie leise wimmernd vor sich stöhnt, hin und wieder äußert sie: Ich hahe hier weder einen Zug, noch eine Bahn, wir haben keine Bahn, wir haben keinen Zug, oder "hier ist kein Zug".

30. Juni. Etwas ruhiger, stumpf hinbrütend.

26. August. Behauptet, alles gehöre ihr, dabei jammert sie aber, sie falle allen hier zur Last und bittet, man möchte sie herauslassen.

10. Dezember. Jetzt wieder etwas ruhiger; stöhnt und schreit, ohne daß sich im Ausdruck ein ausgesprochener Affekt zeigen würde; wo sie hier ist, weiß sie nicht, aber zu Hause sei sie nicht: das Datum kennt sie nicht, weil sie sich nicht darum kümmert.

Fall 68. Kößler, Therese, 59 Jahre.

A na mnese. Seit 2 Jahren traurig, sie müsse sich das Leben nehmen, wollte häufig nichts essen, ging auch einigemal ins Wasser, wo sie schrie und mit den Händen herumfuchtelte, machte aber nie wirklich ernste Suizidversuche. Eine Tochter soll zeitweise wirr im Kopfe sein.

Beobachtung. 5. Dezember 1905 bis 14. Oktober 1906. Pat. ist persönlich, zeitlich und örtlich vollkommen orientiert; ist traurig, ängstlich und ratlos gehemmt; gibt nur sehr einsilbige Antworten; muß zu jeder Antwort stimuliert werden.

24. Dezember. Viel stumpfer, abstiniert, Sondenfütterung; läßt Stuhl und Urin unter sich.

2. Januar 1906. Nicht mehr so ängstlich, aber sehr gleichgültig; ißt selbst, nicht unrein, muß aber sonst besorgt werden.

14. Oktober 1906. Exitus an Dysenterie.

Fall 69. Klika, Adalbert, 80 Jahre.

A nam nese. Seit längerer Zeit sehr stark vergeßlich; seit 2 Monaten schläft er schlecht, war traurig, behauptet, er werde nicht leben können, weinte viel, wollte nichts essen; war dabei sehr reizbar.

Beobachtung. 22. Februar bis 11. März 1909. Ist vollkommen ruhig, geordnet und orientiert, weiß sich auf alles, was in den letzten Tagen geschehen ist, gut zu erinnern, weiß, wie er her kam, und daß er zu Hause traurig war.

25. Februar. Ziemlich vergeßlich, aber sonst orientiert, keine Konfabulationen.

27. Februar. Seit gestern stumpf-ängstliches Wesen, gibt zu, Angst zu haben, weiß aber nicht warum; war auch nachts sehr ängstlich; dem Sohn sagte er beim Besuch, er solle nur schauen, daß er bald wegkomme, damit ihm hier nichts geschehe, alles soll hier verbrannt werden; in diesem ängstlich-stumpfen Zustande verbleibt er bis zum Exitus. 
Mit mehr oder weniger Symptomen der Demenz vermischt, tritt in allen diesen Krankengeschichten eine primäre Depression hervor, zum Teil begleitet von ängstlicher Erregung, Hemmung und Selbstbeschuldigungen; in einigen $\mathrm{kam}$ es auch zu passagerer, ängstlicher Ratlosigkeit und zu hypochondrischen Ideen; letztere waren besonders ausgesprochen im Falle 66, wo sie durch ihre Unsinnigkeit auffallen.

Alle diese sieben Fälle lassen sich ohne weiteres in die Symptomengruppe der Melancholie unterbringen; dabei muß aber berücksichtigt werden, daß das höhere Alter der Kranken auch bereits gewisse Züge der einfachen senilen Verblödung hervorgebracht hatte, durch die der melancholische Symptomenkomplex noch etwas kompliziert wurde.

Fall 70. Kroil, Ferdinand, 65 Jahre.

Anamnese. Dauer der Krankheit mindestens 2 Jahre.

Beobachtung. 21. Januar bis 1. Oktober 1907. Pat. ist zeitlich, örtlich und persönlich orientiert, ist in expansiver, übermütiger Stimmung, sehr redselig, jdeenflüchtig, spricht in alles hinein, glossiert alles, verursacht dadurch sehr viele Zwiste, prahlt von seinen Fähigkeiten, renommiert mit Freunden, reichen und adeligen Verwandten, dem Arzt gegenüber bald kollegial, bald grob, sehr anspruchsvoll und auch manchmal gewalttätig; renommiert mit plumpen Lügen und gibt aber in die Enge getrieben die Unwahrheit zu.

In diesem Zustande verbleibt er bis zu seinem am 1. Oktober erfolgten Exitus an Marasmus.

Fall 71. Tobisch, Franz, 60 Jahre.

Anamnese. Seit $3 / 4$ Jahren ständiges Erbrechen, kam allmählich stark herunter; erst in der letzten Zeit Anfälle von Bewußtlosigkeit angeblich mit Zuckungen in den Fingern; seit mehreren Wochen überlustig, macht unsinnige Bestellungen, wird oft gewalttätig, war einen Monat in einem Sanatorium, in sehr maniakalischer Stimmung, baute Villen, sprach von Tausenden von Arbeitern, baute Fahrstühle, machte Weltreisen und behauptete, er könne nur von Luft leben.

Beobachtung. 27. März bis 7. April 1909. Hochgradig abgemagert; wiegt nur $40 \mathrm{~kg}$, sonst somatiseh, in der Pylorusgegend ein harter Tumor tastbar; er ist leicht hypomanisch, behauptet, seine früheren Ideen wären nur ein Delirium von dem Hunger gewesen, ist sonst vollkommen orientiert; fühlt sich aber sehr wohl, trotzdem er ständig mehr und mehr herunterkommt; da er alles erbricht, wird er nur mit Klysma ernährt; sein Gewicht sinkt auch, trotzdem er von großer Statur ist, auf $36 \mathrm{~kg}$.

7. April 1909. Exitus an Kachexie infolge eines Magencarcinoms.

Bei zwei senilen Individuen tritt uns hier das Krankheitsbild der reinen Manie entgegen; der Fall 71 ist noch kombiniert mit einer Carcinomkachexie, die jedenfalls auch zu den ätiologischen Momenten zuzurechnen ist.

Fall 72. Vyskocil, Antonie, 60 Jahre.

Anamnese. Mutter im Senium geisteskrank gewesen. Seit mehreren Monaten ein Ulcus cruris, seit 2 Monaten stumpf, traurig, spricht mit niemandem; seit 4 Tagen ist sie sehr lustig, singt viel.

Beobachtung. 15. Juli bis 19. Juli 1908. Eingebracht ziemlich unruhig, will alles Bettzeug sofort herauswerfen, spricht viel und inkohärent über angeblich verlorenes Geld und Verrat. 
17. Juli. Sehr lebhaft, geschwätzig, behauptet, sie sei verrückt, verkennt die Umgebung, sehr witzig; örtlich nicht ganz recht orientiert.

18. Juli. Heute ganz ruhig, vollkommen orientiert, weiß, daß sie krank und lustig war.

19. Juli 1908. Exitus plötzlich an Herzkollaps.

Fall 73. Brejnik, Katharina, 66 Jahre.

A namnese. Seit 8 Wochen wortkarg, ängstlich, ratlos, hat Verarmungsund Verständigungsideen, schläft nicht, abstiniert, ist desorientiert.

Beobachtung. 18. Juli bis 12. Dezember 1908. Stumpf, ängstlich; somatisch sehr herabgekommen; sehr einsilbig, trauriges Wesen; Antworten sehr spärlich, einsilbig, mit großen Pausen; weiß, daß sie krank ist, behauptet, sehr vergeßlich zu sein, und im Kopfe sei es so leer, sie könne gar nicht denken.

21. Juli. Nachts schläft sie; tagsüber sehr ängstlich, muß gefüttert werden; rennt hastig, ungeduldig herum; will nicht zu Bett bleiben, jammert vor sich hin: „Was habe ich nur gemacht, was habe ich angestellt", aber nähere Auskünfte nicht erhältlich.

28. September bis 1. Oktober. Phlegmone des Vorderarmes, mit Fieber bis $38,9 \mathrm{C}$

12. November. Ständig ängstlich. gehemmter Zustand, sehr marantisch.

3. Dezember. Seit 14 Tagen ein zirkulärer Zustand, in dem sie abwechselnd stumpf-ängstlich und heiter gesprächig ist; dabei wechselt dieser Zustand regelmäßig in 24 Stunden; in den maniakalischen Phasen unterhält sie sich mit der Umgebung in einem fort, erzählt in ideenflüchtiger Weise Reminiszenzen und flicht häufig Konfabulationen ein: so behauptete sie, gerade etwas gekauft zu haben, sie hätte gerade eine Ziege geschlachtet, sah hier einen schwarzen Storch, viele Leute durch eine enge Gasse rennen, die schmutzig waren und große Pantoffeln hatten, lauter Männer, dann von 2 Gestalten, die Plakate aufkleben wollten; ist sehr marantisch und am 12. Dezember 1908 Exitus an Darmkatarrh und Marasmus.

Die symptomatologische Zugehörigkeit zum manisch-depressiven Irresein unterliegt wohl keinem Zweifel. Fall 72 ist zwar nur kurze Zeit beobachtet worden, und auch nur in einer manischen Phase von zweitägiger Dauer, doch berichtet die Anamnese von einer vorherigen kurzen melancholischen Depression. Beim Fall 73 hat sich der zirkuläre Zustand erst nach einem durch eine Phlegmone verursachten septischen Fieber entwickelt. Bemerkenswert ist, daß das Gehirn dieses Falles bei der mikroskopischen Untersuchung eine hochgradige Zellveränderung aufwies, die sonst nur bei septischen Prozessen zu finden ist, trotzdem die Kranke nach dem fieberhaften Zustande noch $2^{1 / 2}$ Monate gelebt hatte.

Fall 74. Rinda, Franziska, 68 Jahre.

A namnese. Pat. ist vom Jahre 1875 bis 1908 in der Prager Landesirrenanstalt; ursprünglich depressiv, mit Halluzinationen, später Auftreten von Größenideen, dabei häufig sehr erregt, und verbigerierend; 1896 sind Stereotypien in Bewegungen und Worten verzeichnet; allmähliche Verstumpfung.

Beobachtung. 20. Januar bis 4. Februar 1908. Total verblödet; spricht spontan nichts, auf Fragen antwortet sie prompt mit inkohärentem Gefasel; ist manchmal rein, manchmal verunreinigt sie sich; typisches Bild der verblödeten Dementia prïeox.

4. Februar 1908. Plötzlich Exitus infolge von Myomalacia cordis. 
Der obige Fall ist eine typische Dementia praecox, der durch 33 Jahre in Anstaltsbehandlung gestanden war und in hohem Alter starb.

Fall 75. Pazdera, Marie, 51 Jahre.

Anamnese. Ohne äußere Veranlassung seit gestern ein Verwirrtheitszustand.

Beobachtung. 27. Oktober bis 9. November 1907. Eingebracht in hohem Erregungszustand, nicht $\mathrm{zu}$ fixieren, spricht ständig in starker ideenflüchtiger Weise, manchmal in Inkohärenz ühergehend; dabei kommen auch ganz unsinnige Silbenzusammenstellungen vor.

So matisch. Nur Analgesie für Stiche.

30. Oktober. Stïndig motorisch erregt, verbigeriert, perseveriert, macht Grimassen und manirierte Gesten, ist unrein; ißt wenig; spricht viel, zerreißt alles, bei der Untersuchung immer negativistisch.

7. November. Diarhöen, die bis zum 9. November 1907 anhalten; Exitus an Bronchopneumonie und Darmkatarrh.

Fall 76. Honke, Anton, 66 Jahre.

A na mnese. Kein Trinker; vor 20 Jahren war Pat. einige Tage tobsüchtig und war deswegen in einer Zwangsjacke; seit 5 Jahren ,geistesschwach"; wurde zänkisch und eigensinnig, häufig behauptete er, er werde von nichts zu leben haben (trotzdem er in ganz guten Verhältnissen war); vor 5 Tagen fiel er durch verwirrtes Reden auf, wollte die Tochter herausjagen, lief auf die Gasse heraus, wollte eine Frau vergewaltigen, will njchts essen, behauptet, alles stinke, sah einen schwarzen Kerl im Zimmer und hörte Stimmen.

Beobachtung. 7. bis 9. November 1909. Läßit alles ruhig mit sich geschehen, greift immer am Hemd herum. ist unrein, beschmiert sich, und redet ständig inkohärent. Nachts schläft er nicht. Ist beim Ausfragen sehr wenig aufmerksam; auf die Trage reagiert er, knüpft aber sofort wieder an; Namen richtig.

Alter? 45 Jahre, morgens früh zeitlich um 8, 9, $10 \mathrm{Uhr}$, er sei $60,70,80$, 100 Jahre und norh länger verheiratet, das hänge zusammen, weil er schlecht auf dem Gcbiß sei, er muß immer mit den anderen sein, den kann man wie eine Bestie eingraben, er sei begraben worden und im Leintuch haben sie jhn hinausgeworfen wie eine Pickelhaube, ihm sei überhaupt ganz kalt.

Was ihm fehle? In Weißkirchen sei er über Nacht gewesen, Kopfschmerzen und Zahnweh habe er seit $3 / 4,4 / 4,5 / 4,6 / 4$ Jahren, er sei schon 1000 und 10000000 Jahre behandelt worden, vor 22 Jahren war er nientals in "Peschabel" gewesen, dann haben sie ihn in ein Papier gesteckt, Flitterwochen ein Bierglas oder sonst bei Sachsen, durch ein Nullenblatt sei er hergekommen; jetzt sei der Monat 66 im Jahre 118, 1920 ader noch später, das sei ein Stück Pferd und er werde sich noch durchschnoddern, ein Nullenblatt macht man keinen Nagelkopf.

$\mathrm{Ob}$ er verrïckt sei? $\mathrm{Ja}$, er hahe Kopfschmerzen, wenn er nicht hört ein Biertuch oder ein Bierfaß, er habe schon genug Bierfïsser gekauft, tot und lehendig verschimmelt und vermodert und wird Nummero 1, 2, 3, 4, 5, 6 Punkten, er sei 20 oder 50 Jahre Streusand darauf, „Kassenappel“. Er sei ganz unschuldig, vielleicht wird or durch ein Rohr deswegen gerollt, und war nicht oft zugedeckt, und sei derselbe "Steingold aus Sauerrampfer", hat 6, 7,8,9, 10 und noch mehrere Kinder.

Auf die Aufforderung, zu schreiben, wird er weinerlich, macht einen kleinen Klecks und sagt: „Sie können mich ins Wasser ·werfen, Sie können auch einen Spieß durchschlagen, ich muß bestraft werden mit Pulver, ein Nullenfaß, ein Nullenfaß, durch das Zahnfleisch die Wabrheit gefaßt in einen goldenen Stein die Ewigkeit Amen."

Ob er verheiratet ist? „Ja, das erstemal, weil ich durch ein Nullenfaß einen Nullensäbel, weil ich durch ein Nullenfaß erschlagen worden bin." 
9. November. Früh ganz klar und korrekt, gibt richtige Antworten, ist orientiert, weiß, daß er nicht richtig im Kopfe gewesen sein muß; am Nachmittag wird er wieder unruhig, zieht sich aus und rennt zur Tür, will weglaufen, scheint auf Stimmen zu antworten; gegen Abend wird er plötzlich ruhig und stirbt ganz plötzlich auf Grund einer Myodegeneratio cordis.

Die beiden letzten, nur ganz kurz beobachteten Fälle zeigten das Krankheitsbild einer Amentia mit starker motorischer Erregung, zur Inkohärenz gesteigerter Ideenflucht und Sprachverwirrtheit.

Fall 77. Franke, August, 87 Jahre.

A nam nese. Keine.

Beobachtung. 24. Juli 1894 bis 10. März 1906. Gemütlicher Alter, lebhaft, plaudernd, immer heiterer Stimmung, leicht gehobenes Selbstgefühl.

Behauptet, hier als Heiland zu sein; stellt sich als der Nachfolger Gottes vor; er sei nicht das Kind seiner Eltern, er ist der Welterlöser, der Heiland, der alleinige Kaiser, alle anderen Regenten sind nur seinc Berater, und die habe er anf den Thron gesetzt, alles sei in seiner Gewalt, Himmel, Erde und Hölle, er ist der Sohn Gottes, er spricht mit Gott, Gott erscheine ihm, er regiert, sein Geist macht Reisen in der ganzen Welt, in der Türkei, in den Niederlanden, in Rußland, er macht die Reise fliegend in Geistergestalt und sein Körper ist hier; sein Aufent. halt hier ist nur eine Beurlaubung; vor 4 Jahren hätte er einen großen Weltsturz vollendet, der Hauptfeind der Welt sei der Rothschild, der „Rumflieger".

Er werde schon über ihn ,herauskommen", und im nächsten Jahr die Regierung im Himmel antreten; er muß noch einmal absterben, er sei schon zweimal abgestorben; er roch 8 Tage nach Ton und plötzlich war er wie abgelebt; er sei der richtige Leichnam nach dem Gekreuzigten.

1. Dezember 1895. Ist äuferlich ganz geordnet und korrekt, hat sich in die Hausordnung vollkommen eingefügt, verrichtet kleine häusliche Arbeiten; spricht häufig vor sich, gestikuliert dabei, schimpft -.. alles Reaktion auf Halluzinationen. Er sei jetzt seit 4 Jahren der letzte Weltregent; trotzdem er so viel ist, arbeitet er hier, weil die Arbeit das neue System ist. Sein jetziger Vertreter im Himmel ist Ciprian, der 2. ist Moses, und zwar bei der Wasserregierung, und der 3. Columbus der erste Welterfinder, er selbst regiere von hier aus die Söhne, er habe 3 Köpfe, der eine sei der Mensch, der 2. der Sohn, der 3. der heilige Geist, die alte Sonne sei nicht mehr, sie sei ins Wasser heruntergefallen und er hätte dafür eine neue konstruiert; sie sei gebaut wie ein kleiner eiserner Ofen, vorne sei ein Loch und hinten die Ofentür, in dem Loch sind 2 Papiere und eine Glasscheibe, so daB sie einmal gelb und einmal weiß erscheinen kann; sie wird mit Gas geheizt; sein Dienstbuch habe er im Himmel.

1901. Zustand unverändert, spricht immer nur vom „Saturnus, dem alten und dem jungen, die ihn ständig mit ihren Brigaden verfolgen“. Begebenheiten aus seinem Leben erzählt er ganz richtig.

1906. Ist jetzt etwas verstumpft und sehr vergeßlich.

10. März. Exitus an Magencarcinom und Marasmus.

Fall 78. Mayer, Josef, 75 Jahre.

A nam nese. Galt schon seit längerer Zeit (Genaueres unbestimmt) als verrückt, stiehlt, was er kann, und wurde auch wegen Diebstahl dem Gerichte eingeliefert.

Beobachtung. 5. Dezember 1908 bis 29. April 1909. Pat. ist äußerlich ruhig, weiß Namen und Alter; besorgt sich selbst; dabei spricht er in einem fort in inkohärantem Gefasel, hält sich für Gott oder dessen nahen Verwandten, er verkehre mit dem Himnrel, Gott und den Heiligen, erzählt dazwischen zum Teil richtige, zum Teil wahnhafte Erlebnisse aus seinem Leben. 
Wird er etwas gefragt, gibt er darauf eine formal meist richtige Antwort und knüpft aber dann sofort mit dem gewohnten Gefasel an; schläft wenig, spricht auch in der Nacht in seinem gewohnten Gefasel.

Er sei neugeboren und zugleich Tausende von Jahren alt, sei ,göttlicher Sohn und göttlicher Vater".

29. April 1909. Exitus an einer Phlegmone des Beines.

In diesen beiden ziemlich identischen Fällen haben wir das Symptomenbild der inkohärenten katatonen Demenz mit Sprachverwirrtheit vor uns.

Fall 79. Pavlicek, Anton, 69 Jahre.

Anamnese: Keine.

1. Beobachtung.

Beobachtung. 25. Oktober bis 29. Dezember 1901. Ist zeitlich, örtlich und persönlich orientiert, sei seit vielen Jahren blind (hochgradige Amaurose wegen Retinitis pigmentosa). Pat. ziemlich selbstbewußt, spricht mit sehr gehobener Stimme. Aus seinem schwer verständlichen Redeschwall ist zu entnehmen, daß er schon lange Zeit sich verfolgt wähnt, erzählt von Erscheinungen der Muttergottes, von Engeln und Heiligen; behauptet, er spreche stündlich und täglich mit den Heiligen; behauptet, die heilige Maria liege mit ihm täglich im Bette.

1. November. Ist manchmal sehr ungeduldig, unfolgsam, behauptet, die heilige Maria will dies oder jenes nicht und will sich deswegen auch der Anstaltsordnung nicht fïgen; in eine Irrenanstalt transferiert; woselbst er sich bis 8. April 1906 befand.

\section{Beobachtung.}

20. Juni bis 12. Dezember 1906. Wird total verblödet eingebracht; spontan liegt er stumpf da, muß besorgt werden, ist unrein.

Auf Fragen gibt er höchst einsilbige, meist nicht zutreffende oder unzusammenhängende Antworten.

12. Dezember 1906. Exitus an lobulärer Pneumonie.

Fall 80. Rataj, Marie, 54 Jahre.

A namnese. Beginn vor $8 / 4$ Jahren, Kranke wurde nachlässig, kümmerte sich um nichts in der Wirtschaft mehr, ihre einzige Beschäftigung war, Feuer im Herd zu machen, auch dann, wenn es nicht nötig war; ist sehr wortkarg, will immerfort weglaufen.

Beobachtung. 8. September 1906 bis 4. August 1908. Zeigt das Bild stumpfeuphorischer Demenz, nennt Namen und Alter richtig, gibt auch auf einzelne Fragen einsilbige Antworten, gibt ihr Alter bald richtig an, bald behauptet sie, erst $30 \mathrm{Jahre}$ alt zu sein; einzelne kleine Rechenaufgaben löst sie richtig; ist ganz stumpf, kümmert sich um nichts, muß besorgt werden, zeitweise aber etwas un. ruhig, zieht sich aus, und behauptet unter blödem Lächeln, sie müsse nach Hause; so bleibt der Zustand unverändert.

10. Juni 1907. Total verblödet, lächelnder Gesichtsausdruck; das Lächeln verstärkt sich immer, wenn sie ausgefragt wird; sie gibt auf Fragen nur ibren Namen als Antwort, sonst schweigt sie; sich selbst überlassen, blickt sie stumpf vor sich hin, rührt sich stundenlang nicht, ißt selbst, muß aber sonst besorgt werden; verunreinigt sich, wenn sie sich selbst überlassen wird, und bleibt darin sitzen.

Bleibt unverändert bis zum Exitus, der am 4. August 1908 erfolgt, an Bronchopneumonie.

Hier liegt in beiden Fällen eine schwere einfache Verblödung vor, die im Falle 79 ein halluzinatorisches Vorstadium hatte. 
Fall 81. Kühnel, Franz, 60 Jahre.

A nam nese. Seit 2 Jahren kann er schlecht gehen; seit einem Jahre hat er häufig, manchmal mehrmals in der Woche Anfälle, die darin bestehen, daß er sich auszieht, auf den Boden setzt, und mit allem, was ihm gerade in die Hand kommt, spielt; dabei schreit er unartikuliert, läuft manchmal auch sehr rasch herum; nachher ist er wie betäubt, die Gehstörung ist noch stärker und vollkommene Amnesie besteht; war immer sehr hungrig und aß übermäßig viel; die Anfälle waren sehr häufig des Nachts.

Beobachtung. 18. September bis 26. Oktober 1908. 22. September. Ist persönlich, zeitlich und örtlich vollkommen orientiert, beklagt sich über diverse Schmerzen im Körper, weswegen er herkam, um Hilfe zu suchen.

3. Oktober. Nachts sprang er plötzlich aus dem Bette, zog sich nackt aus, ging zum Fenster und versuchte es, aufzumachen und schrie.

4. Oktober. Schläft nachts nicht, zog sich immer das Hemd aus, verlangte seine Kleider, wollte essen, man lasse ihn Hungers sterben.

11. Oktober. Ist jetzt sehr ärgerlich, behauptet, man prügle ihn.

12. Oktober. Schläft schlecht, hat jetzt häufig leichte Fiebersteigerungen, Bronchitis; murmelt unverständlich vor sich hin.

26. Oktober 1908. Exitus an Myomalacia cordis.

Fall 82. Mauthner, Jakob, 52 Jahre.

Anamnese. Vor 4 Jahren Ohrensausen, später Ohnmachtsanfälle, die angeblich auch mit Krämpfen vergesellschaftet waren; seit einem Jahre sehr vergeßlich, dement, leicht gereizt.

Beobachtung. 29. September 1905 bis 9. Oktober 1907. Dement, sehr gesprächig; ist so weit orientiert, daß er sich für krank hält, er hätte kein Gedächtnis, einige Minuten nachher vergesse er alles; vergißt auch sofort alles, hat aber ein ausgezeichnetes Gedächtnis für Zahlen, und rechnet im Kopfe sehr schnell und prompt. Er weiß, daß er Schwindelanfälle hatte, verkennt aber die Umgebung in wechselnder Weise.

5. Oktober. Ist an der Klinik ruhig, nur nachts will er manchmal weggehen; ist desorientiert, glaubt bald zu Hause zu sein, bald im Krankenhause; konfabuliert auch vereinzelt, behauptet, daß er gestern dort oder dort gewesen ist.

10. Oktober. Sehr unverträglich und gerät leicht in Zornaffekte.

17. Januar 1907. Heute ein epileptischer Anfall.

10. Juni. Klagt, er habe keinen Stuhl, gräbt sich den Kot aus dem After; kennt die Ärzte noch nicht.

1. Juni. Kennt bereits die Ärzte, ist jetzt örtlich und zeitlich orientiert, sonst in der gewohnten Weise dement und vergeßlich, aber nichts von Konfabulationen.

9. Oktober 1907. Exitus.

Beide Fälle lassen sich in das bisherige System der Psychosen sehr schwer einreihen; vielleicht könnte man sie am ehesten noch der Epilepsie zurechnen doch sind die Anhaltspunkte dazu nicht vollkommen einwandsfrei. Im Falle 81 sind dies die mit der Amnesie verbundenen, anfallsweise auftretenden Verwirrtheitszustände, welche trotz dem Fehlen von Krampfanfällen epileptischen Äquivalenten am meisten ähneln; im Falle 82 kamen vereinzelt epileptiforme Krämpfe vor, neben denen nur noch eine einfache Demenz bestand.

Fall 83. Fiala, Johann, 51 Jahre.

Anamnese. Seit vielen Jahren trinkt Pat. sehr viel; in der letzten Zeit 
ging es ihm schlecht, er wurde traurig, klagte sich an, er sei ein schlechter Mensch, er müsse sich das Leben nehmen; Intelligenzabnahme.

Beobachtung. 26. Januar 1909 bis 8 . Februar 1910. Pat. ist einfach dement; somatische Zeichen des chronischen Alkoholikers.

Fall 84. Bunzel, Johanna, 69 Jahre.

Anamnese. Pat. leidet seit 20 Jahren an chron. Gelenkrheumatismus; seit 6 Tagen hat sie allgemeine Zuckungen im ganzen Körper, jst sehr unruhig.

Beobachtung. 19. Mai bis 21, Mai 1909. Pat. befindet sich in ständiger Jaktation, bedingt durch fortwährende, zum Teil ausfahrende, zum Teil koordinierte Bewegungen der Extremitz̈ten, Herumrollen des Körpers, Grimassieren; an den Bewegungen ist auch die Zunge beteiligt, wodurch die Sprache erschwert ist. Pat. ist dabei sehr unruhig, schreit manchmal, wird ängstlich; wenn etwas mit ihr geschicht, wird sie ärgerlich; schläft sehr wenig; im Schlafe sistieren die Zuckungen.

21. Mai 1909. Exitus.

Fall 85. Trnka, Marie, 54 Jahre.

A nam nese. Vater hatte im Alter Chorea; Pat. hat seit 10 Jahren choreatische Zuckungen; in der letzten Zeit hätte sie „Halluzinationen“" gehabt und ist auch sehr aufgeregt und unruhig.

Beobachtung. 2. Dezember 1905 bis 4. Juli 1906. Typische Chorea progressiva mit Hypotonie der Extremitäten, dabei sehr unwirsch, Sprache der Sprachmuskeln sehr wenig verständlich, scheint aber sonst orientiert zu sein; nichts von Halluzinationen oder deliranten Zuständen.

4. Juli 1906. Exitus an Bronchopneumonie.

Fall 86. Mika, Wenzel, 55 Jahre.

Anamnese. Seit einem Jahr leidet er an Luckungen des ganzen Körpers, und allmählich wird er dement.

Beobachtung. 24. April 1908 bis 7. Dezember 1908. Pat. ist einfach dement; zeigt in allen Muskelgebieten ständig unkoordinierte Zuckungen, welche im Schlafe schwinden.

Fall 87. Janousek, Marie, 57 Jahre.

Anamnese. Pat. leidet schon mehrere Jahre an Tabes; seit 3 Wochen ist sie nachts unruhig, deliriert.

Beobachtung. 11. Februar bis 2. März 1908. Typische Tabes mit Sacral. decubitus und ständigem Fieber; ziemlich fortgeschrittene Demenz; nachts deliriert sie, wühlt ständig im Bette herum, wehrt Angriffe $a b$.

20. Februar. Depression, Decubitus und sonst unverändert.

2. März 1908. Exitus an Sepsis.

Fall 88. Kocourek, Franz, 60 Jahre.

Anamnese. Alkoholismus; seit einigen Tagen schlaflos, deliranter $\mathrm{Zu}$ stand mit massenhaften Halluzinationen.

Beobachtung. 18. Dezember bis 22. Dezember 1907. Pat. ist leicht benommen, sehr einsilbig, Sprache leicht verwaschen, manchmal versteht er auch Fragen nicht.

Somatisch nichts Besonderes; deliranter Zustand.

22. Dezember. Stark benommen, leichte Nackensteifigkeit, schlechter Puls, enge, reagierende Pupillen.

Nachmittag Exitus.

Pathologisch-anatomischer Befund. Typische tuberkulöse Meningitis.

Fall 89. Novák, Josefine, 82 Jahre.

Anamnese. Keine. 
Beobachtung. 8. bis 9. Januar 1906. In sehr verwahrlostem Zustande eingebracht, verlaust, schweres Emphysem und Ödem des Gesichts und der Extremitäten; ist sehr ängstlich, hatte Angst vor dem Ertrinken (Reinigungsbad). Nachts delirierte sie, glaubt, daß Personen ins Wasser gehen, und warnt sie davor; liegt aber dabei ganz ruhig mit durch Ödem geschlossenen Lidern da. Fieber.

9. Januar. Gibt ruhig Namen und Alter an, und sagt nur, sie sei Bettlerin, mehr Fragen beantwortet sie nicht, stöhnt nur, man möchte sie in Ruhe lassen.

Plötzlicher Exitus nachmittag.

Pathologisch-anatomische Diagnose. Marasmus universalis. Thrombosis auriculae cordis dextrae. Embolia ramorum arter. pulm. Bronchitis supp. Ödema pulmonum.

Die letzten sieben Fälle sind durchweg schwerere Cerebralerkrankungen, die durch verschiedene Ursachen bedingt sind: Fall 83 ist eine alkoholische Demenz; Fall $84-86$ sind Choreaerkrankungen des höheren Alters; Fall 87-89 Fieberdelirien bei Sepsis, tuberkulöser Meningitis und bronchitischem Fieber einer marantischen Greisin.

Auf Grund des vorliegenden Materiales wollen wir nun im Sinne unserer Fragestellung untersuchen, ob die klinische Symptomatologie der Fälle mit Sphärotrichie derart einheitlich ist, daß man imstande wäre, diesem anatomischen Krankheitsprozeß auch ein klinisches Krankheitsbild anzugliedern. Utberblicken wir zu dem Zwecke die betreffenden Krankengeschichten!

Die klinische Zusammengehörigkeit der Fälle 1-41, welche die überwiegende Mehrzahl darstellen, erscheint wohl außer Zweifel; sie zeigen ein Krankheitsbild, welches sich zusammensetzt aus einer Demenz stärkeren Grades und einer hochgradigen Störung der Merkfähigkeit, die mit Konfabulationen einhergeht, wozu sich bei einem Teil der Fälle ein Delirium zugesellt; wir haben also einen Symptomenkomplex vor uns, in dem wir die von Wernickeals Presbyophrenie geschilderte Krankheit des Seniums erkennen. Bei einer kleinen Gruppe der Fälle trat eine stumpfe Demenz dazu; die Krankheitsdauer dieser letzteren Fälle betrug durchschnittlich das Doppelte als die der Fälle ohne Verstumpfung, woraus zu ersehen ist, daß dieVerstumpfung ein Endstadium dieser Krankheit darstellt, die aber selbstverständlich nur dann zur Beobachtung gelangt, wenn der Kranke genügend lange am Leben bleibt; die meisten erleben diesen Zustand eben nicht.

Zu den Fällen, bei denen sich die konfabulierende Merkfähigkeitsstörung mit einem deliranten Zustand kombiniert, reiht sich als ein interessanter Anhang der Fall 33 an, bei dem die Psychose eigentlich nur in einem akuten Delirium bestand, das schnell zum Tode führte. Wir sehen also hier das Delirium von den anderen Symptomen quasi isoliert und durch die gleiche anatomische Veränderung hervorgerufen. Derselbe Fall ist aber noch dadurch bemerkenswert, daß ein ganz ähnlicher deliranter Zustand bereits ein Jahr vorher bestanden hat, der 
vollkommen ausgeheilt war. War dieses erste Delirium auch schon der Ausdruck derselben Cerebropathie, oder aber war es ein anderes selbständiges, vielleicht alkoholisches Delir? Zur Beantwortung dieser Frage haben wir noch wenig beweisende Anhaltspunkte. Wenn man die Erfahrung Wernickes berücksichtigt, der mitteilt, daß unter Umständen die Presbyophrenie auch ausheilen kann, dann könnte man auch für diesen Fall annehmen, daß das erste Delirium nur ein Initialstadium einer intermittierend verlaufenden Erkrankung war; dafür würde auch die große Ähnlichkeit der beiden Delirien sprechen. Auch im Falle 42 sehen wir eine Art Heilung der Presbyophrenie; da blaßte die konfabulierende Merkfähigkeitsstörung nach beinahe einjähriger Dauer ab, und es verblieb nur eine starke einfache Vergeßlichkeit mit leichter Demenz und voller Krankheitseinsicht, also eine Art von Heilung mit nur geringem Defekt. Dadurch ergibt sich auch eine Ähnlichkeit mit den Fällen, die in stumpfer Verblödung endeten, nur daß bei diesen der Defekt viel schwerer war; diesen Unterschied erklärt uns auch die histologische Untersuchung; im Falle 42 waren die Drusen in spärlicher Zahl im Gehirn vertreten, wogegen die anderen Gehirne in viel stärkerem Maße ergriffen und destruiert waren.

Für die klinische Beurteilung des Materiales ist von besonderer Wichtigkeit der Fall 48, der zuerst nur an einer einfachen senilen Demenz erkrankt war und erst später die Symptome der konfabulierenden Merkfähigkeitsstörung und des halluzinatorischen Verfolgungswahns zeigte. Dadurch wird der letztere Fall zu einem Bindeglied zwischen der Gruppe der ersten Fälle und den Fällen 43-46 resp. 47, bei denen neben der Demenz nur noch ein paranoisches Zustandsbild zur Entwicklung kam. Auch diese Fälle leiden an Halluzinationen, doch treten dieselben nicht in deliriöser Massenhaftigkeit auf, sondern setzen sich zu einem paranoischen Komplex zusammen.

Die klinische Zusammengehörigkeit all der bisher besprochenen Fälle dürfte danach wohl kaum einem Zweifel unterliegen; dazu liefert dann die gleichartige anatomische Veränderung eine in jeder Hinsicht beweiskräftige Basis.

In der soeben besprochenen Gruppe hätten wir dann drei verschiedene klinische Symptomenkomplexe vertreten, die zum Teil einzeln und selbständig auftreten können; dies sind:

1. das presbyophrene Delirium;

2. die konfabulierende Merkfähigkeitsstörung;

3. der paranoide Symptomenkomplex.

Diese eigenartige Zusammenstellung der Symptome erinnert in hohem Maße an die alkoholischen Psychosen. Wernicke hat bereits auf die symptomatologische Ähnlichkeit der 
Presbyophrenie mit dem alkoholischen Korsakoff aufmerksam gemacht, doch geht diese Ähnlichkeit noch weiter; es läßt sich nämlich das Delirium, die konfabulierende Merkfähigkeitsstörung und die Paranoia der Senilen in jeder Hinsicht dem Delirium tremens, der Korsak offschen Psychose und der alkoholischen Paranoia zur Seite stellen. Genau so wie bei unseren presbyophrenen Formen, sehen wir auch bei den alkoholischen Psychosen allerlei Übergangsformen, und auch die klinische Ähnlichkeit der alkoholischen Störungen mit den presbyophrenen ist so weitgehend, daß man dieselben eventuell voneinander gar nicht differenzieren könnte, wenn man nicht gerade ätiologische Unterscheidungsmerkmale hätte.

Diese Parallele mit den alkoholischen Psychosen ist nicht ohne Bedeutung. Wir haben die gemeinsame anatomische Basis der eben besprochenen Krankheitsgruppen erwiesen, wir haben Gründe für eine klinische Zusammengehörigkeit angeführt, und wenn wir jetzt zeigen können, daß bei einer anderen Psychose, deren einheitliche Ätiologie bereits außer Zweifel steht, ähnliche Symptome in ähnlicher Gruppierung regelmäßig vorkommen, so gewinnen dadurch unsere Folgerungen eine neue beweisende Basis.

Der restliche kleinere Teil unseres Materiales zeigte auch meistens delirante oder konfabulatorische Züge von mehr oder weniger ausgesprochenem Charakter; doch traten dabei noch einzelne, sonst nicht beobachtete Symptomenkomplexe hinzu; so gibt es da Fälle mit manischem und solche mit melancholischem Symptomenkomplex, dann aber auch Fälle, bei denen katatone Symptome so in den Vordergrund getreten waren, daß sie einer Dementia praecox zum Verwechseln glichen.

Bei der klinischen Durchsicht unseres Materiales ergab sich also bisher, daß sich zwar auf Grund einer gleichen Cerebralveränderung ziemlich mannigfaltige klinische Symptome entwickeln, immerhin läßt sich aber durch dieses scheinbar wirre Durcheinander von Symptomen ein gemeinsamer Symptomenkomplex wie ein roter Faden verfolgen: eine Demenz mit Halluzinationen, schweren Merkdefekten und Konfabulationen. Alle diese Symptome können sich auch noch in verschiedener Stärke kombinieren; wen $\mathbf{n}$ sich die Halluzinationen sehr häufen, kommt es zum senilen Delirium, das Überhandnehmen der Merkdefekte und der Konfabulationen führtzur Wernickeschen Presbyophrenie, die allein ohne Delirium vorkommen, sich aber noch mit dem senilen Delirium kombinieren kann. Die Halluzinationen können auch noch paranoiden Charakter annehmen - dann entsteht das Krankheitsbild der senilen Paranoia. Weiter können auch noch Stimmungsstörungen sowohl 
maniakalischen, als auch melancholischen Charakters hinzutreten, und schließlich auch katatone symptome, wodurch die Fälle jeweilig eine besondere Färbung bekommen.

Dazu muß noch bemerkt werden, daß sich nicht alle der untersuchten Fälle leicht in dieses System einfügen lassen; es ist dies zwar ein verschwindend kleiner Teil — nur drei Fälle —, aber auch die wollen berücksichtigt werden. Dazu gehören die Fälle 52 und 53, welche klinisch nichts anderes als eine stark gehemmte Melancholie darboten, und dann der Fall 56, der ganz unter dem Bilde einer schweren katatonen Demenz verlief, und bei dem das ständige Herumnesteln, wenn auch entfernt, an das Beschäftigungsdelir der senilen Deliranten erinnerte. Diese Fälle sind aber Ausnahmen, die sich dennoch erklären und einreihen lassen. Denn auch bei den Fällen unseres Systems wurden melancholische und katatone Symptome ab und $\mathrm{zu}$ beobachtet; man braucht nur anzunehmen, daß dieselben die anderen Symptome, wenn ich so sagen darf, überwucherten resp. daß die anderen Symptome auf Grund der melancholischen und katatonen Hemmung nicht hervortreten konnten, und man kommt zu einer ganz plausiblen Erklärung. Etwas Derartiges ist aber in der Psychiatrie nichts Neues. Ich erinnere hier nur an die Paral y sef rage; da konnte ich ${ }^{1}$ ) im Anschlusse an Nissl und Alzheimer und in Verfolgung der Kraepelinschen Lehre, daß zur Klassifizierung in erster Linie der pathologische Prozeß zu berücksichtigen ist, zeigen, daß es zweifellose Paralysen gibt, die in ihrem Verlaufe hin und wieder eine andere Psychose imitieren können; es zeigen sich bei diesen Fällen zwar im späteren Verlaufe denn doch die spezifischen paralytischen Symptome, aber zur Zeit, wo die letzteren noch fehlen, ist dann die richtige Diagnose immerhin sehr erschwert, wenn nicht ganz unmöglich. Dabei haben wir es bei der Paralyse noch in mancher Hinsicht viel leichter. Denn da gibt es eine ganze Reihe somatischer Veränderungen, serologischer und cytologischer Eigentümlichkeiten, welche für die Paralyse typisch resp. spezifisch sind derartiges existiert bei der Presbyophrenie aber nicht, deswegen ist auch ein solcher Standpunkt viel schwieriger zu verteidigen.

Aber außer bei der Paralyse sehen wir auch noch bei anderen, allgemein als selbständige Erkrankungen angesehenen Psychosen, daß sie nicht immer den typischen klinischen Symptomenkomplex darbieten, sondern auch manchmal andere Psychosen imitieren: so bei der Dementia praecox, wo auch melancholische, manische, paranoische und Verwirrtheitszustände vorkommen, so auch bei der Epilepsie und der Hysterie.

Die hier geschilderten Krankheitsbilder des Seniums sind im Prinzip nichts Neues; in allen diesbezüglichen Bearbei-

1) Referat über die Lues-Paralyse-Frage. Allg. Zeitschr. f. Psych. 1909. 
tungen und Lehrbüchern findet man unter der Symptomatologie der senilen Demenz auch die hier angeführten Symptomenkomplexe. Die senile Demenz wird daselbst auf die ins Pathologische gesteigerte senile Involution des Gehirns zurückgeführt, die eine pathologische Einbuße der gesamten psychischen Tätigkeit zur Folge hat; und zu dieser Demenz treten manchmal einzelne der geschilderten Symptome hinzu, als: die konfabulierende Amnesie, halluzinatorische Zustände, Verwirrtheit, manische und melancholische Dysthymien. Aus diesen Krankheitsbildern hob Wernicke die amnestisch-konfabulatorische und die delirante Form als eine besondere Abart heraus und nannte sie Presbyophrenie. Kraepelin schildert in seiner Psychiatrie bei der Symptomatologie der Dementia senilis die einfache senile Verblödung, die Wernickesche Presbyophrenie, deliriöse Zustände, den senilen Verfolgungswahn und depressive und maniakalische Verstimmungen, die aber zum manisch-depressiven Irresein zugerechnet werden. Bei der Schilderüng der anatomischen Veränderungen sagt Kraepelin: „Allerdings scheint der Krankheitsvorgang beim Altersblödsinn nicht immer derselbe zu sein, wie wir ja auch klinisch eine Reihe verschiedener Formen auseinanderhalten. Einstweilen ist es jedoch nicht möglich, zwischen den einzelnen klinischen und anatomischen Bildern nähere Beziehungen herzustellen."

Also rein auf Grund der großen klinischen Differenzen postuliert Kraepelin eine verschiedene pathologisch-anatomische Cerebralerkrankung als Ursache der senilen Psychosen - wir gingen den umgekehrten Weg und suchten für eine bestimmte Hirnerkrankung der Senilen die zugehörigen Symptome. Die Sphaerotrichia cerebri ist eine so scharf charakterisierte Hirnveränderung, daß sie - gleichgültig wie auch deren biologische Erklärung ausfallen mag - als eine Cerebralerkrankung sui generis aufgefaßt werden muß; wenn dann auch dazugehörige Symptome gefunden werden können, die sich durch eine gewisse Einheitlichkeit auszeichnen, dann ist die Sphärotrichie nicht nur eine eigenartige pathologische Veränderung des Gehirns, sondern eine Krankheit im anatomischen und klinischen Sinne.

Wir sind also imstande, die senilen Psychosen in folgende 2 Gruppen einzuteilen:

1. in Fälle mit einfacher Hirnatrophie - das sind die einfachen senilen Demenzen,

2. in Fälle mit der Sphaerotrichia cerebri multiplex, welche den gerade besprochenen Symptomenkomplex darbieten, für den ich den Terminus „Presbyophrene Demenz“" vorschlagen würde.

Presbyophren deshalb, weil erstens die Wernickesche Presbyo- 
phrenie das Hauptkontingent der Fälle ausmacht, und zweitens, weil sich die einzelnen Symptome der Presbyophrenie bei den allermeisten der Fälle immer wieder nachweisen lassen; presbyophrene Demenz deshalb, weil der Name Presbyophrenie bereis für ein enger umgrenztes Krankheitsbild geprägt worden ist, und alle Fälle dieser neuen Gruppe, wenn nicht immer am Anfang, so wenigstens doch später eine ausgesprochene Demenz zeigen.

Der soeben erhobene Zusammenhang der Sphaerotrichia cerebri mit der presbyophrenen Demenz läßt sieh aber noch anderweitig begründen.

Im anatomischen Teil wurde erwähnt, daß wir allen Grund haben, den Drusen, je nach ihrer Beschaffenheit und Größe, auch ein verschiedenes Alter zuzusprechen. Wenn dies richtig ist, wenn anderseits die Sphärotrichie die Ursache der Geistesstörung ist, dann müßte sich auch nachweisen lassen, daß die Dauer der Krankheit in einem gewissen Verhältnis zum histologisch nachweisbaren Alter resp. Größe der Drusen steht, d. h. die jüngsten Fälle müßten die kleinsten, die ältesten Fälle die größten und ältesten Drusen aufweisen. Es ist wohl klar, daß eine derartige Frage eigentlich nur auf Grund von Durchschnittszahlen, die einem größeren Materiale entstammen, beantwortet werden kann, weil ja mit der Größe des Materiales auch die Fehlerquellen sinken. Und gerade bei den Senilen ist der Beginn der Erkrankung oft sehr schwer zu bestimmen, da entweder der Anfang der Krankheit bei den an und für sich schon verstumpften Greisen von der Umgebung nicht bemerkt wird, oder weil es den Kranken gar nicht so selten an einer aufmerksamen Umgebung mangelt. Um die Fehlerquellen soviel als möglich zu reduzieren, wurden nicht die einzelnen Fälle verwendet, sondern es wurde die Durchschnittsdauer der einzelnen Gruppen berechnet; zu diesem Zwecke wurde das gesamte untersuchte Material in drei Gruppen eingeteilt. Die erste Gruppe bestand aus Fällen, die Drusenstadien I-III enthielten. Die zweite Gruppe bezog sich auf die Fälle, die nur die Stadien III und IV aufwiesen, und die dritte Gruppe hatte Fälle mit den Drusenstadien IV und V.

Zur ersten Gruppe gehören die Fälle 1, 6, 9, 17, 18, 21, 30, 40, 45, 50. Die Dauer der Erkrankung wurde bei den einzelnen Fällen aus den anamnestischen Angaben und der Länge der Beobachtungszeit berechnet; die Summe der Gesamtdauer all dieser 10 Fälle macht 59 Monate aus, folglich beträgt die durchschnittliche Krankheitsdauer der Fälle dieser Gruppe 6 Monate.

Zur zweiten Gruppe gehören die Fälle 4, 7, 11, 12, 13, 14, 15, 22, 24, $25,27,29,37,42,46,47,48,51,52,54,55$ und 56. Bei diesen 22 Fällen betrug die Gesamtdauer 429 Monate, also bekommt man als Durchschnittsdauer $191 / 2$ Monate. 
Zur dritten Gruppe werden folgende Fälle gerechnet: 2, 10, 19, 34, 35, 36, 38, 39 und 43. Bei diesen 9 Fällen betraf die Gesamtsumme 337 Monate, woraus die Durchschnittsdauer von 37 Monaten resultiert.

Einen besseren Beweis kann man wohl nicht verlangen. Doch möchte ich noch erwähnen, daß bei der großen Zahl der Fälle und der großen Differenz der erhaltenen Zahlen ein Zufall wohl so gut wie ausgeschlossen ist. Trotzdem wurden verschiedene Gegenproben versucht, indem das Material nach anderen histologischen Eigentümlichkeiten zusammengestellt wurde; also nach der Größe und Zahl der Keulen, nach der Schwere der Zellerkrankung und nach der Art der Gefäßveränderung, und wie man auch diese Gruppen zusammenstellte, so kam doch immer nur eine annähernd gleiche Durchschnittsdauer heraus, die zwischen 18-20 Monaten schwankte.

Wenn wir jetzt von Größe und Alter der Drusen sprachen, so hatten wir nur die Stadien I-V vor Augen; die Stadien VI-VIII haben wir nicht berücksichtigt; zu statistischen Vergleichen können die Stadien VI und VII nicht herangezogen werden, weil sie nur bei sehr wenigen Fällen vorgefunden wurden. Dagegen hat sich die Formation VIII, d. h. die diffuse Infiltration des Gewebes durch die Fädchenmassen, bei mehreren Fällen vorgefunden, so daß eine statistische Zusammenstellung versucht werden konnte. Vom anatomischen Standpunkte ist die Beurteilung des Alters dieses Stadiums sehr schwierig; trotz ihrer räumlichen Größe kann aber diese Formation nicht als sehr alt angesehen werden, da eine scharfe Abgrenzung gegen das nervöse Gewebe fehlt; es macht vielmehr den Eindruck, daß sich die Fädchen schneller als sonst und in größeren Massen bilden und das Gewebe erdrücken. Weiter kann man aus der Dauer der Erkrankung der dieses Stadium enthaltenden Fälle auf das Alter dieser Formation selbst schon deswegen nicht schließen, weil dieses Stadium immer neben den anderen, wohl älteren vorkommt.

Das Stadium VIII fand sich bei folgenden 14 Fällen: 1, 9, 12, 17, $18,22,25,28,29,30,33,50,51$ und 55. Von all diesen Fällen waren mit Ausnahme der Fälle 1, 50 und 51 alle wenigstens gegen Ende der Erkrankung delirant; man könnte also auch annehmen, daß dieses infiltrierende Stadium mit der deliranten Phase der Psychose in ätiologischem Zusammenhang stehen könnte, welcher Zusammenhang darin liegen würde, daß das Delirium, welches doch einem stärkeren Reizzustande der Hirnrinde entspricht, durch eine mehr diffuse und intensiver wirkende Schädigung verursacht wird, die die nervösen Elemente nicht mehr verdrängt, sondern direkt und in größeren Mengen zerstört. Wenn nun dieses Stadium das Delirium wirklich erzeugt, so sollte man auch aus der Durchschnittsdauer des deliranten Zustandes auf 
das Alter des Stadiums schließen können, vorausgesetzt, daß der delirante Zustand auch immer bis zum Tode angedauert hat; bei allen den Fällen traf letzteres auch tatsächlich zu. Bei diesen 11 Fällen betrug nun die Durchschnittsdauer der ganzen Erkrankung 13 und die des deliranten Zustandes 5 Monate, jedenfalls ein interessantes Resultat, das die anatomische Annahme, daß das Stadium VIII jüngeren Datums ist, weiter festigt. Von den anderen Fällen könnte man den Fall 50 und 51, die eine starke maniakalische Erregung zeigten, auch in gewisser Hinsicht zuzählen, der Fall 1 zeigte aber nichts Delirantes. Es ist jedenfalls interessant und nicht als zufällig anzusehen, $\mathrm{daBmehr}$ als ein Drittel der deliranten Fälle dieses infiltrative Stadium aufwies und daß anderseits unter 14 Fällen mit infiltrativem Stadium 11 ein terminales Delirium darboten; zweifellos spricht dies für einen, wenigstens teilweise zutreffenden ätiologischen Zusammenhang.

Bei dem so massenhaften Auftreten der Drusen in den betroffenen Gehirnen ist es nur verwunderlich, daß nicht mehr schwerere Defekte oder Lähmungssymptome sich zeigen; denn trotz schwerster Veränderung der einzelnen Projektionszentren war bei keinem Fall ein gröberer merkbarer Ausfall deren somatischer Funktion zu verzeichnen, und diejenigen Fälle, welche Lähmungen oder andere somatische Ausfallserscheinungen cerebraler Genese darboten, hatten an der entsprechenden Stelle gröbere Hirndefekte, bedingt entweder durch Erweichung oder durch den ",spongiösen Rindenschwund“.

Die Sphärotrichie ist demnach eine die Rinde diffus befallende und das Gehirn in seiner Gesamtfunktion schädigende Erkrankung. Ein derartiges Verhalten sehen wir auch noch bei allen Psychosen, für die eine histopathologische Veränderung des Gehirns feststeht. So verhält sich die progressive Paralyse, die Schlafkrankheit, die amaurotische Idiotie, dasselbe Verhalten fand man auch schon bei der Dementia praecox. Wie bei allen diesen Krankheiten die Symptomatologie - wegen der diffusen Hirnschädigung nicht von der Lokalisation abhängen kann, so muß auch bei der presbyophrenen Demenz dieklinische Eigenart eben auch nur in der Besonderheit des pathologischen Prozesses ihre Ursache haben. Diese Besonderheit kann entweder in der durch die Drusen verursachten Schädigung der nervösen Elemente oder in einer Art von Giftwirkung gesucht werden; ersteres ist durch die histologisch sichtbare Schädigung der an die Drusen angrenzenden Achsencylinder erwiesen, letzteres wird durch die diffusen schweren Ganglienzellsehädigungen wahrscheinlich gemacht.

Bei der Paralyse kommt es aber außer den durch die diffuse Cerebropathie verursachten Symptomen noch häufig zu speziellen Ausfalls- 
erscheinungen, welche auf eine stärkere Erkrankung in einem Projektionszentrum zurückgeführt werden können; etwas Derartiges könnte man auch hier erwarten; doch konnte ich unter meinen Fällen keinen derartigen Fall ausfindig machen, was um so bemerkenswerter ist, als bei vielen Fällen die Rinde durch die massenhaft aufgetretenen Drusen intensiv geschädigt sein mußte.

In allen von der Sphärotrichie befallenen Gehirnen fanden sich auch schwere Veränderungen der Ganglienzellen, der Neuroglia und der Gefäße; je nach der Art dieser Veränderungen wurden alle Fälle gruppiert und deren Symptome zusammengestellt - aber dieser Versuch führte zu keinem Resultat, das diesen Veränderungen irgendeine nennenswerte klinische Bedeutung zusprechen könnte.

Nach dem bisherigen Resultat unserer Untersuchungen könnten wir auf Grund einiger weniger klinischer Symptome ganz leicht und sicher die durch die Sphärotrichie gesetzte Veränderung erkennen. Doch gar so einfach ist die Sache nicht, a uch hier gibt es ein kleines „,aber", welches eine Anzahl von Fällen schwerer arteriosklerotischer Hirnveränderung darstellt. Bisher habe ich nur diejenigen Fälle von arteriosklerotischer Erweichung des Gehirns angeführt, bei denen sich auch die Sphärotrichie nachweisen ließ; es sind dies die Fälle 9, 10, 15, 16, 24 und 53 .

Die übrigen sollen jetzt folgen:

Fall 90. Becan, Josef, 48 Jahre.

Anamnese. Seit 6 Jahren rechtsseitige Hemiplegie mit Sprachverlust.

Beobachtung. 21. April 1901 bis 22. April 1907. Rechtsseitige Hemiplegie mit motorischer Aphasie, starke Arteriosklerose; nur leichte Demenz.

Im Gehirn fand sich eine alte Erweichung im Gebiete der Art. fossae Svlvii der linken Seite.

Fall 9]. Bousa, Josef, 61 Jahre.

Anamnese. Seit 1/2 Jahr sehr reizbar, woraus häufig Tobsuchtsanfälle resultieren; von Schlaganfall nichts bekannt.

Beobachtung. 8. Dezember 1907 bis 26. März 1908. Linksseitige Hemiplegie, leichte Verstumpfung, sonst vollkommen orientiert.

22. März. Unverständlich paraphatischer Jargon, wirft immer die Decke weg.

23. März. Leichte Temperatursteigerung von 37,8 , zerreißt nachts das Hemd, wollte vom Bette weggehen.

25. März. Starke Parotitis, starkes Fieber.

26. März 1908. Exitus.

Im Gehirn fanden sich in beiden Sehhügeln und beiden Linsenkernen mehrere kleine cystische Erweichungen. Sonst bestand leichte Atrophie.

Fall 92. Farkac, Ludmilla, 52 Jahre.

Anamnese. Seit 2 Jahren zunehmende Schwäche und Sprachstörung; wird stumpf und dement; manchmal ist sie ohne Ursache auf die Umgebung sehr böse, schimpft, schlägt die Umgebung, will dann weglaufen; klagt viel über Kopfschmerzen.

Beobachtung. 7. Mai bis 1. August 1905. Linksseitige leichte Hemiplegie mit Hemianopsie; einfach dement und stumpf. 
Dementsprechend war der ganze Cuneus der rechten Seite vollkommen erweicht, und im Linsenkern derselben Seite saßen mehrere kleine cystische Erweichungen. Starke Arteriosklerose besonders der cerebralen Gefäße.

Fall 93. Hellebrand, Johann, 61 Jahre.

Anamnese. Vor 2 Tagen verlor er die Sprache.

Beobachtung. 2. November 1903 bis 20. Oktober 1904. Wird in etwas benommenen Zustande eingebracht; totale Aphasie, dieselbe besserte sich im Laufe einer Woche, bis zu einer Paraphasie, und schließlich verblieb nur eine leichte amnestische Aphasie.

2. Januar. Pat. wird jetzt ganz geordnet, einfach dement, euphorisch und sehr vergeßlich ohne Konfabulationen.

15. März. Anfälle von Sopor mit rechtsseitiger Deviation conjugée; nachher Auftreten einer rechtsseitigen Hemianopsie.

10. April. Wesentlich dementer.

Im Gehirn saßen im Bereiche des linken Linsenkerns und im Pons mehrere kleine cystische Erweichungen, weiter befand sich im linken Linsenkern eine linsengroße frische Blutung. Starke Arteriosklerose.

Fall 94. Hos podsky, Josefine, 72 Jahre.

Anamnese. Heute früh in schweren choreatischen Krämpfen der linken Seite vorgefunden.

Beobachtung. 19. bis 22. Juli 1907. Schwerer linksseitiger Hemiballismus; psychisch normal.

Bei der Untersuchung des Gehirns fand sich eine bohnengroße frische Blutung im rechten Corpus subthalamicum.

Fall 95. Klein, Eduard, 55 Jahre.

Anamnese. Vor 3 Jahren ein rechtsseitiger Schlaganfall mit Sprachverlust; nach einigen Tagen Besserung der Sprache; vor 8 Monaten linksseitiger Schlaganfall; vor 3 Wochen Bewußtlosigkeit, nachher sprach er ganz unsinnig.

Beobachtung. 3.)bis 10. Januar 1910. Rechtsseitige Hemiplegie, sehr herabgekommenes Individuum; stumpf, soporös; spricht sehr wenig, nestelt mit der linken Hand herum; auf Ansprache bekommt man nur wenig und sehr einsilbige Antworten, die zum Teil auch paraphatisch sind.

Im Gehirn in beiden Hemisphären mehrere kleine eystische Erweichungen in dem Schwanz- und Linsenkern.

Fall 96. Kosik, Josef, 83 Jahre.

Anam nese. Pat. erlitt vor 5 Wochen einen Schlaganfall, war nachher 3 Wochen „bewußtlos, redete wirres Zeug". Dann war die Sprache schlecht und unverständlich, er wurde sehr reizbar und jähzornig.

Beobachtung. 23. Januar 1900 bis 27. September 1908. Reizbarer egoistischer Alter, der sich mit niemandem vertragen kann; leichte einfache Demenz, ausgesprochener Agrammatismus; Zustand bleibt unverändert bis zum Exitus.

In beiden Schläfelappen, und zwar an symmetrischen Stellen der 2. Schläfewindung fanden sich ältere Erweichungsherde.

Fall 97. Matousek, Josef, 69 Jahre.

A na m nese. Vor 8 Jahren linksseitige Hemiplegie; seit 2 Jahren zunehmende Vergeßlichkeit, will häufig weglaufen, trotzdem er sich kaum fortbewegen kann; kennt die Umgebung nicht; ist unrein.

Beobachtung. 9. Mai bis 7. Oktober 1904. Linksseitige Hemiplegie; ist sehr stumpf, unrein, interesselos, die Sprache langsam, schlecht artikuliert.

Weiß sein Alter nicht, weiß, wo er war und daß er schon längere Zeit krank ist; weiß, daß er an der linken Seite vom Schlag getroffen wurde; kennt alle ihm 
gezeigten Gegenstände und bezeichnet sie richtig; weiß, daß er gerade hergekommen ist.

10. Juni. Liegt stumpf da, spricht spontan nichts, unrein; muß gefüttert werden, nachts schläft er meist, manchmal schreit er, so wie wenn er jemanden rufen wollte.

11. Juni. Sehr stumpf; auf alles, was er gefragt wird, antwortet er heute mit „nein".

Wäre nicht bei der Bahn gewesen, hätte keine Frau, hätte nicht beim Militär gedient, trotzdem er im Anfang erzählte, wo er gedient hat und daß er auch einen Feldzug mitgemacht hatte; daß er nicht verheiratet ist und keine Kinder habe. Wo er ist, weiß er nicht.

20. Juli. Einfach dement, stumpf.

7. Oktober 1904. Exitus an Marasmus.

Das Gehirn stark atrophisch; im rechten Nucleus lentiformis 2 kleine cystische Erweichungen.

Fall 98. Steyrer, Camil, 5l Jahre.

Anamnese. Seit 2 Jahren klagte er über Ohrensausen, hatte wiederholt Schwindelanfälle, soll auch einigemal vollkommen bewußtlos gewesen sein; zunehmende Vergeßlichkeit, jetzt bettlägerig.

Beobachtung. 30. Dezember 1905 bis 1. Februar 1906. Sehr herabgekommen, stumpf, manchmal weinerlich; kommt auch manchmal ins Zwangsweinen; sehr dekrepid, beide Beine steif, kann kaum gehen; ist ziemlich orientiert, hat Krankheitsansicht; nichts von Konfabulationen.

Das Gehirn stark atrophisch; im Markweiß, in den Stammganglien beider Seiten und im Pons viele ganz kleine cystisch resorbierte Erweichungsherde.

Fall 99. Tiegl, Dagobert, 63 Jahre.

A namnese. Starker Alkoholiker, in der Jugend Lues. Seit 6 Jahren dement und roh; nichts von Sehlaganfällen beobachtet.

Beobachtung. 18. Oktober 1904 bis 10. April 1910. Pat. zeigt eine einfache stumpfe Demenz, die sich später noch steigert, so daß er in schwerer Demenz an Marasmus zugrunde geht.

Im Gehirn zeigte sich starke Atrophie, die Ventrikel erweitert, in den Stammganglien beider Seiten und im Pons mehrere cystische Erweichungen, basalen Gefäße verdickt.

Fall 100. Vacek, Franz, 73 Jahre.

A nam nese. Seit 4 Wochen Kopfschmerzen, seit einer Woche rechtsseitige Hemiplegie, ohne Bewußtseinsverlust entstanden.

Beobachtung. 16. September 1907 bis 5. März 1909. Hat eine rechtsseitige Hemiplegie und Hemianopsie. Versteht Ansprache zum größten Teil, antwortet aber darauf nur in Paraphasie; keine Apraxie; Pat. ist attent, merkt seine Defekte, ist häufig darüber weinerlich, sonst scheint er immer orientiert, mit der Zeit bessert sich die Sprachstörung etwas. Zum Schluß unrein, mit häufigen Zwangsweinen.

5. März 1909. Exitus.

In der linken Hemisphäre der Occipitalpol vollkommen erweicht; dịe Erweichung erstreckt sich auch auf die hintere Partie des Parietallappens und die hintere Partie des Schläfelappens.

Fall 101. Zika, Ludwig, 52 Jahre.

Anamnese. Potator gewesen. Vor 8,6 und vor $1 \mathrm{Jahr}$ Schlaganfälle; seit dem letzten Anfall rechtsseitige Lähmung, Sprachstörung, Vergeßlichkeit und Verblödung. 
Beobachtung. 5. Februar 1908 bis 10. Februar 1910. Rechtsseitige Hemiplegie mit sensorischer Aphasie, einfache Demenz mit leichter Verminderung der Merkfähigkeit; die Demenz steigert sich, er wird stumpf und marantisch.

Das Gehirn von außen atrophiert, die Ventrikel erweitert, der linke Nucleus jentiformis durch eine alte Erweichung total zerstört.

Fall 102. Ascher, Hubert, 62 Jahre.

Anamnese. Vor $1 / 2$ Jahr rechtsseitige Hemianopsie ohne Schlaganfall aufgetreten; 6 Wochen später wurde Pat. nachts bewußtlos aufgefunden, beim Aufkommen bestand Ungeschicklichkeit der rechten Hand und Verschlechterung der Sprache; allmählich wurde er vergeßlich und reizbar. In der letzten Zeit lustige Verstimmung, große Geschäftigkeit und Größenideen.

Beobachtung. 2. Dezember 1904 bis 12. Mai 1905. Pat. ist somatisch sehr herabgekommen, hat eine leichte Facialisparese, rechtsseitige Hemianopsie; die Sprache ist sehr langsam, stolpernd, manchmal bebend; die Pupillen weit, entrundet, ungleich und lichtstarr; starker Tremor der Zunge und Finger, Schrift mühsam, zitterig und ausfahrend, nach einigen Worten nicht mehr leserlich, mit Aus lassen einzelner Buchstaben.

Pat. ist insofern orientiert, als er das Datum und sein Alter weiß; er weiß, da $ß$ und wie lange er krank ist, wie seine Krankheit begonnen hat, daß seine Sprache schlecht ist. Er ist bester Stimmung, überglücklich, prahlt mit großen Reichtümern, denn er hätte das große Los gewonnen; dabei wären aber seine Reichtümer verhältnismäßig größer als das vermeintlich gewonnene Los; dieser Widerspruch läßt ihn aber ganz kalt; will mit den schönsten Pferden nach Hause fahren und schöne Geschenke einkaufen, läßt sich aber immer wieder davon abbringen und so geht das mehrmals im Tage.

20. Dezember. Hochgradige Störung der Merkfähigkeit; er vergißt z. B., daß er vor $1 / 2$ Stunde Besuch hatte, daß er gegessen hatte; dazu Auftreten von Konfabulationen: erzählt von großen Verlobungen in seiner Familie, von vielen Geschenken, weiß nicht, wie lange er hier ist, verkennt die Ärtte und Mitpatienten.

8. Mai. Urinretention, Katheterismus; zunehmender Verfall, die Sprache wird immer schlechter, bis zur Unverständlichkeit; starker Tremor der Extremitäten.

12. Mai 1905. Fixitus an einer Phlegmone.

Das Gehirn leicht atrophisch, leichte Meningealverdickung. In der Rinde mehrfache Erweichungen älteren Datums und zwar links der ganze Occipitallappen erweicht, dann ein größerer Herd in der Brocaschen Windung nnd ein kleinerer im Parietallappen; rechts zwei kleine Herde im Parietallappen, zwei in der vorderen Zentralwindung, einer im Lobulus lingualis.

Mikroskopisch fand sich nichts von Paralyse.

Fall 103. Ascher, Wilhelm, 61 Jahre.

Anamnese. Seit 15 Jahren Diabetes; keine Heredität; vor 7 Monaten allmählich eintretende Schwäche des rechten Beines, vor 6 Monaten rechtsseitiger Schlaganfall ohne Sprachstörung; vor 3 Monaten Anfall mit sensorischer Aphasie und Echolalie; seit 4 Wochen ist Pat. unrein, bettlägerig, will aber immer wieder aus dem Bett steigen.

Beobachtung. 12. bis 22. Januar 1905. Rechtsseitige Hemiparese, Para. phasie, Apraxie; ist bei der Einbringung unruhig, will immerfort weggehen, zerwirft das Bettzeug, zerreißt sein Hemd.

18. Januar. Stumpf-dementer Zustand, zeitweise unruhig, kriecht aus dem Bette heraus, trotzdem er sich sehr schwer fortbewegen kann, zerwirft das Bettzeug, nimmt die Decke in die Hand und will damit weggehen; häufig weint er. 
Das Gehirn leicht atrophisch, im Markweiß und in den Stammganglien beider Hemisphären und im Pons mehrfache kleine cystische Erweichungsherde. Arteriosklerose der cerebralen Gefäße.

Fall 104. Floßmann, Anna, 56 Jahre.

Anamnese. Vor einem Jahre linksseitige Hemiplegie; nach 3 Wochen vollkommene Besserung; seit der Zeit wird sie dement, vergißt alles, verdirbt das Essen, die Wohnung hat sie in Unordnung, in der letzten Zeit auch unrein geworden.

Beobachtung. 18. Februar bis 26. März 1908. Linksseitige Hemiplegie, dementes Wesen; gibt ihr Alter unrichtig an, weiß nicht die Zahl ihrer Kinder; gerät häufig in Zwangsweinen; dabei verwaschene häufig paraphatische Sprache; Pupillenstarre, fehlende Sehnenreflexe an den Beinen, breitspurig-schwankender Gang.

22. Februar. Unrein, rafft häufig Kleider und Bettzeug zusammen und will damit weggehen, wie man sie anspricht, gerät sie in Zwangsweinen.

12. März. Decubitus.

Das Gehirn leicht atrophiert; in der linken Hemisphäre im Mark des Stirnlappens eine große Erweichungscyste; im Linsen- und Schwanzkern der rechten Seite mehrere kleine Erweichungsherde.

Im Rückenmark alte Tabes, mikroskopisch nichts von progressiver Paralyse.

Fall 105. Silbernagel, Anton, 54 Jahre.

Anamnese. Vor 4 Jahren ein rechtsseitiger Schlaganfall mit vorübergehendem Sprachverlust; die Sprache bleibt nach schneller Besserung immer schwerfällig; vor einem Jahr wieder ein rechtsseitiger Schlaganfall; seit einigen Monaten wird Pat. dement, will von zu Hause weglaufen und weiß angeblich nicht wohin.

Beobachtung. 24. März bis 22. Mai 1908. Einfach dementer Alter, der persönlich ganz gut orientiert ist, soweit ihn seine Sprache nicht hindert; für gezeigte Gegenstände hat er die Bezeichnung ziemlich prompt, wogegen er sich in der gewöhnlichen Rede sehr häufig auf die einzelnen Bezeichnungen nicht besinnt; Schrift stark gestört.

27. März. Bei Tag ist er immer ruhig, bei Nacht wird er ängstlich, will aus dem Bette, schreit um Hilfe, man wolle ihn totschlagen; läuft zur Tür.

1. Mai. Zustand unverändert, bei Tag verstumpftes Wesen.

20. Mai. Zustand unverändert.

22. Mai. 1908. Exitus.

Das Gehirn leicht atrophisch; in beiden Linsenkernen und im Pons mehrere kleine cystische Erweichungsherde.

Fall 106. Stauber, Margarethe, 72 Jahre.

Anam nese. Keine.

Beobachtung. 16. bis 26. Juli 1907. Sehr gebrechliche demente Alte; liegt stumpf da, glaubt hier einige Tage zu sein; wie lange sie Witwe ist, weiß sie nicht, aber sie wäre 20 Jahre verheiratet gewesen; nachher gefragt, wie lange sie da ist, sagt sie: 20 Jahre, glaubt hier zu Hause zu sein, helfe hier so bei der Arbeit, hätte schon früh die Stube rein gemacht; nachher gefragt, wie lange sie hier ist, sagt sie: $1 / 2$ Jahr. Verkennt die Umgebung als ihre früheren Bekannten.

Somatisch linksseitige Hemiplegie, wobei auch eine Hemianopsie zu sein scheint; ungestörte Sensibilität der linken Hand.

24. Juli. Lymphangitis von einer Kratzwunde am Bein.

26. Juli 1907. Exitus.

Das Gehirn im allgemeinen atrophiert. In der linken Hemisphäre der ganze Occipitallappen, der Gyrus supramarginalis und die hintere Partie der dritten Schläfewindung vollkommen erweicht, die Erweichung bereits in Resorption begriffen. 
Fall 107. Kassowitz, Pauline, 67 Jahre.

Anam nese. Seit längerer Zeit sehr vergeßlich und dement; näheres unbekannt.

Beobachtung. 3. September 1908 bis 7. April 1909. Sehr gesprächig, euphorisch-dement; hochgradig vergeßlich, weiß, daß sie sich in der Anstalt befindet, weiß, von wo sie kam; gibt das Alter und einen kurzen Abriß ihrer Lebensgeschichte richtig an; weiß, daß sie sehr vergeßlich ist und beklagt sich, daß man sie für verrückt bezeichnet hat; weiß, daß ihr Mann schon tot ist.

18. September. Pat. schläft in der Nacht sehr schlecht, ist über die Tageszeiten nicht orientiert, höchst vergeßlich, behauptet, daß alles, was sie sieht, ihr gehöre, rafft alles zusammen und will es forttragen, verlangt weggelassen zu werden, da sie das oder jenes zu besorgen habe; konfabuliert ständig; behauptet, der Mann lebe noch, gerade vor einer Weile hätte sie mit ihm gesprochen, oder erzählt, wo sie gerade gewesen wäre, was sie eingekauft hätte, oder beklagt sich, daß man sie mißhandelt hätte, man stehle ihr alles; den Arzt kennt sie nicht, verkennt ihn oder behauptet, ihn gerade am Spaziergang gesehen zu haben, schildert ins kleinste Detail seine Toilette. Beschuldigt auch zeitweise den Mann ehelicher Untreue.

22. März 1909. Ein Anfall von Bewußtlosigkeit mit Pupillenstarre.

Nachher durch eine Woche leichte rechtsseitige Hemiparese und lallende und schwerverständliche Sprache. (Andeutung von motorischer Aphasie.)

Im Gehirn fand sich an vielen Stellen in großer Ausdehnung bräunliche Verfärbung der verdickten Meningen, unter denen die Hirnsubstanz in die Tiefe von 2-3 mm erweicht und sklerosiert war; dieselbe Veränderung fand sich auch am Hirnstamm besonders schön an den Vierhügeln. Die cerebralen Gefäße stark verdickt.

Die Fälle 90-101 sind grobe arteriosklerotische Herderkrankungen mit den gewöhnlichen somatischen Ausfallserscheinungen und einer mehr oder weniger schweren stumpfen Demenz.

Bei den Fällen 102-107 kommen aber auch außerdem psychische Symptome vor, welche denen der Presbyophrenie sehr ähneln. Die Fälle 102, 106 und 107 hatten eine ausgesprochene konfabulierende Merkfähigkeitsstörung, bei den anderen Fällen waren meist nur Andeutungen von nächtlicher deliranter Unruhe; die Kranken waren häufig schlaflos, beschäftigten sich mit dem Bettzeug, machten daraus Bündel und wollten weggehen. Alle diese Fälle haben als gemeinsame Zerebralveränderung eine starke Arteriosklerose, die zu schweren ausgedehnten und meist multiplen Erweichungsherden geführt hatte, und betreffen dazu noch durchwegs senile Individuen.

Dieser Umstand könnte als Einwand gegen die hier vertretene Ansicht von der klinischen Bedeutung der Sphärotrichie verwendet werden; doch wäre dies nicht berechtigt. Es kommt ja immer wieder darauf an, was man als Wesen des Klassifikationsbegriffes „Krankheit "auffaßt. In der Psychiatrie hat man sich eben gewöhnt, immer nur einen enger begrenzten klinischen Symptomenkomplex als das wesentliche Merkmal der Krankheitseinheit aufzufassen, trotzdem die somatische Medizin wiederholt mit Hilfe der pathologischen Anatomie erfahren hat, daß die klinische Symptomatologic bei ganz verschiedenen 
Krankheitsprozessen desselben Organs gleich sein kann, trotzdem sich in der Pathologie bereits die Anschauung Bahn gebrochen hat, daß wir als Krankheit eine immer einheitlich auftretende Veränderung der Organe zusammenfassen, und trotzdem man doch heute bereits auf dem Standpunkt angelangt ist, daß die Psychosen doch nur Folgen einer Hirnerkrankung sind. Kraepelin macht in dieser Frage einen strengen Unterschied zwischen Zustandsbildern und Krankheitsvorgängen, und hat wiederholt gezeigt, daß wir auch rein klinisch eine derartige mehr wissenschaftliche Scheidung vornehmen können. Man muß zugeben, daß die symptomatologisierende klinische Richtung ihre Berechtigung dort noch hat, wo uns pathologische Anatomie oder ein anderer Wissenszweig kein anderes Einteilungsprinzip gegeben hat, dort aber, wo letzteres bereits zutrifft, kommt eine rationellere Einteilung, eine Einteilung auf mehr naturwissenschaftlicher Basis zur Geltung. Bei diesem Sachverhalt kann es uns auch nicht Wunder nehmen, wenn wir in mancher Hinsicht ähnliche Symptome bei verschiedenen pathologischen Prozessen des Gehirns sehen.

Bei der Differentialdiagnose des hier in Frage stehenden Symptomenkomplexes kommen nach unseren Erhebungen also folgende drei pathologische Prozesse in Betracht:

I. diejenige schwere Intoxikation, die auf Grund des chronischen Alkoholismus entsteht.

II. die durch die Sphärotrichie verursachte schwere Destruktion der Hirnrinde, die zur presbyophrenen Demenz führt.

III. die schwere arteriosklerotische Degeneration des Gehirns; die bei den Fällen 102-107 beobachteten presbyophrenen Symptome, die ja auch sonst schon längst bekannt sind, würde ich hier unter dem Namen ,arteriosklerotische Pseudopresbyophrenie" zusammenfassen; sie bilden darnach eine kleine Untergruppe der arteriosklerotischen Demenz.

Diese drei grundverschiedenen und in ihrer klinischen Symptomatologie doch manchmal so ähnlichen Zerebralerkrankungen, müssen auch einer klinischen Differentialdiagnose zugänglich sein; dies ist möglich, wenn auch fallweise eine Entscheidung nicht so leicht durchführbar ist.

Die alkoholischen Psychosen basieren meistens auf einer vorübergehenden Giftwirkung und führen dadurch zu reparablen Störungen, die meist ohne schwerere Ausfallserscheinungen vorübergehen; sie treten meistens im jüngeren Alter auf und werden auch von somatischen Symptomen begleitet, von denen die tremolierende Sprache und neuritische Symptome immer eine differentialdiagnostische Bedeutung haben werden.

Die presbyophrene Demenz und die arteriosklerotische Pseudopresbyophrenie sind durchwegs Erkrankungen des höheren Alters, 
der pathologische Prozeß führt in beiden Krankheiten zu einem dauernden Ausfall von Nervensubstanz; dementsprechend ist auch die Psychose mit wenigen Ausnahmen unheilbar und geht bei entsprechend längerer Dauer in Verblödung über. Stark ausgesprochene presbyophrene Züge bei noch relativ geringer Demenz sprechen mehr für die presbyophrene Demenz, wogegen Symptome von schwerer groborganischer Hirnläsion bei wenig ausgesprochenen presbyophrenen Zügen auf eine Pseudopresbyophrenie hinweisen. Doch dürfte die Diagnose auch häufig schwierig werden, weil es Fälle von arteriosklerotischen Herderkrankungen gibt, die auch von der Sphärotrichie befallen werden; eine weitere Schwierigkeit könnte z. B. ein Fall von alkoholischem Delirium bei einem Senilen darstellen; für solche Fälle haben wir einstweilen keine sicheren differentialdiagnostischen Symptome ${ }^{1}$ ).

Wie schwierig die Diagnose unter Umständen sein kann, sollen die folgenden 2 Fälle zeigen, die auf den ersten Blick die Frage nur noch komplizieren, die sich aber bei näherem Zusehen doch ohne größere Schwierigkeiten in das obige Symptom einreihen lassen.

Fall 108. Prisker, Franziska, 70 Jahre.

Anamnese. Stammt aus einer sehr degenerierten Familie, ein Bruder, eine Schwester, drei Neffen und ein Sohn waren geisteskrank; sie war immer absonderlich, unverträglich, war nie sehr intelligent, leichtsinnig, vernachlässigte ihre Wirtschaft; während einer Schwangerschaft soll sie sehr erregt gewesen sein. Seit mehreren Jahren äußert sie Größenideen; sie bildet sich ein, daß ein Arzt sie heiraten wolle, spricht viel von Fürsten und hohen Herrschaften, die ihr nachlaufen, dann behauptet sie, daß sie eine große Erbschaft von 300 Millionen erwarte; in den letzten Jahren vernachlässigt sie sich immer mehr, wie sie zu Geld komme, kaufe sie sich Naschwerk, vagierte herum.

Beobachtung. 30. Oktober 1904 bis 2. Februar 1909. Eingebracht sehr verwahrlost; sie ist sehr lebhaft, sehr lustig, plaudert viel; ist persönlich, zeitlich und örtlich vollkommen orientiert, ist sehr selbstbewußt, leugnet, daß sie vagabundiert hätte, leugnet, daß sie Ungeziefer hätte, behauptet, im Gegenteil, sie werde eine große Erbschaft machen, der Prozeß sei schon im Gange, sie hätte eine schöne Wohnung; ist sehr unverträglich, spricht im Zimmer immerfort, mischt sich in alles hinein, gerät dadurch sehr viel in Streitigkeiten, ist mit nichts zufrieden, alles will sie besser wissen und besser haben, hat keine Krankheitseinsicht und will deswegen entlassen werden.

Zustand bleibt unverändert.

10. August 1905. Ein Ohnmachtsanfall.

1. September 1906. In der letzten Zeit starker Gedächtnisdefekt; Pat. ist desorientiert, konfabuliert ständig, bald in euphorischer Richtung, bald wieder persekutorisch, depressiv, indem sie meint, man wolle sie nachts aufhängen oder chloroformieren, behauptet, sie hätte das gehört.

1. Juni 1907. Gleicher Zustand, hochgradig vergeßlich, indem sie in sehr kurzer Zeit alles vergißt; weiß aber nichts von ihrer Merkfähigkeitsstörung, sondern hat für alles eine konfabulierte Darlegung ; so wechseln die Angaben von Minute

1) Es muß noch erwähnt werden, daß unter Umständen auch eine progressive Paralyse differentialdiagnostisch in Betracht kommt, besonders wenn es sich um eine senile Paralyse handelt. 
zu Minute über die Länge ihres Aufenthaltes; auch ihr Alter wechselt ständig, ihre Eltern sind bald tot, baild leben sie noch.

Darüber ausgefragt, was sie gerade oder gestern oder vor ein paar Tagen machte, gibt sie ganz wechselnde konfabulatorische Antworten: bald mache sie Besuche, bald bekomme sie Besuche, bald war sie spazieren, bald in der Wirtschaft beschäftigt.

Merkwürdig ist, daß sie nicht alles, was um sie geschieht, vergißt, sondern Einzelheiten, auch wenn sie nur einmal vorgekommen sind, längere Zeit behält; ihre Vergeßlichkeit ist manchmal so groß, daß sie während des Satzes vergißt, was sie sagen wollte und auf etwas ganz anderes überspringt. Neben ihr liegt eine kleine vierjährige Idiotin, diese bezeichnet sie bald als ihre Tochter, bald als Nichte, bald als Enkel, gibt ihr verschiedene Namen und behauptet, sie unterhalte sich mit ihr (das Kind ist stumm); auch über die Tageszeiten vollkommen desorientiert.

Eines Tages werden ihr zwei Zahlen zu merken gegeben ( 35 und 27), nach 30 Sekunden weiß sie nur die Zahl 27; ebenso nach einer Stunde, am nächsten Tage darüber befragt, sagt sie: Sie haben mir gesagt, daß am 7. und 27. des Monats etwas sein wird, aber ich weiß nicht was, ,ich habe einen dummen Schädel“".

Wenn sie über ihre Mutter spricht, gibt sie auch bei der ein wechselndes Alter an, so daß sie die Mutter bald als jünger, bald als älter als sie selbst bezeichnet.

In diesem Zustande bleibt sie im großen und ganzen unverändert; sie ist sehr lebhaft, lustig und konfabulierend.

1. März 1908. Ist etwas ruhiger, äußert Konfabulationen nur auf Fragen.

2. Februar 1909. Exitus an Marasmus und Bronchopneumonie.

Das Gehirn ist hochgradig atrophiert, es wiegt im mit Formol fixierten $\mathrm{Zu}$ stande nur $950 \mathrm{~g}$. Die Atrophie sitzt in beiden Hemisphären und zwar genau symmetrisch, dabei rechts aber etwas intensiver.

In der linken Hemisphäre sitzt die Atrophie an allen Seiten des Stirnlappens, in den Zentralwindungen und im vorderen Drittel des Schläfelappens. In der rechten Hemisphäre sitzt die Atrophie an denselben Stellen, nur daß sie sich außerdem noch auf den ganzen Schläfelappen erstreckt und noch einen Teil des angrenzenden Occipitallappens ergriffen hat. Die Atrophie ist derartig, daß die Windungen hochgradig verschmälert, stellenweise kammartig geschrumpft sind, das Mark ist in den betreffenden Hirnteilen hochgradig zusammengesunken, so daß daraus eine ganz gewaltige Erweiterung der Ventrikel resultiert. Die Meningen sind nur ganz leicht verdickt, die basalen Gefäße stark verdickt und stellenweise von Kalkringen durchsetzt.

Die mikroskopische Untersuchung ergab keinerlei entzündliche Veränderungen, Drusen fehlen ebenfalls. Es bestand eine hochgradige Arteriosklerose der Rindengefäße, die aber nirgends zu vollkommenem Verschluß geführt hatte. Die atrophischen Hirnpartien zeigten einen einfachen, aber ganz enormen Schwund des nervösen Gewebes mit nur relativ geringer Wucherung der Neuroglia.

Fall 109. Ponec, Josef, 68 Jahre.

Anamnese. Stammt aus stark hereditär belasteter Familie; es waren geisteskrank: der Großvater, der Vater, eine Schwester, ein Neffe, zwei Cousins und eine Cousine. Seit etwa 6 Jahren ist er geisteskrank, ist verstimmt, traurig, schläft sehr schlecht; in der letzten Zeit ist er besonders nachts sehr unruhig, manchmal auch gewalttätig.

Beobachtung. 7. Januar bis 23. Juli 1909. Pat. ist äußerlich ruhig, heiterer Stimmung, singt, ohne viel Aufsehen zu erregen, still Liedchen vor sich hin, hochgradig vergeßlich, konfabuliert und ist persönlich, zeitlich und örtlich ständig 
desorientiert; über sein Alter gibt er die widersprechendsten Angaben; ebenso sind seine Angaben über Zeit und Ort; je nach Art der Fragestellung erzählt er, wo, wann und was er gerade gearbeitet hätte, und malt immer, aber durch die Art der Fragestellung beeinflußt, das Konfabulierte ins größte Detail aus; spontan produziert er keine Konfabulationen.

Nachts schläft er wenig, geht herum, aber deliriert nicht.

23. Juli. Exitus an Bronchopneumonie.

Das Gehirn ist stark atrophiert, wiegt in formolfixiertem Zustande nur $1060 \mathrm{~g}$. Die rechte Hemisphäre ist etwas stärker atrophisch. Außerdem zeigt sich eine scharf abgegrenzte Schrumpfung sehr hohen Grades in der ersten und zweiten Stirnwindung beider Seiten, die sich nach hinten scharf gegen die Zentralwindung absetzt. Diese geschrumpften Windungen sind kammartig zusammengesunken und haben eine rauhe wie narbige Oberfläche. Die Ventrikel sind hochgradig erweitert.

Die mikroskopische Untersuchung ergab keinerlei entzündliche Veränderungen, überall in der Hirnrinde starken Substanzausfall mit nicht sehr starker Wucherung der Neuroglia, nur an den stark geschrumpften Partien findet sich in sehr schön ausgesprochener Art der ,spongiöse Rindenschwund“. Die Rindengefäße durchwegs zart und beinahe gar nicht verändert.

Klinisch sind diese beiden Fälle ganz ausgesprochene Presbyophrenien im Sinne Wer nickes in der Form einer Korsak off schen Psychose ohne Delirium, anatomisch fehlt die Sphärotrichie; beiden Fällen ist aber ein exzessiver, sehr ausgebreiteter Schwund des Gehirns gemeinsam, der im ersten Falle durch hochgradige Arteriosklerose, im zweiten Falle druch den spongiösen Rindenschwund verursacht war. Also beiden Fällen liegt eine sehr schwere, mehr diffuse Rindenschädigung zugrunde, doch ist dies eine Schädigung, ich möchte sagen mehr makroskopischer Art und dadurch der groben arteriosklerotischen Hirndestruktion etwas verwandt. Deswegen rechne ich auch diese 2 Fälle zur arteriosklerotischen Pseudopresbyophrenie. Als bemerkenswert soll hervorgehoben werden, daß beide letzten Fälle aus hereditär stark belasteten Familien stammen, was um so auffälliger ist, als bei den anderen kaum etwas von Heredität erwähnt wurde. Ob etwa die Heredität gerade bei dieser immerhin eigenartigen Form eine größere Rolle spielt, kann auf Grund dieser 2 Fälle nicht entschieden werden; weitere Beobachtungen müssen dazu noch abgewartet werden.

Zur Kontrolle habe ich noch 9 Gehirne von psychisch normalen Greisen im Alter von 65-93 Jahren untersucht. Die ersten 6 stammten von Greisen, die wegen somatischer Leiden im Krankenhause verstorben sind und deren Krankenjournale nichts von psychischen Störungen berichteten; bei 3 derselben war jedoch eine, wenn auch nicht sehr hochgradige, so doch ganz deutliche Sphärotrichie vorhanden. Deswegen wurde über das Verhalten der Kranken genauer nachgefragt und es ergab sich, daß 2 von den letzteren nachts unruhig waren und verwirrt gesprochen hätten. Aus diesem Grunde untersuchte ich eine Zeitlang die auf einigen internen Abteilungen 
liegenden Greise und als drei von diesen geistig intakt Befundenen starben, erwies sich das Gehirn frei von Sphärotrichie.

Diese Erfahrung lehrt, wie vorsichtig man mit dem Kontrollmaterial sein $m u B$; um einwandfrei Kontrolle üben zu können, muß man eben über Fälle verfügen, welche auch psychiatrisch genau von einem bestimmten Gesichtspunkte aus untersucht wurden, und dies muß besonders deswegen hervorgehoben werden, weil, wie auf Seite 417 gezeigt worden ist, die presbyophrenen Symptome vorübergehen können und dann eventuell nur eine stumpfe Demenz verbleiben kann.

Es wirft sich jetzt die Frage auf, in welchem Verhältnis der Beginn der Psychose zum Beginn der Sphärotrichie steht; diese Frage kann auf Grund unserer bisherigen Kenntnis eigentlich kaum angegangen, geschweige denn gelöst werden; doch können die folgenden 2 Fälle immerhin gewisse Anhaltspunkte in dieser Richtung liefern.

Fall 110. Minárik, Franz, 59 Jahre.

A n a $m$ nese. Seit $1 / 2$ Jahr linksseitige Hemiplegie ; seit einiger Zeit sehr reizbar.

Beobachtung. 24. März 1903 bis 8. Juli 1905. Linksseitige Hemiplegie; Pat. ist sehr weinerlich, schläft sehr schlecht, behauptet, er hätte nachts die Mutter Gottes gesehen, die ihm zurief, er werde gesund werden; nachts hätte er auch ein Klopfen gehört, das ihn sehr beunruhigte.

19. Juni. Zeitlich und örtlich vollkommen orientiert; hypochondrische Ideen.

1. August. Pat. ist vollkommen stumpf, dement, häufiges Zwangsweinen.

16. August bis 4. Januar 1904. Diabetes insipidus, bis zu $11 \mathrm{~L}$. maximaler Tagesmenge; allmählicher Rückgang.

15. Dezember. Epileptischer Anfall.

1. Mai 1905. Stumpfe Demenz.

8. Juli 1905. Exitus an Bronchitis.

Im Gehirn fand sich der rechte Schläfelappen vollkommen erweicht; die Erweichung auch auf den Linsenkern übergehend. Die basalen Gefäße fleckig verdickt.

Mikroskopisch. Leichte atrophische Veränderungen der Hirnrinde. In beiden Stirnlappen spärlich verstreute, meist ganz kleine Drusen im Stadium II und III.

Fall 111. Müller, Eleonora, 73 Jahre.

Anamnese. In den Jahren 1875, 1878-1885 und 1889 wegen Melancholie in Anstaltsbehandlung; seit 2 Monaten wieder depressiv mit Selbstmordideen.

1. Beobachtung. 27. Dezember 1898 bis 22. Juli 1900. Zustand einer Hypomelancholie mit hypochondrischen Ideen.

II. Aufenthalt.

Anamnese. Seit einem Jahr wieder depressiv.

2. Beobachtung. 14. Oktober 1903 bis 10. März 1907. Kommt zuerst in Depression, mit Selbstanklagen, hypochondrischen Ideen und vereinzelten Beziehungsideen depressiven Inhalts; der Affekt wird allmählich immer schwächer, zum Schluß ist Pat. nur dann etwas depressiv, wenn man von ihren früheren Ideen spricht; sonst eine stumpf zufriedene Alte. Nichts von sonstigen Wahnideen.

Exitus an Marasmus. 
Das Gehirn von außen leicht atrophisch, leichte Ventrikelerweiterung.

Mikroskopisch. Sehr spärliche Drusen, meist im Stadium II und III, vornehmlich in der Stirn sitzend.

Der erste dieser Fälle ist eine einfache Demenz bei arteriosklerotischer Hirndegeneration; der zweite eine melancholische Psychose des Seniums; in keinem der Fälle konnten presbyophrene Symptome nachgewiesen werden, wenn man die nächtliche Unruhe, die Fall 110 gezeigt hatte, nicht dazu rechnen wollte; und doch hatten beide Fälle eine, wenn auch nicht sehr stark ausgesprochene Sphärotrichie. Wenn wir eine größere Anzahl solcher Fälle hätten, denen gegenüber sich nur wenige Psychosen mit Sphärotrichie vorgefunden hätten, dann könnte von einem Zusammenhange dieser Cerebropathie mit irgendeiner psychischen Störung keine Rede sein; wenn man aber bedenkt, daß einer so großen Zahl von positiven Fällen nur zwei negative gegenüberstehen, und wenn in diesen letzteren Fällen die Drusen nur spärlich und nicht in allen Hirnpartien vorgefunden wurden, dann kann auch dieser Widerspruch in der Weise erklärt werden, daß die Sphärotrichie schon einer gewissen Ausbreitung bedarf, um psychische Symptome hervorrufen zu können, und daß bei diesen 2 Fällen wohl noch die entsprechenden Symptome sich entwickelt hätten, wenn sie noch längere Zeit am Leben geblieben wären. Darnach können diese 2 Fälle die durch unser gesamtes Material wohl begründete Bedeutung der Spaerotrichia cerebri nicht stürzen, genau so wie dies auch jener bekannte Fall Alzheimers ${ }^{1}$ ) nicht tat, der einen Selbstmörder betraf, dessen Gehirn sich histologisch ausgesprochen paralytisch erwies, und der seiner Umgebung in keiner Weise als psychotisch vorkam.

Es ist noch angezeigt, auf die Fälle zurückzukommen, die nach dem 50. Jahre psychotisch wurden und in deren Gehirn sich keine Sphärotrichie vorfand. Dazu muß betont werden, daß sich in den meisten dieser Fälle bereits makroskopisch, in allen mikroskopisch eine Atrophie des Gehirns nachweisen ließ. Wenn wir den Fall 74 ausnehmen, der nur eine sehr alt gewordene Dementia praecox ist, dann die Fälle 83-89, deren psychische Erkrankung auf differente, verschieden bedingte cerebrale Prozesse zurückzuführen ist, und dann die Fälle 81 und 82 , deren klinische Einreihung schwer durchgeführt werden kann, bleiben uns Fälle, die sich nach den klinischen Symptomen in 3 Gruppen einreihen lassen:

a) in solche mit einer einfachen Demenz, der unkomplizierten Einbuße aller psychischen Fähigkeiten;

b) in Fälle mit Symptomen des manisch-depressiven Irreseins Kraepelins, und zwar sind hier Fälle mit nur manischen,

1) Histologische Studien zur Differentialdiagnose der progressiven Paralyse in $\mathrm{Nissls} \mathrm{Histologische} \mathrm{und} \mathrm{histo-pathol.} \mathrm{Arbeiten} \mathrm{über} \mathrm{die} \mathrm{Großhirnrinde} \mathrm{1,} 199$. 
solche mit nur melancholischen Phasen und auch solche mit zirkulärem Verlauf;

c) in Fälle, deren Symptomatologie am ehesten denen der Dementia praecox gleichkommt.

Die Fälle der Gruppe a sind zweifellos einfache senile Demenzen. Die Einteilung der anderen Gruppen dürfte aber Schwierigkeiten bereiten; Fälle von der Symptomatologie der Gruppe $c$ finden sich in der Literatur eigentlich sehr wenig gewürdigt, die Gruppe b würde Kraepelin zum manisch-depressiven Irresein rechnen. Wenn man aber bedenkt, daß allen diesen Fällen doch eine gewisse Demenz eigen war, könnte man sie auch der senilen Demenz zurechnen. Dann könnte man das Krankheitsbild der senilen Demenz so auffassen, wie es bereits bei der Paralyse durchgeführt wurde und wie wir es hier auch bezüglich der presbyophrenen Demenz versucht haben, daß sich auf einer bestimmten anatomischen Basis im allgemeinen zwar auch ein bestimmter klinischer Symptomenkomplex entwickelt, der aber auch manchmal gewisse Ausnahmesymptome zeigt, die sonst nur anderen Psychosen eigen sind; unter Umständen können diese Ausnahmesymptome die anderen überwuchern und imitieren dann eine andere Psychose. Also genau so, wie wir bei der Paralyse eine typische und verschiedene atypische Verlaufsarten unterscheiden, genau so wie wir hier für die presbyophrene Demenz zeigen konnten, daß ein einheitlicher anatomischer Prozeß verschiedene Symptomenkomplexe hervorbringen kann - genau so könnten wir auch folgern, daß die einfache senile Hirnatrophie im allgemeinen zu einer einfachen Verblödung führt, die aber, wie unser Material es auch zeigt, unter Umständen auch manisch-depressive und Dementia-praecox-ähnliche Züge hervorbringt. Damit soll aber nicht gesagt sein, daß sich im Senium nicht auch sogenannte einfache Psychosen entwickeln können, genau so wie sie sich in anderen Lebensabschnitten entwickelten (Fürstner); so wie sich ein manisch-depressives Irresein auf Grund eines uns noch unbekannten Krankheitsprozesses in jüngeren Jahren entwickeln kann, so kann derselbe Krankheitsprozeß auch im Senium einsetzen und zu demselben klinischen Krankheitsbilde führen. Um diese einzelnen Psychosen voneinander unterscheiden zu können, müßten wir den Krankheitsprozeß des manisch-depressiven Irreseins kennen und ihn von dem Krankheitsprozesse der pathologischen senilen Hirninvolution unterscheiden können. Doch dazu reichen unsere Kenntnisse noch nicht, vielleicht wird uns die Zukunft und neue Methoden (ich habe hier vornehmlich die Methoden der Darstellung der Abbauprodukte nach Alzheimer vor Augen) noch andere Aufschlüsse geben.

Es wären nur noch die wenigen Arbeiten zu besprechen, die sich mit den geschilderten Veränderungen des Gehirns befaßt haben. 
Die Drusen beschrieb zuerst Redlich (Jahrbücher f. Psych. und Neur. Bd. 17.), die er bei 2 Fällen von seniler Demenz vorfand und miliare Sklerose benannte. In beiden Fällen war die Hirnrinde von den Drusen übersät, die sich mit Carmin intensiv färbten; im Zentrum zeigten sie ein homogenes, leicht körniges Gefüge, ,während in der Peripherie noch ein feiner Faserfilz nachweisbar war, der einen allmählichen Übergang bildete $\mathrm{zu}$ der umgebenden Gliasubstanz". Im Zentrum fand sich dann noch häufig der Rest eines Kernes, ein Protoplasma- oder Pigmentklümpchen. Redlich hielt diese Drusen für Gliawucherungen, welche auf Grund kleinster Substanzverluste in der Rinde einsetzten. 1906 fand Miyake (Obersteiners Arbeiten Bd. XIII) ebenfalls bei 2 Senil-Dementen dieselbe Veränderung; Alzhei mer demonstrierte in demselben Jahre in der Versammlung Südwestdeutscher Irrenärzte in Tübingen Präparate des später zu besprechenden Falles 1 von Perusini, ,als miliare Herdchen, welche durch Einlagerung eines eigenartigen Stoffes in der Hirnrinde bedingt waren". (Auf letztere Mitteilung bin ich erst durch Perusini aufmerksam gemacht worden.)

Ein Jahr später berichtete ich über Untersuchungen (1. c.), die ich an einem größeren Material seniler Gehirne gemacht hatte, wobei ich hervorhob, daß die beste Darstellungsweise der Drusen die Bielschowsky-Methode ist. Ich schilderte bereits damals einige Stadien derselben, und als merkwürdigste Veränderung hob ich die keulenförmige Wucherung der Achsencylinder hervor; ich nannte die Veränderung ,miliare drusige Nekrose", trotzdem ich bemerkte, daß es sich am ehesten um Einlagerung einer fremden Masse handelt, die das nervöse Gewebe auseinanderdrängt. Weiter machte ich darauf aufmerksam, daß sich ein klinischer Unterschied zwischen Fällen mit und ohne Drusen nachweisen lasse, indem die ersteren Symptome der Wernickeschen Presbyophrenie aufweisen und folgerte daraus, da $\beta$ wir in den Drusen das wichtigste anatomische Substrat der Presbyophrenie haben.

1908 berichtete ich in einem Vortrage in der Jahresversammlung des Deutschen Vereins für Psychiatrie in Berlin über weitere Untersuchungen über diesen Gegenstand; ich konnte die meisten der hier beschriebenen Stadien demonstrieren und machte auch schon damals auf das infiltrative Vorkommen der Fädchen aufmerksam. Weiter hob ich die eigenartige Ähnlichkeit der Drusen mit Bakterienkolonien hervor, ohne daß ich imstande gewesen wäre (oder etwas Derartiges versucht hätte, gegenüber einigen unrichtigen Auffassungen in der Literatur), die Drusen direkt als Bakterien zu bezeichnen.

Im Archiv für Psych. und Neurol. 46, H. 2 publizierte Hübner weitere Untersuchungen über diesen Gegenstand. Hübner unter- 
suchte 32 Fälle auf das Vorhandensein der besprochenen Cerebropathie. Uber die klinischen Symptome derselben wird nur folgendes berichtet: ,2 Fälle betrafen geistig gesunde Leute im Alter von über 60 Jahren, 16 Gehirne stammten von älteren Individuen, bei denen Dementia senilis, multiple Erweichungsherde, Gehirnarteriosklerose, Presbyophrenie, senile Verwirrheit, seniler Verfolgungswahn, Spätepilepsie und verschiedentlich auch Aphasie auf Grund von Gehirnatrophie festgestellt worden war. Die übrigen Beobachtungen betrafen Kranke im Alter von 18-60 Jahren mit den verschiedensten Gehirnkrankheiten (Tumor cerebri, tuberkulöse Meningitis, eiterige Meningitis, Hirnabsceß, multiple Sklerose, manisch-depressives Irresein, Angstpsychosen, Dementia praecox, progressive Paralyse)". Außer diesen Fällen hat Hübner noch eine Reihe einzelner Bielschowsky-Präparate von verschiedenen nicht senilen Psychosen durchgesehen, hat aber die Plaques darin nicht gefunden.

Hübner beschreibt einige der Formen der Sphärotrichie, hebt aber hervor, daß die fädige Struktur nicht sehr häufig zu sehen ist, manchmal waren die Massen strukturlos, und diese ungenaue Struktur resp. Strukturlosigkeit zeigen auch seine Abbildungen. Demgegenüber muß ich betonen, daß ich unter meinen ersten Präparaten auch mehr strukturlose Drusen hatte, daß je mehr ich aber untersuchte und je frischeres Material ich verwendete, desto seltener wurden die strukturlosen Drusen, wenn man die Formen der Fig. 12, 13, 14, 15 nicht einrechnet. Hübner findet auch in einigen Fällen die Keulen und beschreibt darin fibrilläre Streifung; er betont auch die verschiedene Verteilung in verschiedenen Gegenden des Gehirns und die Nähe der Blutgefäße.

Nach der Meinung von $\mathrm{H} \ddot{u} b$ ner sind die Drusen abgelagerte $\mathrm{Ab}$ baumaterialien, die nur bei senilen und geistig schwachen Personen vorkommen, aber für eine bestimmte Alterspsychose nicht als charakteristisch angesehen werden können. Man könne aus einem derartigen Befunde nur den Schluß ziehen, daß das betreffende Gehirn von einem geistig oder gehirnkranken älteren Individuum herrühre.

Auf die histologischen Ausführungen Hübners brauche ich nicht einzugehen, da alles, was ich anzuführen hätte, bereits in der histologischen Schilderung und Besprechung enthalten ist. Zum klinischen Teil seiner Arbeit habe ich aber zu bemerken, daß er viel zu wenig Angaben über die Symptomatologie dieser Fälle bringt. Er erwähnt nur mit einigen kurzen Worten die Symptomatologie von 4 Fällen, bei denen die Drusen sich fanden und welche gegen meine damals bereits geäußerte Ansicht, daß die Drusen für die Presbyophrenie charakteristisch sind, sprechen sollen.

Der erste Fall ist eine 79jährige Frau mit manisch-depressivem 
Irresein, doch ist nicht erwähnt, wie lange die Psychose gedauert hatte; ob es sich um eine Psychose gehandelt hatte, die erst im Senium entstand oder sich noch ins Senium fortsetzte. Der zweite Fall war ein 66 jähriger Trinker, der einen deliriumartigen Zustand bekam und daran zugrunde ging; der dritte eine ,paralytische Form der senilen Demenz" ohne weitere Schilderung der Symptome, und daneben ein Fall von einfacher seniler Demenz. Ich glaube, da $B$ nach den Ausführungen des klinischen Teiles dieser Arbeit auch diese Fälle sich leicht in das dort aufgestellte System einreihen lassen könnten.

Im Neurologischen Zentralblatt 1909 findet sich eine weitere Mitteilung über diesen Gegenstand von G. Oppenheim. Dieser Autor bestätigt, daß sich die „,Drusen“ nur in senilen Gehirnen fanden. Er untersuchte 14 Gehirne von senilen Individuen, und zwar:

6 Fälle von seniler Demenz mit presbyophrenen Zügen, von denen 3 Fälle Drusen hatten, 3 Fälle drusenfrei sich erwiesen. Bei 3 Fällen einfacher seniler Demenz fehlten die Drusen. Und von geistig gesunden Greisen hatte einer reichliche Drusen, trotzdem er sich bis zum Schlusse einer ungewöhnlichen geistigen Frische erfreute. Daraus schließt Oppenheim, daß es nicht berechtigt sei, in den Drusen das wichtigste anatomische Substrat der Presbyophrenie zu erblicken, wie ich es ausgesprochen habe. Dagegen habe ich mit nichts anderem zu antworten, als mit dem in der jetzigen Beschreibung gebrachten Material; auch ich habe Abweichungen und scheinbare Widersprüche bringen können. Wenn sich aber eine neu beobachtete pathologische Veränderung so regelmäßig mit bestimmten klinischen Symptomen verknüpft, dann heißt es, eventuelle Ausnahmen ganz genau zu ergründen, bevor man alles wieder aufgibt, was uns pathologische Anatomie, Klinik und Logik aufbauen ließ.

Oppenheim hat ferner in einem seiner Fälle die Keulen auch mit der Weigertschen Gliafärbung darstellen können und schildert, daß diese Keulen auch mit Fortsätzen gewucherter Gliazellen in Verbindung standen. Demgegenüber habe ich zu betonen, da $\beta$ es mir nie gelang, die Keulen mit der Gliafärbung darzustellen, daß die Keulen sich mit Bielschowskys Pyridinsilberfärbung genau so darstellen ließen, trotzdem die gesamte Neuroglia dabei ungefärbt blieb. Und wenn auch eventuell (bei $O$ p penheim fehlen Abbildungen) sich manchmal keulenartige Bildungen als Glia erweisen, so ist damit noch nicht erwiesen, da $B$ alle Keulen gliös sind. Bilder, wie meine Fig. 25, 28, 29, 30 b lassen übrigens keinen $Z$ weifel auf, daß die gezeichneten Keulen etwas anderes als Auswüchse der Achsencylinder sein könnten.

Sarteschi beschrieb in der Rivista sperimentale di Freniatria Vol. 35, 1909 einen Fall von einer 67jährigen Frau, bei der sich die 
Drusen ebenfalls vorfanden; Sarteschi erklärt die Drusen für veränderte Spinnenzellen.

Die bisher ausführlichste Arbeit über diesen Gegenstand erschien in Nissl-Alzheimers 3. Band der histologischen und histopathologischen Arbeiten über die Großhirnrinde. Daselbst berichtet Perusini über 4 Fälle, welche diese Veränderung in der Hirnrinde aufwiesen. Diese Fälle waren:

1. $56^{1} / 2$ Jahre alte Frau; ziemlich schnell entwickelte sich Situationsverkennung und Abnahme des Gedächtnisses, paranoide Symptome, Ratlosigkeit, aphatische Symptome und tiefe Verblödung. Tod nach 5jähriger Dauer.

2. Fall, 46 Jahre alter Mann. Seit etwa 6 Jahren zunehmende Vergeßlichkeit, die sich mit der Zeit mit einer schweren Gedächtnisund Merkfähigkeitsstörung mit vollkommener Desorientiertheit ausbildete; zunehmende Verblödung, später auch halluzinatorische Angstzustände.

3. Fall, 65jährige Frau. Seit 5 Jahren zunehmend dement, desorientiert, paraphatische Zustände.

4. Fall, 67jähriger Mann. Vor 30 Jahren luetisch infiziert. Gedächtnisschwäche, Desorientiertheit, Halluzinationen, delirante Zustände, Tod unter Marasmus.

Perusini untersuchte diese Fälle mit verschiedenen Färbemethoden, wobei er besonderen Wert auf die Färbungen legte, welche in der letzten Zeit in Alzheimers Laboratorium besonders zum Studium der Abbauprodukte und der protoplasmatischen Glia ausgearbeitet worden sind. Er findet in allen diesen Fällen die Drusen und außerdem die grobfaserigen Fibrillenwucherungen der Ganglienzellen und gibt eine genauere Schilderung des Verhältnisses von Glia, Gefäßen und Ganglienzellen. Kolbige Wucherungen der Achsencylinder hat er nicht beobachten können.

Die Hauptsätze Perusinis sind:

1. Das erste Stadium der Plaques ist eine Veränderung des diffusen plasmatischen Gliareticulums, in welchem verschieden färbbare schollige und körnige Einschlüsse sich finden und darunter auch die Fädchen, die sich nach Bielschowsky sehr schön färben;

2. neben den Plaques gehen eigenartige Veränderungen der Ganglienzellen einher (grobfaserige Fibrillenwucherung);

3. die Ansicht von der Spezifität der Plaques für die Presbyophrenie hält er für unrichtig, denn: ,wenn wir dann noch weiter sehen, daß unsere Fälle zum Teil noch jüngeren Jahren angehörten, daß die senile Demenz nach unseren Erfahrungen vor dem 65. Jahre sehr selten ist, und wenn wir weiter sehen, daß das klinische Bild wesentlich von 
der senilen Demenz abweicht, indem sich sehr starke psychische Erscheinungen und Herdsymptome bemerkbar machen, dann müssen wir wohl Bedenken haben, unsere Fälle der senilen Demenz einzureihen".

Ich habe in dieser Arbeit die sonst bei anderen Prozessen bereits bekannten Veränderungen des Gehirns destruktiver Art nicht des Genaueren geschildert - nur um das Thema der Arbeit nicht zu komplizieren - und will daher auch auf die diesbezüglichen Bemerkungen Perusinis nicht weiter eingehen.

Die Methodik, die Perusini anwendete, habe ich nicht angewendet, dadurch sind unsere Resultate verschieden, ich habe auch keine Veränderung des Gliareticulums gesehen, aber ich muß Perusini einwenden, daß er seiner Schilderung nach keine der kleinsten Drusen (Stadium I) beobachtet hat, welche nur aus den feinsten Fädchen bestehen, und welche mit keiner anderen als der Silbermethode darstellbar sind; für diese kleinsten Drusen müßte man erst beweisen, daß auch sie im gewucherten Gliareticulum entstehen. Hier kommt es zuerst auf den Beweis resp. die Ansicht an, was man als das Charakteristische der Bildung ansieht. Ob die Fädchendrusen oder die anderen Substanzen, die in den Drusen zu finden sind und welche wir im allgemeinen wohl zu den Abbauprodukten rechnen müssen. Ich glaube, daß die Bildungen, die Perusini abbildet, den Stadien gleichen, welche in meinen Abbildungen etwa in Fig. 13, 15 auch dargestellt sind; da sind ebenfalls Destruktionsmassen vorhanden, die ich aber zu den Fädchen in Beziehung bringe. Für mich sind nach den Bildern der Bielschowsky-Methode die Fädchen das Wichtige, das Charakteristische und die anderen korpuskulären Elemente Nebenund Folgeerscheinungen.

U̇ber die eigenartige klumpige Veränderung der Fibrillen hätte ich $\mathrm{zu}$ sagen, daß sie gar keine integrierende Veränderung derartig veränderter Gehirne sind, weil sie sich in meinem Materiale nur in einem geringen Prozentsatz (17\%) vorfanden.

Was nun die klinische Seite unserer Frage anbelangt, so meine ich, daß Perusini wohl im Nachteile ist, weil er nur über 4 Fälle berichten konnte. Wenn man aber seine Fälle mit meinen vergleicht resp. meinem Materiale anreiht, sieht man, daß das klinische Bild seiner Fälle aus dem geschilderten Rahmen gar nicht heraustritt. Gewiß gebe ich Perusini zu, daß im allgemeinen die senile Demenz vor dem 65. Jahre nicht auftritt, aber das gilt nur für die senile Demenz, als Folge der einfachen, etwas über das Normalmaß hinausgehenden Hirnatrophie des Seniums; für die anderen Formen, welche ich in die presbyophrene Demenz einreihe, kann dies nur so lange gelten, als wir keine dem widersprechenden Erfahrungen besitzen, für diese Erkrankung bildet das hohe 
Alter (über 65 Jahre) nicht die Vorbedingung, bei dieser Erkrankung erscheint die Sphärotrichie als ausschlaggebendes ursächliches Moment. Daß sich dies so verhält, beweist eben der 2. Fall Perusinis, der im Alter von 46 Jahren starb und eine vollkommen ausgebildete Sphärotrichie im Gehirn zeigte, sowie einige meiner Fälle, die in den fünfziger Jahren erkrankten. Dieser Fall Perusinis ist zwar nach dem bisher vorliegenden Material, was das Alter anlangt, eine Ausnahme und infolgedessen insofern interessant, als er wiẹder eine kleine Parallele mit der Paralyse gestattet. Auch die Paralyse hielt man zuerst für eine Erkrankung nur einer bestimmten Altersgrenze, zwischen 35-50 Jahren; damals wußte man noch nicht, daß die Paralyse auch bei Kindern auftreten kann, und erst die histologische Untersuchung lehrte uns, daß unter Umständen als einfach idiotisch angesehene Kinder eigentlich infolge einer progressiven Paralyse verblödeten; und auch den 2. Fall Per usin is erklärt die histologische Untersuchung und läßt ihn uns einer Gruppe von Fällen einreihen, welche sonst nur im Senium vorzukommen pflegen.

Ich bin am Schlusse meiner Ausführungen angelangt. Wenn wir nun unsere Untersuchungsresultate überblicken, so kommen wir zu dem Schlusse, da B wir in der Sphärotrichie nicht nur eine eigenartige und besondere Veränderung des Gehirns vor uns haben, sondern eine Hirnkrankheit im klinischen und pathologisch - anatomischen Sinne und daß wir sie als Ursache einer ganz bestimmten, klassifizierbaren und auch klinisch diagnostizierbaren Psychose ansehen müssen. Wenn wir also auf Grund der pathologischen Anatomie sonst verschiedenen Gruppen zugerechnete Krankheitsbilder herausgreifen, auf einer einheitlichen Basis zusammenfassen und dadurch eine neue Krankheitsgruppe umgrenzen können, so spricht dieses Resultat wieder einmal für die große Bedeutung, welche die Histopathologie für die klinische Psychiatrie hat und eröffnet die Hoffnung, daß wir mit neueren und besseren Methoden in dieser Richtung noch weiter kommen werden. Dann wird es vielleicht dazu kommen, daß die Histopathologie für die Klinik der Psychosen das werden wird, was im vorigen Jahrhundert die pathologische Anatomie für die Klinik der internen Krankheiten geworden ist.

\section{Tafelerklärung.}

Mit Ausnahme der Figg. 38, 43 und 44 sind alle Abbildungen nach Biels c how sk y.Präparaten hergestellt.

Tafel VII.

Fig. 1. Initialstadien der Drusen; bei a Stadium I, bei b Konglomerieren der einzelnen Sternchen; bei a ist schon das Ausweichen der Achsencylinder sichtbar. Vergr. $1000 \times$. 
Fig. 2 und 3. Stadium II mit metachromatischer Färbung. Vergr. $1000 \times$.

Fig. 4. Stadium II mit starker Retraktion des Gewebes; Strähnchen im Auswachsen begriffen, dadurch Übergang zu Stadium III. Vergr. $1000 \times$.

Fig. 5. Stadium III. Speichenbildung durch auswachsende Faserzöpfe.

\section{Tafel VIII.}

Fig. 6. Die auswachsenden Faserzöpfe dringen ins Gewebe und bilden einen Halbring. Übergang zum Stadium IV. Vergr. $1400 \times$.

Fig. 7. Stadium IV; die ganze Druse metachromatisch gefärbt. Vergr. $1400 \times$.

Fig. 8. Kleines Stadium IV; die ganze Druse schwarz gefärbt; der Randring macht den Eindruck einer Verdichtung der Fibrillen des umliegenden Gewebes. Vergr. $800 \times$.

Fig. 9. Metachromatisch gefärbte Drusen mit regelmäßig angegliederten kleinen Sternchen, Drusen und Zöpfen. Bei * eine kolbige Aufsplitterung eines Achsencylinders. Vergr. $1000 \times$.

Fig. 10 und 11. Stadium IV in doppelter Färbung; der Randring schwarz, die zentralen Partien braun. Fig. 10 bei $800 \times$, Fig. 11 bei $1000 \times$ Vergr.

\section{Tafel IX.}

Fig. 12. Stadium VII; durch die Mitte der Druse zieht ein Achsencylinder, bei a ein Kernrest. Vergr. $1000 \times$.

Fig. 13. Stadium VII. Rotfärbung der Schollen, U̇bergang (?) der Fädchen in die Schollen. Vergr. $1000 \times$.

Fig. 14. Stadium VII; die Schollen sehen aus wie Zellreste; bei * ein Kern einer wahrscheinlich zugrunde gehenden Zelle. Vergr. $1000 \times$.

Fig. 15. Stadium VII; bei a ein freies kleines Sternchenstadium.

\section{Tafel X.}

Fig. 16. Stadium V. Vergr. $350 \times$.

Fig. 17 und 18. Stadium VIII. Schwere Zellerkrankung; Schwund der Achsencylinder; bei a freies kleines Sternchen. Fig. 17 bei $500 \times$, Fig. 18 bei $1200 \times$. Vergr.

Fig. 19. Kugelförmige, perivasculäre Drusenformation. Vergr. $200 \times$.

\section{Tafel XI.}

Fig. 20. Metachromatisch gefärbte perivasculäre Drusen an einem Gefäß. Die Drusen sitzen außerhalb der Adventitia. Vergr. $100 \times$.

Fig. 21. Durch den Fädchenbesatz destruiertes Gefäß; die Fädchen hängen mit der randartig den Perivasculärraum umgebenden Druse zusammen; bei a eine kolbige Achsencylinderwucherung. Vergr. $500 \times$.

Fig. 22. „Pelzbesatz" zweier Gefäßchen. Vergr. $450 \times$.

Fig. 23. Destruktion eines etwas größeren Gefäßes. Vergr. $550 \times$.

Fig. 24. „Pelzbesatz" eines Gefäßchens aus der Molekularschicht des Kleinhirns. Schwere Veränderung der Intima und krümeliger Zerfall der Fädchenmassen. Vergr. $600 \times$.

In Fig. 25-31 sind nur die Achsencylinder und deren Auswüchse ausgeführt, die Drusen sind nur grau angedeutet.

\section{Tafel XII.}

Fig. 25. Kranzartige Anordnung der kleinen Keulen. Bei a kolbiges Ende eines unterbrochenen Achsencylinders; b kleeblattartige Anordnung dreier Endkeulen; c spindelige Verdickung eines Achsencylinders von sehr großen Dimensionen. 


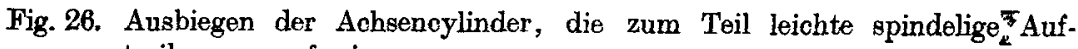
treibungen aufweisen.

Fig. 27. Ein Kranz langgezogener Keulen um die Druse. Die in der Mitte der Druse gezeichnete Stelle, an der sich die dünnen fädigen Enden der Keulen kreuzen, entspricht nicht dem Zentrum der Druse, sondern liegt mehr zur Oberfläche hin.

Fig. 28. Längsgetroffene Faser, die über einer Druse hinzieht und mehrere seitliche Auswüchse zeigt.

Fig. 29. Dichter Kranz von Endkeulen. Der mehrfach spindelförmig verdickte Achsencylinder, welcher die Druse durchzieht und in mehrere End- und Seitenkeulen endigt, liegt nicht im Zentrum der Druse, sondern in der Peripherie.

\section{Tafel XIII.}

Fig. 30. Versohiedene Formen der Keulen. Bei b konnte der zugehörende Achsencylinder durch drei Immersionsfelder als glatte Faser verfolgt werden; bei $d$ Spaltung eines Achsencylinders; bei $d$ und e fibrilläre Aufsplitterung von spindeligen Verdickungen des Achsencylinders.

\section{Tafel XIV.}

Fig. 31. Verschiedene Keulenformen, die zum Teil eine fibrilläre Aufsplitterung zeigen.

Fig. 32. Druse, die einem Gefäße anliegt, mit Keulen. Bei a eine Keule, die mit einem länger verfolgbaren Achsencylinder zusammenhängt.

Fig. 33. a Keulen im Querschnitte bei $1200 \times$ Vergr.; das fibrilläre Netz befindet sich nur an der Oberfläche. b eigenartige hyaline oder nur leicht gekörnte Körperchen, die man wiederholt antrifft; mehrfach liegen darin Fädchenreste. Vergr. $600 \times$.

\section{Tafel XV.}

Fig. 34. Grobfaserige Fibrillenwucherung; bei a ließen sich die sonst groben Fi. brillen in massenhafte, feine, parallel verlaufende Fibrillen auflösen; die Zelle ist kernlos.

Fig. 35. Eigenartige Konglomerate gewucherter Fibrillen, die wahrscheinlich der grobfaserigen Fibrillenwucherung entstammen. Das nervöse Fibrillennetz ist nicht vollkommen ausgezeichnet, damit die gewucherten Fibrillen mehr hervortreten können.

Fig. 36. Grobfaserige Fibrillenwucherung aus der Molekularschichte des Kleinhirns, kernartiges Gebilde in der Mitte.

Fig. 37. Stadium I.

\section{Tafel XVI.}

Fig. 38. Stadium IV nach einem Hämatoxylinpräparate. Man sieht den zentralen Morgenstern und peripheren Ring.

Fig. 39. Photogramm der Fig. I4.

Fig. 40. Druse im Stadium III, wo aber der Randring sehr große Dimensionen annimmt und das Gewebe bereits infiltriert.

\section{Tafel XVII.}

Fig. 41. Zeigt die Massenhaftigkeit der Drusen in der Rinde. Stadium V.

Fig. 42. Eine große Druse (Stadium V) in der Zonalschichte.

Fig. 43 und 44. Drusen bei Markscheidenfärbung; bei schwächerer und stärkerer Vergrößerung. 


\section{Tafel XVII.}

Fig. 45. Perivasculäre infiltrative Fädchenwucherung.

Fig. 46, 47 und 48. Infiltratives Wuchern der Fädchen; darin das Konfluieren aus einzelnen Herden sichtbar.

\section{Tafel XIX.}

Fig. 49. Beginn eines infiltrativen Stadiums.

Fig. 50. Stadium VI, bei schwacher Vergrößerung; man sieht, wie der Prozeß das ganze Gefäße begleitet.

Fig. 51. Mikrophotogramm einer Druse von der Beschaffenheit wie auf Fig. 15. 